\title{
Perovskitas Preparadas pelo Método do Citrato como Catalisadores para a Reação de Redução de NO com CO
}

Janaína de Souza Garcia

Dissertação apresentada ao Instituto de Química de São Carlos da Universidade de São Paulo para obtenção do título de Mestre em Ciências (Físico-Química).

Orientadora: Prof ${ }^{a}$ Dra Elisabete Moreira Assaf

São Carlos

2003 
Garcia, Janaína de Souza.

Perovskitas Preparadas pelo Método do Citrato como Catalisadores para a Reação de Redução de NO com CO/ Janaína de Souza Garcia - São Carlos, 2003.

$121 p$.

Dissertação (Mestrado) - Instituto de Química de São Carlos - Universidade de São Paulo, 2003.

Orientador: Prof ${ }^{\mathrm{a}} \mathrm{Dr}^{\mathrm{a}}$ Elisabete Moreira Assaf.

1. Catalisador. 2. Redução de NO com CO. 3. Perovskitas. I. Título 
Dedico este trabalho com todo carinho a meus pais, meu irmão e ao Airton. 
Agradecimentos

Antes gostaria de agradecer a Deus pela oportunidade de estar aqui, pela paciência e força para completar esse trabalho.

Agradeço aos meus pais por estarem sempre dispostos a me proporcionar o melhor caminho. Ao meu irmão por ser meu irmão.

Ao Airton, por estar sempre perto, me ajudando nas horas mais difíceis.

À Melina, à Érika e à Lidiane pela companhia e o esforço em sempre querer ajudar e dizendo que tudo daria certo.

À Marina pela cumplicidade, amizade, discussões e otimismo.

Ao pessoal do laboratório por todos os momentos de festa, de discussões e de problemas.

Ao Espanhol, sempre disponível para quebrar aquele galho.

Ao Camilo, Supô, Mou, que desde sempre estiveram lá, para desabafos e conselhos.

À Professora Elisabete Assaf, pelo trabalho durante esse período e ao professor Mansur, pelo auxílio e oportunidade de desenvolver trabalhos na UFSCar.

A todos vocês, muito obrigada. 
“A sabedoria está em não pensares que sabes aquilo que não sabes". (Sócrates) 


\section{SUMÁRIO}

LISTA DE FIGURAS

iii

LISTA DE TABELAS__ viii

LISTA DE ABREVIATURAS__

RESUMO_ xi

ABSTRACT_ Xii

1 INTRODUÇÃO__ 1

2 OBJETIVOS_

3 REVISÃO BIBLIOGRÁFICA

3.1 Poluição Atmosférica__ 6

3.1.1 Óxidos de Nitrogênio___

3.1.1.1 O Problema do Ozônio___ 10

3.1.2 Emissões Automotivas__ 13

3.1.2.1 Catalisador Automotivo Comercial ("Três vias") _ 14

3.2 Reações para Redução de $\mathrm{NO}_{x}$

3.2.1 Decomposição Direta de NO__ 17

3.2.2 Redução de $\mathrm{NO}$ com $\mathrm{NH}_{3}$

3.2.3 Redução de NO com Hidrocarbonetos__ 19

3.2.4 Redução de $\mathrm{NO}$ com $\mathrm{CO}$ ou $\mathrm{H}_{2}$

3.2.4.1 Catalisadores para a Redução de $\mathrm{NO}$ com CO__ 22

3.2.4.1.1 Metais Nobres__ 22

3.2.4.1.2 Catalisadores Suportados___ 23

3.2.4.1.3 Perovskitas___ 24 
4 MATERIAIS E MÉTODOS

4.1 Reagentes e Gases 31

4.2 Preparação dos Catalisadores 32

4.2.1 Método do Citrato 32

4.3 Caracterização dos Catalisadores 35

4.3.1 Fisissorção de Nitrogênio (B.E.T.) 36

4.3.2 Redução à Temperatura Programada (RTP) 37

4.3.3 Difração de Raios-X pelo Método do Pó 39

4.3.4 Análise da Composição dos Sólidos 41

4.3.4.1 Espectrometria de Emissão Atômica por Plasma Induzido 42

4.3.4.1 Espectrofotometria de Absorção Atômica por Atomização por Chama 42

4.3.5 Ensaio catalítico 44

5 RESULTADOS E DISCUSSÃO 49

5.1 Difração de Raios-X 49

5.2 Redução a Temperatura Programada (RTP) 58

5.3 Análise da Composição dos Sólidos 79

5.4 Área Superficial 81

5.5 Ensaios Catalíticos 82 6 CONCLUSÕES 103 7 REFERÊNCIAS BIBLIOGRÁFICAS 107 ANEXO A: Curva de Calibração para os Ensaios de RTP 113 APÊNDICE A: Danos à vegetação e à saúde atribuídos ao ozônio 115 APÊNDICE B: Constantes Termodinâmicas dos compostos 117 APÊNDICE C: Determinação da Lei de Bragg 


\section{LISTA DE FIGURAS}

Figura 1: Conversor catalítico utilizado nos automóveis. 15

Figura 2: Estrutura da Perovskita $\mathrm{ABO}_{3}$. 25

Figura 3: Estrutura $\mathrm{K}_{2} \mathrm{NiF}_{4}$ tetragonal. 27

Figura 4: Mecanismo de formação do polímero precursor. 34

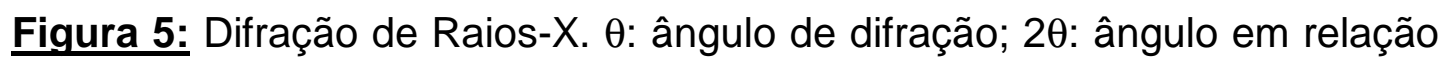
à referência. 39

Figura 6: Linha de ensaios catalíticos. 45

Figura 7: Reator de vidro utilizado para os ensaios catalíticos. 46

Figura 8: Difratogramas das amostras $\mathbf{A} 1, \mathbf{A} 2$ e padrão de $\mathrm{La}_{2} \mathrm{CuO}_{4}$. A1 - amostra de La/ Cu pré-calcinada em $600^{\circ} \mathrm{C}$ e calcinada em $900^{\circ} \mathrm{C}$; A2 - amostra de La/ Cu pré-calcinada em $600^{\circ} \mathrm{C}$ e calcinada em $800^{\circ} \mathrm{C} . *-\mathrm{CuO} ;{ }^{\circ}-\mathrm{La}_{2} \mathrm{O}_{3} ; \cdots \mathrm{La}_{2} \mathrm{CuO}_{4}$ tetragonal. 50

Figura 9: Difratogramas das amostras B1, B2 e padrão de $\mathrm{La}_{2} \mathrm{CuO}_{4}$. B1 - amostra de La/Ce/Cu pré-calcinada em $600^{\circ} \mathrm{C}$ e calcinada em $900^{\circ} \mathrm{C}$; B2 - amostra de La/Ce/Cu pré-calcinada em $600^{\circ} \mathrm{C} \mathrm{e}$ calcinada em $800^{\circ} \mathrm{C} . *-\mathrm{CuO} ;-\mathrm{CeO}_{2}$. 52

Figura 10: Difratogramas das amostras $\mathrm{C} 1$, C2 e padrão de $\mathrm{La}_{2} \mathrm{Mo}_{2} \mathrm{O}_{9}$. C1 - amostra de La/ Mo pré-calcinada em $600^{\circ} \mathrm{C}$ e calcinada em $900^{\circ} \mathrm{C}$; C2 - amostra de La/ Mo pré-calcinada em $600^{\circ} \mathrm{C}$ e calcinada em $800^{\circ} \mathrm{C}$. 54 
Figura 11: Difratogramas das amostras D1, D2 e padrão de $\mathrm{LaCoO}_{3}$. D1 - amostra de La/ Co pré-calcinada em $600^{\circ} \mathrm{C}$ e calcinada em $900^{\circ} \mathrm{C}$; D2 - amostra de La/ Co pré-calcinada em $600^{\circ} \mathrm{C}$ e calcinada em $800^{\circ} \mathrm{C}$. 55

Figura 12: Difratogramas das amostras E1, E2 e padrão de $\mathrm{LaNiO}_{3}$. E1 - amostra de La/Ni, pré-calcinada em $600^{\circ} \mathrm{C}$ e calcinada em $900^{\circ} \mathrm{C}$; E2 - amostra de $\mathrm{La} / \mathrm{Ni}$, pré-calcinada em $600^{\circ} \mathrm{C}$ e calcinada em $800^{\circ} \mathrm{C}$. 56

Figura 13: Difratogramas das amostras F1, F2 e padrões de $\mathrm{La}_{2} \mathrm{CuO}_{4} \mathrm{e}$ $\mathrm{LaNiO}_{3} . \mathbf{F} 1$ - amostra de $\mathrm{La} / \mathrm{Cu} / \mathrm{Ni}$, pré-calcinada em $600^{\circ} \mathrm{C}$ e calcinada em $900^{\circ} \mathrm{C}$; $\mathbf{F} 2$ - amostra de $\mathrm{La} / \mathrm{Cu} / \mathrm{Ni}$, pré-calcinada em $600^{\circ} \mathrm{C}$ e calcinada em $800^{\circ} \mathrm{C}$. 57

Figura 14: Perfil de RTP da amostra A1. A1 - amostra de La/ Cu précalcinada em $600^{\circ} \mathrm{C}$ e calcinada em $900^{\circ} \mathrm{C}$. 59

Figura 15: Perfil de RTP da amostra A2. A2 - amostra de La/ Cu précalcinada em $600^{\circ} \mathrm{C}$ e calcinada em $800^{\circ} \mathrm{C}$. 60

Figura 16: Perfil de RTP da amostra B1. B1 - amostra de La/ Ce/ Cu précalcinada em $600^{\circ} \mathrm{C}$ e calcinada em $900^{\circ} \mathrm{C}$. 63

Figura 17: Perfil de RTP da amostra B2. B2 - amostra de La/ Ce/ Cu précalcinada em $600^{\circ} \mathrm{C}$ e calcinada em $800^{\circ} \mathrm{C}$. 64

Figura 18: Perfil de RTP da amostra C1. C1 - amostra de La/ Mo précalcinada em $600^{\circ} \mathrm{C}$ e calcinada em $900^{\circ} \mathrm{C}$. 67

Figura 19: Perfil de RTP da amostra C2. C2 - amostra de La/ Mo précalcinada em $600^{\circ} \mathrm{C}$ e calcinada em $800^{\circ} \mathrm{C}$. 68 
Figura 20: Perfil de RTP da amostra D1. D1 - amostra de La/ Co précalcinada em $600^{\circ} \mathrm{C}$ e calcinada em $900^{\circ} \mathrm{C}$. 71

Figura 21: Perfil de RTP da amostra D2. D2 - amostra de La/ Co précalcinada em $600^{\circ} \mathrm{C}$ e calcinada em $800^{\circ} \mathrm{C}$. 72

Figura 22: Perfil de RTP da amostra E1. E1 - amostra de La/ Ni précalcinada em $600^{\circ} \mathrm{C}$ e calcinada em $900^{\circ} \mathrm{C}$. 74

Figura 23: Perfil de RTP da amostra E2. E2 - amostra de La/ Ni précalcinada em $600^{\circ} \mathrm{C}$ e calcinada em $800^{\circ} \mathrm{C}$. 75

Figura 24: Perfil de RTP da amostra F1. F1 - amostra de La/ Cu/ Ni précalcinada em $600^{\circ} \mathrm{C}$ e calcinada em $900^{\circ} \mathrm{C}$. 77

Figura 25: Perfil de RTP da amostra F2. F2 - amostra de La/ Cu/ Ni précalcinada em $600^{\circ} \mathrm{C}$ e calcinada em $800^{\circ} \mathrm{C}$. 78

Figura 26: Conversão de NO e CO da amostra A1. A1 - amostra de La/ Cu pré-calcinada em $600^{\circ} \mathrm{C}$ e calcinada em $900^{\circ} \mathrm{C}$. 85

Figura 27: Produção de $\mathrm{N}_{2}$ da amostra A1. A1 - amostra de La/ Cu précalcinada em $600^{\circ} \mathrm{C}$ e calcinada em $900^{\circ} \mathrm{C}$. 85

Figura 28: Conversão de $\mathrm{NO}$ e $\mathrm{CO}$ da amostra A2. A2 - amostra de $\mathrm{La} / \mathrm{Cu}$ pré-calcinada em $600^{\circ} \mathrm{C}$ e calcinada em $800^{\circ} \mathrm{C}$. 87

Figura 29: Produção de $\mathrm{N}_{2}$ da amostra A2. A2 - amostra de La/ Cu précalcinada em $600^{\circ} \mathrm{C}$ e calcinada em $800^{\circ} \mathrm{C}$. 87

Figura 30: Conversão de NO e CO da amostra B1. B1 - amostra de La/ Ce/ Cu pré-calcinada em $600^{\circ} \mathrm{C}$ e calcinada em $900^{\circ} \mathrm{C}$. 88

Figura 31: Produção de $\mathrm{N}_{2}$ da amostra B1. B1 - amostra de La/ Ce/ Cu précalcinada em $600^{\circ} \mathrm{C}$ e calcinada em $900^{\circ} \mathrm{C}$. 88 
Figura 32: Conversão de NO e CO da amostra B2. B2 - amostra de La/ Ce/ Cu pré-calcinada em $600^{\circ} \mathrm{C}$ e calcinada em $800^{\circ} \mathrm{C}$. 89

Figura 33: Produção de $\mathrm{N}_{2}$ da amostra B2. B2 - amostra de La/ Ce/ Cu précalcinada em $600^{\circ} \mathrm{C}$ e calcinada em $800^{\circ} \mathrm{C}$. 89

Figura 34: Conversão de NO e CO da amostra C1. C1 - amostra de La/ Mo pré-calcinada em $600^{\circ} \mathrm{C}$ e calcinada em $900^{\circ} \mathrm{C}$. 90

Figura 35: Produção de $\mathrm{N}_{2}$ da amostra C1. C1 - amostra de La/ Mo précalcinada em $600^{\circ} \mathrm{C}$ e calcinada em $900^{\circ} \mathrm{C}$. 90

Figura 36: Conversão de NO e CO da amostra C2. C2 - amostra de La/ Mo pré-calcinada em $600^{\circ} \mathrm{C}$ e calcinada em $800^{\circ} \mathrm{C}$. 91

Figura 37: Produção de $\mathrm{N}_{2}$ da amostra C2. C2 - amostra de La/ Mo précalcinada em $600^{\circ} \mathrm{C}$ e calcinada em $800^{\circ} \mathrm{C}$. 91

Figura 38: Conversão de NO e CO da amostra D1. D1 - amostra de La/ Co pré-calcinada em $600^{\circ} \mathrm{C}$ e calcinada em $900^{\circ} \mathrm{C}$. 92

Figura 39: Produção de $\mathrm{N}_{2}$ da amostra D1. D1 - amostra de La/ Co précalcinada em $600^{\circ} \mathrm{C}$ e calcinada em $900^{\circ} \mathrm{C}$. 93

Figura 40: Conversão de NO e CO da amostra D2. D2 - amostra de La/ Co pré-calcinada em $600^{\circ} \mathrm{C}$ e calcinada em $800^{\circ} \mathrm{C}$. 93

Figura 41: Produção de $\mathrm{N}_{2}$ da amostra D2. D2 - amostra de La/ Co précalcinada em $600^{\circ} \mathrm{C}$ e calcinada em $800^{\circ} \mathrm{C}$. 94

Figura 42: Conversão de NO e CO da amostra E1. E1 - amostra de La/ Ni pré-calcinada em $600^{\circ} \mathrm{C}$ e calcinada em $900^{\circ} \mathrm{C}$. 95

Figura 43: Produção de $\mathrm{N}_{2}$ da amostra E1. E1 - amostra de La/ Ni précalcinada em $600^{\circ} \mathrm{C}$ e calcinada em $900^{\circ} \mathrm{C}$. 95 
Figura 44: Conversão de NO e CO da amostra E2. E2 - amostra de La/ Ni pré-calcinada em $600^{\circ} \mathrm{C}$ e calcinada em $800^{\circ} \mathrm{C}$. 96

Figura 45: Produção de $\mathrm{N}_{2}$ da amostra E2. E2 - amostra de La/ Ni précalcinada em $600^{\circ} \mathrm{C}$ e calcinada em $800^{\circ} \mathrm{C}$. 96

Fiqura 46: Conversão de NO e CO da amostra F1. F1 - amostra de La/ Cu/ Ni pré-calcinada em $600^{\circ} \mathrm{C}$ e calcinada em $900^{\circ} \mathrm{C}$. 98

Figura 47: Produção de $\mathrm{N}_{2}$ da amostra F1. F1 - amostra de La/ Cu/ Ni précalcinada em $600^{\circ} \mathrm{C}$ e calcinada em $900^{\circ} \mathrm{C}$. 99

Figura 48: Conversão de NO e CO da amostra F2. F2 - amostra de $\mathrm{La} / \mathrm{Cu} / \mathrm{Ni}$ pré-calcinada em $600^{\circ} \mathrm{C}$ e calcinada em $800^{\circ} \mathrm{C}$. 99

Figura 49: Produção de $\mathrm{N}_{2}$ da amostra F2. F2 - amostra de La/ Cu/ Ni précalcinada em $600^{\circ} \mathrm{C}$ e calcinada em $800^{\circ} \mathrm{C}$. 100

Figura 50: Perfil de RTP da amostra de CuO (calibração). 113

Figura 51: Esquema da difração dos raios-X. 1 e 2: raios-X incidentes; $\theta$ : ângulo de reflexão dos raios-X; 1' e 2': raios-X difratados; RL: distância entre os planos; $M L+L N$ : diferença de caminho percorrido entre os raios 1 e 2 . 118 


\section{LISTA DE TABELAS}

Tabela 1: Nome das amostras e temperaturas de calcinação. 35

Tabela 2: Temperatura, área e número de moles de $\mathrm{H}_{2}$ consumido em cada pico do perfil de RTP da amostra A1 (Figura 14). 59

Tabela 3: Temperatura, área e número de moles de $\mathrm{H}_{2}$ consumido em cada pico do perfil de RTP da amostra A2 (Figura 15). 60

Tabela 4: Número estimado de moles de $\mathrm{La}_{2} \mathrm{CuO}_{4}$ e valores obtidos experimentalmente, correspondentes à massa reduzida nas amostras $\mathbf{A} 1$ e $\mathbf{A} 2$. 61

Tabela 5: Temperatura, área e número de moles de $\mathrm{H}_{2}$ consumido em cada pico do perfil de RTP da amostra B1 (Figura 16). 63

Tabela 6: Temperatura, área e número de moles de $\mathrm{H}_{2}$ consumido em cada pico do perfil de RTP da amostra B2 (Figura 17). 64

Tabela 7: Temperatura, área e número de moles de $\mathrm{H}_{2}$ consumido em cada pico do perfil de RTP da amostra C1 (Figura 18). 67

Tabela 8: Temperatura, área e número de moles de $\mathrm{H}_{2}$ consumido em cada pico do perfil de RTP da amostra C2 (Figura 19). 68

Tabela 9: Número estimado de moles de $\mathrm{Mo}^{6+}$ nas amostras C1 e C2 correspondente à massa reduzida e valores obtidos experimentalmente. 69

Tabela 10: Temperatura, área e número de moles de $\mathrm{H}_{2}$ consumido em cada pico do perfil de RTP da amostra D1 (Figura 20). 71 
Tabela 11: Temperatura, área e número de moles de $\mathrm{H}_{2}$ consumido em cada pico do perfil de RTP da amostra D2 (Figura 21). 72

Tabela 12: Número estimado de moles de $\mathrm{LaCoO}_{3}$ e valores obtidos experimentalmente, correspondentes à massa reduzida nas amostras D1 e D2. 73

Tabela 13: Temperatura, área e número de moles de $\mathrm{H}_{2}$ consumido em cada pico do perfil de RTP da amostra E1 (Figura 22). 74

Tabela 14: Temperatura, área e número de moles de $\mathrm{H}_{2}$ consumido em cada pico do perfil de RTP da amostra E2 (Figura 23). 75

Tabela 15: Número estimado de moles de $\mathrm{LaNiO}_{3}$ e valores obtidos experimentalmente, correspondentes à massa reduzida nas amostras E1 e E2. 76

Tabela 16: Temperatura, área e número de moles de $\mathrm{H}_{2}$ consumido em cada pico do perfil de RTP da amostra F1 (Figura 24). 77

Tabela 17: Temperatura, área e número de moles de $\mathrm{H}_{2}$ consumido em cada pico do perfil de RTP da amostra F2 (Figura 25). 78

Tabela 18: Mistura de óxidos após a pré-calcinação em $600^{\circ} \mathrm{C}$ por 3 horas, perovskita formada após calcinação e massa molecular da mistura de óxidos. 79

Tabela 19: Concentração de metais nas amostras (\% em massa). 80

Tabela 20: Área específica obtida por fisissorção de nitrogênio (B.E.T.). 81

Tabela 21: Dados termodinâmicos dos compostos envolvidos na reação de redução do $\mathrm{NO}$ com $\mathrm{CO}$ ou $\mathrm{H}_{2}$. 


\section{LISTA DE ABREVIATURAS}

(ads) - adsorvido;

B.E.T. (equação de Brunnauer - Emmet - Teller) - Análise de Área Superficial por Fisissorção de Nitrogênio;

COV(s) - Compostos Orgânicos Voláteis;

CO - Monóxido de Carbono;

$\mathrm{CO}_{2}$ - Dióxido de Carbono;

DRX - Difração de Raios-X;

HC - Hidrocarbonetos;

NO - Monóxido de Nitrogênio;

$\mathrm{NO}_{2}$ - Dióxido de Nitrogênio;

$\mathrm{NO}_{\mathrm{x}}$ - Óxidos de Nitrogênio $\left(\mathrm{NO}+\mathrm{NO}_{2}\right)$;

$\mathrm{N}_{2} \mathrm{O}$ - Óxido Nitroso;

$N_{2}$ - Nitrogênio;

$\mathrm{O}_{2}$ - Oxigênio;

$\mathrm{O}_{3}$ - Ozônio;

PROCONVE - Programa de Controle da Poluição do Ar por Veículos Automotores;

RTP - Redução a Temperatura Programada;

$\mathrm{SO}_{\mathrm{x}}-$ Óxidos de Enxofre;

u.a. - Unidades Arbitrárias. 


\section{RESUMO}

Um dos maiores problemas que o homem tem encontrado em função de seu desenvolvimento é a poluição. Os principais responsáveis pela poluição atmosférica são os veículos automotores e para minimizar a poluição gerada por estes fez-se necessário o uso de catalisadores. Estes catalisadores, chamados de catalisadores de "três vias", atualmente têm como sítios ativos metais nobres, o que eleva muito o seu custo e leva motoristas a dispensarem este equipamento. $\mathrm{O}$ objetivo deste estudo foi preparar, caracterizar e estudar materiais tipo perovskitas $\left(\mathrm{La}_{2} \mathrm{CuO}_{4}\right.$, $\left.\mathrm{La}_{(2-x)} \mathrm{Ce}_{x} \mathrm{CuO}_{4}, \quad \mathrm{La}_{2} \mathrm{Mo}_{2} \mathrm{O}_{9}, \quad \mathrm{LaCoO}_{3}, \quad \mathrm{LaNiO}_{3}, \quad \mathrm{La}_{2} \mathrm{CuO}_{4} / \mathrm{LaNiO}_{3}\right)$ como catalisadores para a reação de redução de $\mathrm{NO}$ com $\mathrm{CO}$, com a finalidade de encontrar uma alternativa para substituir os metais nobres nos conversores catalíticos comerciais. Os catalisadores foram preparados pelo método do citrato, calcinados em 800 ou $900^{\circ} \mathrm{C}$, caracterizados por difração de raios- $\mathrm{X}$, redução a temperatura programada, área específica e análise química, sendo observada a formação de perovskita em todas as caracterizações. Durante os ensaios catalíticos frente a reação de redução de $\mathrm{NO}$ com $\mathrm{CO}$, os catalisadores calcinados em $800^{\circ} \mathrm{C}$ foram mais ativos em relação aos calcinados em $900^{\circ} \mathrm{C}$ e em relação aos metais componentes da perovskita, quanto mais preenchida a banda de valência do metal na estrutura perovskita, maior a sua atividade. 


\section{ABSTRACT}

One of the biggest problems that man has found because of his development is the pollution. The main responsible for atmospheric pollution are the automotive vehicles and to minimize the pollution produced by them it has been necessary to use catalysts. These catalysts, called "three way catalysts", actually have noble metals like active sites, what takes up very much their cost and let drivers dispense this equipment. The objective oh this study was to prepare, characterize and study materials of perovskites kind $\left(\mathrm{La}_{2} \mathrm{CuO}_{4}, \mathrm{La}_{(2-x)} \mathrm{Ce}_{x} \mathrm{CuO}_{4}, \mathrm{La}_{2} \mathrm{Mo}_{2} \mathrm{O}_{9}, \mathrm{LaCoO}_{3}, \mathrm{LaNiO}_{3}, \mathrm{La}_{2} \mathrm{CuO}_{4} / \mathrm{LaNiO}_{3}\right)$ like catalysts to the reaction of reduction of $\mathrm{NO}$ with $\mathrm{CO}$, with the end of find a alternative to substitute the noble metal in the commercial catalytic conversers. The catalysts were prepared by citrate method, calcined at 800 or $900^{\circ} \mathrm{C}$, characterized by X-ray diffraction, temperature programmed reduction, specific area and chemical analysis, being observed the formation of perovskite in all characterizations. During the catalytic research to the reaction of $\mathrm{NO}$ with $\mathrm{CO}$, the catalysts calcined at $800^{\circ} \mathrm{C}$ were more active compared to those calcined at $900^{\circ}$ and, in relation to the component metal of the perovskite, how more filled the valence band of the metal in the structure of perovskite, better its activity. 


\section{INTRODUÇÃO}

Considera-se poluição a presença ou introdução, no meio ambiente, de substâncias nocivas à saúde humana, a outros animais e às plantas, ou que prejudicam o equilíbrio ecológico. Da mesma forma, poluente é qualquer substância presente no ar, no solo ou na água e que, pela sua concentração, possa torná-los impróprios, nocivos ou ofensivos à saúde, inconvenientes ao bem estar público, danosos aos materiais, à fauna e à flora ou prejudiciais à segurança, ao uso e ao gozo da propriedade e às atividades normais da comunidade ${ }^{(1)}$.

As principais fontes de poluição do ar não naturais são os veículos automotores, processos industriais, queima de resíduos, movimentação e estocagem de combustíveis (evaporação) etc. Dentre as fontes naturais pode-se destacar as tempestades de poeira, incêndios florestais e atividades vulcânicas.

Dentre os poluentes atmosféricos podemos considerar os óxidos de nitrogênio $\left(\mathrm{NO}_{\mathrm{x}}\right)$ os mais prejudiciais, pois, além de serem altamente tóxicos e irritantes ao sistema respiratório humano, eles contribuem para a chuva ácida e geram ozônio $\left(\mathrm{O}_{3}\right)$, poluente secundário que tem apresentado grandes problemas em todo o mundo e responsável pela "fumaça urbana".

Os óxidos de nitrogênio podem ser provenientes tanto de plantas industriais, quanto de gases de exaustão automotivos, sendo os automóveis as principais fontes de emissão destes poluentes. Para cada uma dessas situações há sistemas catalíticos e condições de abatimento diferentes a 
serem utilizados: redução de $\mathrm{NO}$ com $\mathrm{NH}_{3}$, com $\mathrm{CO}$, com $\mathrm{H}_{2}$, com hidrocarbonetos e decomposição direta.

No caso da exaustão automotiva o catalisador utilizado comercialmente é do tipo "três vias", que oxida hidrocarbonetos e $\mathrm{CO}$ à $\mathrm{CO}_{2}$ e $\mathrm{H}_{2} \mathrm{O}$, enquanto o $\mathrm{NO}_{x}$ é reduzido à $\mathrm{N}_{2}$. Com a implantação do Programa de Controle da Poluição do Ar por Veículos Automotores (PROCONVE) ${ }^{(2)}$ em 1986, se fez necessário o uso deste tipo de catalisador nos automóveis para que as metas de emissão da segunda fase do programa (1992) fossem $\operatorname{atingidas}^{(2-3)}$.

O catalisador de "três vias" comercial utiliza os metais nobres ródio, platina e paládio como sítios ativos para as reações citadas acima. Estes são metais raros e de custo elevado, tornando o catalisador automotivo, que é um acessório obrigatório ao automóvel, caro e, muitas vezes, os proprietários dos veículos preferem retirá-lo a substituí-lo por um novo, como medida de economia. No ano de 2000 a Secretaria Municipal do Meio Ambiente de São Paulo estimava que, no Brasil, havia uma frota de 20 milhões de veículos e que cerca de 3 milhões circulavam com catalisadores falsos ou que não eram ativos ${ }^{(4)}$.

Assim, a procura por catalisadores que tenham a mesma atividade dos metais nobres para a catálise dos gases de exaustão automotiva, mas que sejam mais baratos ao consumidor, poderia mudar este quadro e ajudar na minimização da poluição atmosférica.

Um bom catalisador automotivo deve ter habilidade para reduzir seletivamente o óxido nítrico para nitrogênio, na presença de hidrogênio, sem produzir amônia. O catalisador deve ser ativo na presença de enxofre, 
oxigênio e água, presentes no gás de exaustão automotivo.

A natureza de vários catalisadores já foi investigada, porém ainda não se encontrou o sistema ideal, que seja ativo, seletivo e estável para estas reações.

Alguns materiais que vêm sendo investigados quanto às suas propriedades catalíticas são as perovskitas $\left(\mathrm{ABO}_{3}\right)$. Tem sido mostrado que perovskitas contendo lantânio levam a uma melhoria nas propriedades catalíticas, especialmente no que diz respeito à estabilidade da reação. Há estudos de perovskitas contendo metais nobres e é esperado que seja possível substituir estes metais por metais mais abundantes para as reações de eliminação de NO. Também foram estudadas perovskitas contendo lantânio juntamente com cobalto, níquel, manganês ou ferro como catalisadores para esta reação, tendo estes apresentado uma boa atividade, mas nem sempre com muita seletividade para $\mathrm{N}_{2}{ }^{(5)}$.

Dentre os metais estudados, uma atenção especial tem sido dada ao cobre na forma de óxido, tanto como metal suportado, como componente de perovskita, sendo o cobre ativo para esta reação no estado de oxidação +2 ${ }^{(5-8)}$. Outros registros reportam que o uso de molibdênio como promotor em catalisadores de paládio melhora a atividade para a redução de NO, com alta seletividade para $\mathrm{N}_{2}{ }^{(9-10)}$.

Assim, este trabalho buscou estudar a aplicação de catalisadores do tipo perovskitas contendo lantânio com cobre, níquel, cobalto ou molibdênio para a reação de redução de $\mathrm{NO}$ com $\mathrm{CO}$, pois estes óxidos apresentam grande potencial para reações como esta, que requerem estabilidade térmica, resistência à desativação e atividade catalítica. Também foi 
estudada a substituição parcial do lantânio por cério, já que o catalisador de "três vias" utiliza cério como um dos aditivos, aproveitando a propriedade deste metal de armazenar oxigênio, mudando facilmente de estado de oxidação. 


\section{OBJETIVOS}

Em vista da necessidade de buscar outros compostos para substituir os metais nobres nos conversores catalíticos automotivos, o objetivo deste trabalho foi preparar catalisadores tipo perovskitas pelo método do citrato, com calcinação em 800 ou $900^{\circ} \mathrm{C}$, caracterizar e estudar a atividade destes catalisadores frente a reação de redução de NO com CO.

Os catalisadores estudados foram:

- $\mathrm{La}_{2} \mathrm{CuO}_{4}$

- $\mathrm{La}_{(2-x)} \mathrm{Ce}_{x} \mathrm{CuO}_{4}$;

- $\mathrm{La}_{2}\left(\mathrm{MoO}_{4}\right)_{3}$;

- $\mathrm{LaNiO}_{3}$

- $\mathrm{LaCoO}_{3}$

- $\mathrm{LaCu}_{(1-\mathrm{x})} \mathrm{Ni}_{\times} \mathrm{O}_{3}\left(\mathrm{La}_{2} \mathrm{CuO}_{4} / \mathrm{LaNiO}_{3}\right)$. 


\section{REVISÃO BIBLIOGRÁFICA}

Os óxidos de nitrogênio, $\mathrm{NO}_{x}$, são os maiores poluentes atmosféricos e sua remoção é o objetivo de muitos projetos de pesquisa na área de proteção ambiental.

\subsection{Poluição Atmosférica}

O desenvolvimento econômico, além de trazer benefícios sociais para uma região, também pode gerar alguns prejuízos ambientais, como se tem observado ao longo dos anos em centros em desenvolvimento ou já desenvolvidos.

As fontes de poluição da água e do solo são muitas e vão desde esgotos industriais e domésticos não tratados despejados nos rios, até acidentes e vazamentos de produtos químicos. A poluição do ar é causada pela liberação na atmosfera de gases ou partículas sólidas ou líquidas finamente dispersas, em quantidades muito grandes para que possam ser dissipadas ou incorporadas à água ou ao solo, sendo as principais fontes de emissão não naturais os veículos automotores, processos industriais, queima de resíduos, movimentação e estocagem de combustíveis (evaporação) etc. Dentre as fontes naturais de poluição atmosférica podemos destacar as tempestades de poeira, incêndios florestais e atividades vulcânicas.

Os veículos automotores são responsáveis por grande parte da poluição atmosférica devido às emissões dos gases resultantes da queima 
do combustível, ao desgaste dos pneus e à evaporação do combustível nas operações de transferência e do tanque dos veículos.

Além dos poluentes considerados primários por serem diretamente emitidos pelas fontes, existem também os poluentes secundários, que são formados na atmosfera a partir dos poluentes primários ou de substâncias menos tóxicas. O poluente secundário que tem apresentado maiores problemas é o ozônio $\left(\mathrm{O}_{3}\right)$, que, embora seja necessário na estratosfera, onde forma a camada de ozônio que nos protege da radiação ultravioleta, é um poluente fortemente irritante e tóxico na troposfera (camada mais baixa da atmosfera). O ozônio é formado na troposfera por reações fotoquímicas envolvendo os óxidos de nitrogênio e compostos orgânicos voláteis $(\mathrm{COVs})^{(11)}$

\subsection{1 Óxidos de Nitrogênio}

As principais fontes de emissão dos óxidos de nitrogênio $\left(N O_{x}\right)$ são os escapamentos dos automóveis, as indústrias de fertilizantes, as usinas de ferro e aço, as indústrias químicas e as usinas termoelétricas ${ }^{(12)}$, sendo as emissões automotivas as principais e responsáveis pela emissão de cerca de 360 t de óxidos de nitrogênio por ano na Região Metropolitana de São Paulo ${ }^{(1)}$. Na natureza, os óxidos de nitrogênio são formados durante as tempestades, quando ocorrem raios e relâmpagos.

Os $\mathrm{NO}_{\mathrm{x}}$ provenientes dos gases de exaustão automotiva podem ser gerados através de duas fontes: a partir do nitrogênio do ar e a partir do nitrogênio presente no combustível. O primeiro é chamado de $\mathrm{NO}_{\mathrm{x}}$ térmico, 
uma vez que sua produção depende da temperatura de queima do combustível, e o segundo é conhecido como $\mathrm{NO}_{x}$ do combustível e sua formação é influenciada principalmente pela disponibilidade de oxigênio na zona de reação ${ }^{(13)}$.

O óxido nítrico térmico tem sua formação favorecida no interior de motores, pela temperatura alta, reagindo o oxigênio e o nitrogênio do ar (Equação 3.1):

$$
\mathrm{N}_{2}+\mathrm{O}_{2} \rightarrow 2 \mathrm{NO} \quad \Delta \mathrm{H}>0
$$

Como essa reação é endotérmica, ela necessita de altas temperaturas, sendo que em baixas temperaturas não ocorre formação de NO.

A nomenclatura $\mathrm{NO}_{x}$ inclui o monóxido e o dióxido de nitrogênio, pois estes dois óxidos se interconvertem continuamente na presença de oxigênio ${ }^{(5,14)}$, sob ação da radiação solar. Este processo pode ser descrito pela Equação 3.2:

$$
\mathrm{NO}_{2}+\mathrm{O}_{2} \underset{\text { troposfera }}{\stackrel{\text { estratosfera }}{\stackrel{h v}{\rightleftarrows}}} \mathrm{NO}+\mathrm{O}_{3}
$$

A queda da concentração do ozônio na estratosfera, causando o buraco na camada de ozônio, bem como o aumento da concentração deste na troposfera, é, em grande parte, devido à reação com as espécies de óxidos de nitrogênio. Segundo J. G. Calvert ${ }^{(14)}$, as diferenças de temperatura e pressão entre a troposfera e a estratosfera favorecem a 
geração de ozônio e $\mathrm{NO}$ no primeiro caso e formação de $\mathrm{NO}_{2}$ e destruição de ozônio no segundo caso, onde está presente a camada de ozônio (Equação 3.2).

O monóxido de nitrogênio (NO) é um gás que, diretamente, não causa problemas à nossa saúde, mas tem habilidade de gerar contaminantes secundários $\left(\mathrm{NO}_{2}, \mathrm{~N}_{2} \mathrm{O}, \mathrm{O}_{3}\right)$ através de sua interação com outros poluentes primários (como carbonilas, radicais alcoólicos, etc.), também resultantes de processos industriais e da combustão de óleos. O NO também tem um papel importante na qualidade da atmosfera, pois ele reage com poluentes fotoquímicos, tais como ozônio, formando mais óxidos de nitrogênio e nitratos orgânicos. As Equações 3.3 e 3.4 descrevem como o óxido nítrico (NO) pode destruir a camada de ozônio ${ }^{(14)}$ :

$$
\begin{aligned}
& \mathrm{NO}+\mathrm{O}_{3} \rightarrow \mathrm{NO}_{2}+\mathrm{O}_{2} \\
& \mathrm{NO}_{2}+\mathrm{O} \rightarrow \mathrm{NO}+\mathrm{O}_{2}
\end{aligned}
$$

Podemos observar a semelhança entre essas reações (Equações 3.3 e 3.4) e as reações que resumem o efeito do cloro na destruição do ozônio (Equações 3.5 e 3.6$)^{(14)}$ :

$$
\begin{aligned}
& \mathrm{Cl}+\mathrm{O}_{3} \rightarrow \mathrm{ClO}+\mathrm{O}_{2} \\
& \mathrm{ClO}+\mathrm{O} \rightarrow \mathrm{Cl}+\mathrm{O}_{2}
\end{aligned}
$$


Em ambos os casos a molécula que destrói o ozônio é regenerada, permitindo que mais moléculas de ozônio sejam destruídas, antes que essas substâncias sejam, de alguma forma, removidas da estratosfera ${ }^{(14)}$.

Já o dióxido de nitrogênio $\left(\mathrm{NO}_{2}\right)$ é uma substância altamente tóxica, sendo diretamente prejudicial ao ser humano. $\mathrm{O} \mathrm{NO}_{2}$ é um irritante das mucosas do aparelho respiratório e, ao penetrar em nosso organismo, pode levar à formação de compostos carcinogênicos, além de provocar no sistema nervoso central letargia, perda da consciência, ansiedade e confusão mental. $\mathrm{O} \mathrm{NO}_{2}$ também contribui substancialmente para as "chuvas ácidas" e para o ciclo de formação e destruição do ozônio $\left(\mathrm{O}_{3}\right)^{(1,14)}$.

O dióxido de nitrogênio pode ser produzido pela oxidação do NO (Equação 3.7):

$$
\mathrm{NO}+1 / 2 \mathrm{O}_{2} \rightarrow \mathrm{NO}_{2}
$$

\subsubsection{O Problema do Ozônio}

O ozônio é formado na estratosfera como resultado de reações químicas iniciadas pela radiação solar de curto comprimento de onda ${ }^{(15)}$.

$\mathrm{Na}$ troposfera, como já foi mencionado, poluentes fotoquímicos são formados a partir de reações envolvendo óxidos de nitrogênio $\left(\mathrm{NO}_{\mathrm{x}}=\mathrm{NO}+\mathrm{NO}_{2}\right)$, compostos orgânicos voláteis (COVs) e monóxido de carbono (CO) na presença de luz solar ${ }^{(3,15)}$.

Depois de liberados, estes precursores $\left(\mathrm{NO}_{\mathrm{x}}, \mathrm{CO}\right.$ e COVs) são dispersos pelo vento e turbulência atmosférica. Os poluentes recém emitidos 
se misturam a outros poluentes já presentes no ar, inclusive ozônio, e um complicado processo de reações químicas paralelas e diluições contínuas se inicia $^{(15-16)}$.

A fotólise do $\mathrm{NO}_{2}$ é a maior responsável pela produção fotoquímica do ozônio, pois gera óxido nítrico (NO) e um átomo de oxigênio "livre", que reage com uma molécula de $\mathrm{O}_{2}$ formando $\mathrm{O}_{3}$ (Equações 3.8 e 3.9) ${ }^{(15,17)}$.

$$
\begin{aligned}
& \mathrm{NO}_{2}+h v \rightarrow \mathrm{NO}+\mathrm{O}^{\bullet} \\
& \mathrm{O}^{\bullet}+\mathrm{O}_{2} \rightarrow \mathrm{O}_{3}
\end{aligned}
$$

$\mathrm{O}_{3}$ formado, próximo às fontes de emissão de $\mathrm{NO}$ (ou seja, NO em alta concentração), reage com este gerando oxigênio e $\mathrm{NO}_{2}$ (Equação 3.10) $(15,17)$.

$$
\mathrm{O}_{3}+\mathrm{NO} \rightarrow \mathrm{O}_{2}+\mathrm{NO}_{2}
$$

Este ciclo de reações se mantém em equilíbrio na ausência de COVs, mas, quando estes estão presentes, o equilíbrio é deslocado para a conversão de $\mathrm{NO}$ a $\mathrm{NO}_{2}$ sem o intermediário $\mathrm{O}_{3}$ (Equação 3.14), e a fotólise do $\mathrm{NO}_{2}$ leva à formação de elevados níveis de $\mathrm{O}_{3}$. Os COVs são inicialmente degradados por radicais hidroxilas $(\mathrm{OH})$, gerando radicais livres que reagem deslocando o equilíbrio do ciclo de formação do ozônio (Equações 3.11 - 14) ${ }^{(15,17)}$. O NO também tem um papel importante na regeneração dos radicais reativos e na continuidade das reações (Equações 3.12 e 3.14$)^{(15-17)}$. 


$$
\begin{aligned}
& \mathrm{COV}+{ }^{\circ} \mathrm{OH} \stackrel{\mathrm{O} 2, \mathrm{hv}}{\rightarrow} \mathrm{RO}_{2}^{\bullet} \\
& \mathrm{RO}_{2}^{\bullet}+\mathrm{NO} \rightarrow \mathrm{O}_{2}+\mathrm{RO}^{\bullet} \\
& \mathrm{RO}^{\bullet}+\mathrm{O}_{2} \rightarrow \mathrm{HO}_{2}^{\bullet}+\text { produtos } \\
& \mathrm{HO}_{2}^{\bullet}+\mathrm{NO} \rightarrow \mathrm{NO}_{2}+\mathrm{OH}
\end{aligned}
$$

COVs atuam como "combustível" no processo de formação do ozônio, no qual o NO funciona praticamente como um catalisador, já que ele é regenerado durante o processo. Entretanto, a química dos COVs ainda não é inteiramente compreendida como o ciclo do nitrogênio ${ }^{(15)}$, o que dificulta a representação dos processos químicos e impossibilitando a demonstração de todas as reações laterais.

Os óxidos de nitrogênio também são importantes para o processo de acidificação (Equação 3.15) ${ }^{(16)}$.

$$
\cdot \mathrm{OH}+\mathrm{NO}_{2} \rightarrow \mathrm{HNO}_{3}
$$

Esta reação compete com a reação representada pela Equação 3.10 e, em baixas razões $\mathrm{COV} / \mathrm{NO}_{x}$, essa competição é maior, retirando da atmosfera tanto radicais ${ }^{\circ} \mathrm{OH}$, como $\mathrm{NO}_{x}$, diminuindo a formação de ozônio, que depende da quantidade de $\mathrm{NO}_{2}$ disponível para fotólise (Equação 3.8) e da evolução da cadeia de reações desencadeadas pela reação de COV com o radical ${ }^{\bullet} \mathrm{OH}(\text { Equação } 3.11)^{(15)}$.

Altas concentrações de NO recém emitido, localmente, consomem $\mathrm{O}_{3}$, no processo que leva à formação de $\mathrm{NO}_{2}{ }^{(16)}$ (Equação 3.10). Próximo a 
esses pontos este processo pode ser considerado como inibidor de $\mathrm{O}_{3}$. Em adição, altas concentrações de $\mathrm{NO}_{2}$ desviam o processo inicial de oxidação de COVs para a formação de outros produtos, como por exemplo o ácido nítrico, evitando a formação de ozônio ${ }^{(16)}$.

Outros problemas atribuídos ao ozônio são apresentados no Apêndice A.

\subsubsection{Emissões Automotivas}

Dentre os poluentes das emissões automotivas podemos citar como os mais preocupantes os hidrocarbonetos $(\mathrm{HC})$, os óxidos de nitrogênio $\left(\mathrm{NO}_{\mathrm{x}}\right)$, os óxidos de enxofre $\left(\mathrm{SO}_{\mathrm{x}}\right)$ e o monóxido de carbono $(\mathrm{CO})$.

Os $\mathrm{SO}_{\mathrm{x}}$ são provenientes do enxofre presente nos combustíveis e os $\mathrm{NO}_{x}$ são formados a partir do nitrogênio do combustível e pelo $\mathrm{N}_{2}$ do ar, que, com a alta temperatura do motor, tem a molécula quebrada e o nitrogênio reage com o oxigênio do ar formando $\mathrm{NO}_{x}$ (Equação 3.1). A produção de CO e HC pelo motor do automóvel está diretamente relacionada à concentração de ar $\left(\mathrm{O}_{2}\right)$ para a combustão e à temperatura da câmara de combustão. A produção de $\mathrm{NO}_{x}$ está relacionada à temperatura da câmara de combustão.

Se a relação ar/combustível for baixa, a produção de CO e HC será alta, enquanto a de $\mathrm{NO}_{x}$ será baixa, pois a temperatura estará baixa devido à combustão incompleta. Quando a razão ar/combustível for alta, a produção de CO e HC será baixa (diminui a combustão incompleta), a temperatura estará alta e a produção de $\mathrm{NO}_{x}$ será alta. Se a razão ar/combustível for 
maior ainda, o excesso de ar levará à diminuição da temperatura da câmara de combustão, o que diminui a produção de $\mathrm{NO}_{x}$ e aumenta a de $\mathrm{HC}$ (aumenta a combustão incompleta).

Para controlar essa razão ar/combustível, hoje os automóveis são equipados com dispositivos que asseguram as melhores condições para a combustão, como por exemplo, a injeção eletrônica.

\subsubsection{Catalisador Automotivo Comercial ("Três vias")}

A primeira geração dos conversores catalíticos somente controlava as emissões de monóxido de carbono $(\mathrm{CO})$ e hidrocarbonetos $(\mathrm{HC})$, e por isso eram chamados de catalisadores de "duas vias". No início dos anos 80, catalisadores capazes de controlar as emissões de óxidos de nitrogênio $\left(\mathrm{NO}_{\mathrm{x}}\right)$, além das emissões de $\mathrm{CO}$ e $\mathrm{HC}$, foram introduzidos no mercado e hoje, todos os automóveis vendidos são equipados com esse tipo de conversor catalítico, conhecido como catalisador de "três vias" (18).

O conversor catalítico é formado por uma colméia metálica e cerâmica $\left(\mathrm{Al}_{2} \mathrm{O}_{3}\right)$ - metal coberto com $\mathrm{Al}_{2} \mathrm{O}_{3}$ - impregnada com metais nobres ( $\mathrm{Rh}, \mathrm{Pt}$ e $\mathrm{Pd}$ ) e $\mathrm{CeO}_{2}$, que é adicionado como promotor devido à capacidade do cério de estocagem de oxigênio ${ }^{(19-20)}$. A seguir ele é enrolado em uma manta termoexpansiva que fixa, veda, isola termicamente e dá proteção mecânica ao componente. Por fim, o catalisador é montado dentro de uma carcaça de aço inoxidável, dando origem ao conversor catalítico. Esse conjunto é instalado no cano de escape do automóvel (Figura 1). 


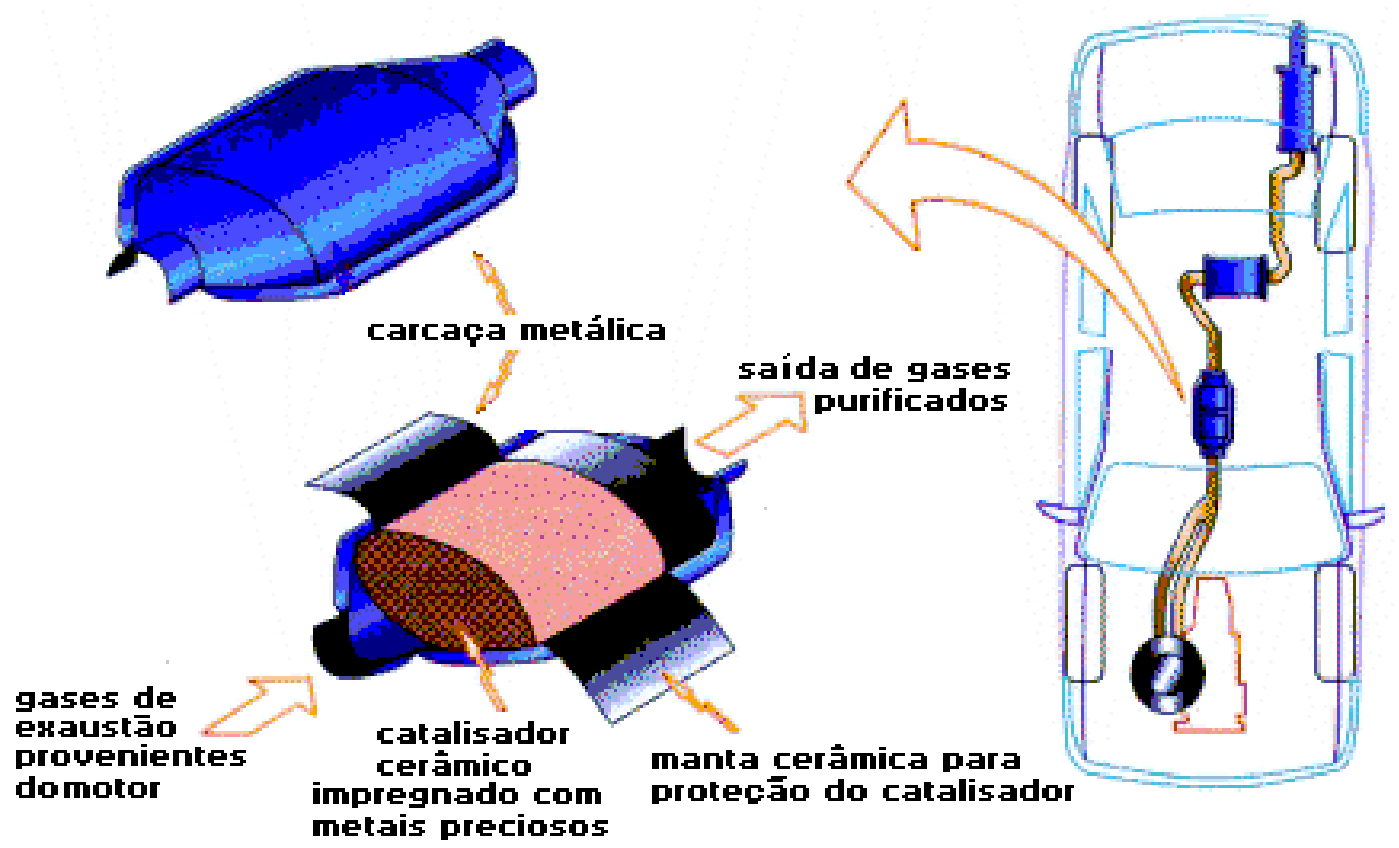

Figura 1: Conversor catalítico utilizado nos automóveis.

O óxido de cério é um componente bastante importante no conversor catalítico. Devido à sua facilidade em armazenar e liberar oxigênio $\left(\mathrm{CeO}_{2} \rightleftarrows \mathrm{Ce}_{2} \mathrm{O}_{3}\right)$ o óxido de cério regula a pressão parcial de oxigênio no sistema. Com o motor trabalhando sob condições de alta concentração de oxigênio, o cério remove excesso de oxigênio do gás de exaustão, favorecendo a redução catalítica de $\mathrm{NO}_{x}$ pelo $\mathrm{CO}$ e por $\mathrm{HC}$. Durante ciclos com baixa concentração de oxigênio, o óxido de cério libera oxigênio armazenado para oxidar monóxido de carbono e $\mathrm{HC}$ a $\mathrm{CO}_{2}$ em condições ótimas ${ }^{(21)}$.

Estes catalisadores atingem $50 \%$ de conversão quando a temperatura da reação atinge $300^{\circ} \mathrm{C}$. No momento que o automóvel é ligado, a temperatura do gás na entrada do catalisador é cerca de $56^{\circ} \mathrm{C}$, após 20 segundos $144^{\circ} \mathrm{C}$ e com 28 segundos chega a $300^{\circ} \mathrm{C}$. A quantidade de 
poluentes gerada neste período corresponde a $98 \%$ de todos os poluentes gerados até o desligamento do motor, pois a conversão do catalisador chega a quase $100 \%$ após 30 segundos que o motor foi ligado, ou seja, em temperaturas acima de $300^{\circ} \mathrm{C}^{(22)}$.

Chegou a ser anunciada a produção de conversores catalíticos que utilizavam molibdênio em substituição ao ródio, para controle das emissões de veículos movidos a álcool, mas atualmente os carros a álcool utilizam o mesmo catalisador que os automóveis movidos a gasool $(75 \%$ de gasolina e $25 \%$ de álcool). O catalisador utilizado para controle das emissões de veículos a diesel tem um sistema muito próximo ao apresentado anteriormente (conversor catalítico de veículos a gasool), com a adição de um filtro para material particulado, que é posteriormente transformado em $\mathrm{CO}_{2}$ e $\mathrm{H}_{2} \mathrm{O}$.

\subsection{Reações para Redução de $\mathrm{NO}_{\mathrm{x}}$}

A redução da emissão de óxidos de nitrogênio tornou-se hoje um dos grandes desafios para os pesquisadores da área de proteção ambiental. 0 interesse por este assunto é refletido nas várias conferências mundiais e pelos inúmeros trabalhos publicados a cada ano.

A natureza do catalisador tem grande importância nestas reações. Várias categorias já foram testadas: metálicos, metais suportados, óxidos e misturas de óxidos, zeólitas, etc., e para cada catalisador há um caminho diferente de reação. É possível dividir em quatro categorias: 
- Decomposição direta de óxidos de nitrogênio, que elimina o uso de agentes redutores e, com isso, a possível poluição adicional;

- Redução catalítica seletiva de óxidos de nitrogênio com amônia, típica de plantas químicas industriais;

- Redução catalítica seletiva de óxidos de nitrogênio na presença de hidrocarbonetos e mais particularmente metano, método este que pode ser aplicado tanto para controle de poluição automotiva quanto para plantas industriais;

- Redução catalítica de óxidos de nitrogênio na presença de monóxido de carbono e/ou hidrogênio, típica de controle de poluição automotiva.

O uso de agentes redutores nas reações leva a um decréscimo nos valores da energia livre de Gibbs. Isto explica porque tais reações são usadas em aplicações práticas ${ }^{(5)}$.

\subsubsection{Decomposição Direta de NO}

O monóxido de nitrogênio (NO) é termodinamicamente instável se comparado a $\mathrm{N}_{2}$ e $\mathrm{O}_{2}$ em temperaturas abaixo de $1000^{\circ} \mathrm{C}$ e sua decomposição catalítica (Equação 3.16) é um método simples e barato para remoção de NO de gases de exaustão ${ }^{(23)}$. 


$$
\begin{array}{r}
2 \mathrm{NO} \rightarrow \mathrm{N}_{2}+\mathrm{O}_{2} \\
\Delta \mathrm{H}=-180,5 \mathrm{~kJ} \mathrm{~mol}^{-1} \text { (a) }
\end{array}
$$

No desenvolvimento de um catalisador para a decomposição direta do NO o principal problema é a promoção da dessorção do oxigênio formado do catalisador. O oxigênio da dissociação do NO é ligado à superfície do catalisador muito fortemente, envenenando os sítios e impedindo posteriores dissociações de NO ${ }^{(23)}$. Portanto, normalmente para esta reação, os catalisadores são desativados muito facilmente.

\subsubsection{Redução de $\mathrm{NO}$ com $\mathrm{NH}_{3}$}

A redução catalítica de óxidos de nitrogênio de gases efluentes de várias indústrias, principalmente plantas de ácido nítrico, pode ser feita seletivamente, usando amônia ou uréia. Este processo é chamado de Redução Catalítica Seletiva. Esta é a técnica mais utilizada para controle de emissões de $\mathrm{NO}_{x}$. As reações ocorrem num intervalo curto de temperatura e a principal reação é a redução de $\mathrm{NO}$ ou $\mathrm{NO}_{2}$ a $\mathrm{N}_{2}$.

Geralmente amônia líquida é injetada no gás residual antes da reação catalítica acontecer, através de um sofisticado sistema de distribuição.

Os catalisadores baseados em óxidos metálicos (V, Cr, Fe, Cu, Co, Ni) são os sistemas mais estudados e eficientes para a reação ${ }^{(5)}$.

\footnotetext{
(a) A tabela com valores de entalpia e energia livre de Gibbs é apresentada no Apêndice B.
} 


\subsubsection{Redução de NO com Hidrocarbonetos}

A remoção de $\mathrm{NO}_{x}$ com hidrocarbonetos é, em geral, dependente do tipo de HC, o que dificulta sua aplicação, já que várias espécies de HC estão presentes nos combustíveis.

Este processo não tem um mecanismo de reação claramente elucidado ${ }^{(24)}$. Vários mecanismos de reação foram propostos e podem ser separados em ${ }^{(5)}$ :

- Oxidação de $\mathrm{NO}$ para $\mathrm{NO}_{2}$ reativo, que reage com hidrocarbonetos: este mecanismo é típico da redução catalítica seletiva do $\mathrm{NO} \operatorname{com~} \mathrm{CH}_{4}$;

- Conversão oxidativa de hidrocarbonetos pela reação com $\mathrm{NO}_{\mathrm{x}}$, formando um intermediário;

- Mecanismo redox envolvendo sucessivas oxidações e reduções da superfície do catalisador pelo NO e hidrocarbonetos.

A Redução catalítica Seletiva de NO com hidrocarbonetos é uma reação muito complexa e, normalmente, pouco seletiva para a formação de $\mathrm{N}_{2}{ }^{(25)}$.

\subsubsection{Redução de $\mathrm{NO}$ com $\mathrm{CO}$ ou $\mathrm{H}_{2}$}

Hidrogênio e monóxido de carbono, que são normalmente produzidos a partir de vários tipos de combustíveis, são redutores para o $\mathrm{NO}_{\mathrm{x}}$ bastante estudados e com mecanismo de reação simples ${ }^{(24)}$. A reação com um 
destes dois compostos foi a primeira possibilidade estudada para a remoção do NO do gás de exaustão automotivo ${ }^{(5)}$. A reação de NO com CO é apresentada pela Equação 3.17:

$$
\begin{array}{r}
\mathrm{CO}+\mathrm{NO} \rightarrow 1 / 2 \mathrm{~N}_{2}+\mathrm{CO}_{2} \\
\Delta \mathrm{H}=-373,23 \mathrm{~kJ} \mathrm{~mol}^{-1}
\end{array}
$$

Esta é uma das principais reações que ocorre no catalisador automotivo. Devido à presença de pequena quantidade de hidrogênio no gás de exaustão automotivo, a seguinte reação também ocorre (Equação 3.18):

$$
\begin{array}{r}
\mathrm{H}_{2(\mathrm{~g})}+\mathrm{NO}_{(\mathrm{g})} \rightarrow \mathrm{N}_{2(\mathrm{~g})}\left(\mathrm{ou} \mathrm{NH} \mathrm{NH}_{3}, \mathrm{~N}_{2} \mathrm{O}\right)+\mathrm{H}_{2} \mathrm{O}_{(\mathrm{l})} \quad \text { (Equação 3.18) } \\
\Delta \mathrm{H}=-376,08 \mathrm{~kJ} \mathrm{~mol}^{-1}
\end{array}
$$

Nem a reação de redução de $\mathrm{NO}$ com $\mathrm{CO}$, nem a redução com $\mathrm{H}_{2}$ pode ser considerada altamente seletiva, devido à possibilidade de formação de outros compostos nitrogenados, tais como $\mathrm{NH}_{3}$ ou $\mathrm{N}_{2} \mathrm{O}$, juntamente com $\mathrm{N}_{2}$. A formação de $\mathrm{N}_{2} \mathrm{O}$, por exemplo, pode acontecer (Equação 3.19) ${ }^{(5)}$ :

$$
\begin{array}{r}
\mathrm{CO}+2 \mathrm{NO} \rightarrow \mathrm{N}_{2} \mathrm{O}+\mathrm{CO}_{2} \\
\Delta \mathrm{H}=-381,43 \mathrm{~kJ} \mathrm{~mol}^{-1}
\end{array}
$$

Segundo K. Yokota et al. ${ }^{(24)}$, em catalisadores de metais nobres, ativos tanto para a reação de redução de $\mathrm{NO}$ com $\mathrm{CO}$, quanto para a 
redução de $\mathrm{NO}$ com $\mathrm{H}_{2}$, a temperatura de conversão para a reação de $\mathrm{NO}$ com $\mathrm{H}_{2}$ é menor, o que leva a maior formação de $\mathrm{N}_{2} \mathrm{O}$ neste caso, já que esta reação é favorecida em temperaturas mais baixas ${ }^{(5,24)}$.

Durante a reação NO/CO, o catalisador participa do mecanismo de redução, onde o catalisador é oxidado pelo NO e reduzido pelo carbono, através de uma transferência de oxigênio do metal oxidado para o carbono. Como conseqüência, o comportamento do catalisador é relacionado com: (i) o estado inicial do metal antes da reação (preferencialmente num estado reduzido), (ii) sua afinidade com $\mathrm{NO}$ e (iii) suas propriedades redox, isto é, a tendência do catalisador de ser oxidado por NO e a tendência do óxido resultante de ser reduzido pelo carbono durante a reação ${ }^{(26)}$.

O oxigênio, sempre presente em gases de exaustão, pode afetar a estrutura do catalisador, modificando o estado de oxidação do metal, e conseqüentemente, a atividade catalítica do metal ${ }^{(26)}$.

A redução de $\mathrm{NO}$ com $\mathrm{CO}$ pode ser representada por:

$\begin{array}{ll}\mathrm{NO} & \leftrightarrow \mathrm{NO}_{\text {ads }} \\ \mathrm{NO}_{\text {ads }} & \rightarrow \mathrm{N}_{\text {ads }}+\mathrm{O}_{\text {ads }} \\ \mathrm{NO}_{\text {ads }}+\mathrm{N}_{\text {ads }} & \rightarrow \mathrm{N}_{2} \mathrm{O} \\ 2 \mathrm{~N}_{\text {ads }} & \rightarrow \mathrm{N}_{2} \\ \mathrm{CO} & \leftrightarrow \mathrm{CO}_{\text {ads }} \\ \mathrm{CO}_{\text {ads }}+\mathrm{O}_{\text {ads }} & \rightarrow \mathrm{CO}_{2}\end{array}$


E importante considerar que devido às reações laterais que ocorrem e a dificuldade de obter-se estabilidade dos catalisadores por longos tempos na presença de água, de compostos de enxofre e de metais pesados, somente poucos sistemas catalíticos podem ser usados na prática.

\subsubsection{Catalisadores para a Redução de NO com CO}

O catalisador para eliminação de $\mathrm{NO}_{x}$, proveniente de motores a combustão, deve ser estável hidrotermicamente e ativo em temperaturas relativamente baixas na presença de oxigênio, vapor d'água e compostos de enxofre.

Algumas categorias de catalisadores têm sido estudadas: óxidos metálicos, misturas de óxidos, tipo perovskitas, metais suportados e zeólitas ${ }^{(24,27-32)}$.

\subsection{Metais Nobres}

O principal fator que controla a redução de $\mathrm{NO}$ em presença de $\mathrm{CO}$ é a natureza do metal nobre e do suporte, o tamanho do metal suportado e a temperatura de reação. A temperatura das reações sobre metais nobres é inferior a $700 \mathrm{~K}$.

K. Yokota et al. (24) investigaram a atividade de $\mathrm{Rh}, \mathrm{Pd}$ e $\mathrm{Pt}$, suportados em $\mathrm{Al}_{2} \mathrm{O}_{3}$ para a reação de redução de $\mathrm{NO}$ com $\mathrm{H}_{2}$ na presença de oxigênio e observaram que a platina apresenta maior conversão para esta reação. Outro sistema estudado foi paládio suportado com e sem 
adição de promotores ${ }^{(5,9-10)}$. Tem sido reportado que a adição de molibdênio como promotor melhora a atividade para a redução de NO com alta seletividade para $N_{2}$, na presença de oxigênio e também foi averiguado 0 comportamento do catalisador $\mathrm{MoO} / \mathrm{Al}_{2} \mathrm{O}_{3}$ com adição de $\mathrm{Pd}{ }^{(9-10)}$.

Em catalisadores de $\mathrm{Rh}$ e $\mathrm{Pd}$ a formação de $\mathrm{N}_{2} \mathrm{O}$ como produto intermediário aparece na reação de redução de $\mathrm{NO}$ com $\mathrm{CO}$, sendo que em temperaturas baixas a formação de $\mathrm{N}_{2} \mathrm{O}$ é favorecida, enquanto que em temperaturas mais altas a seletividade para a formação de $\mathrm{N}_{2}$ é preferencial, sempre maior que $80 \%{ }^{(30)}$.

\subsection{Catalisadores Suportados}

Um dos metais que tem apresentado melhor atividade para a redução de NO com CO é o cobre. Sabe-se que o Cu é ativo nesta reação no estado de oxidação +2 e que o cobre depositado em alumina $\left(\mathrm{Cu} / \mathrm{Al}_{2} \mathrm{O}_{3}\right)$ é mais ativo do que o óxido de cobre $(\mathrm{CuO})$, mesmo a concentração de átomos de cobre na superfície sendo menor ${ }^{(5)}$. Também foram estudados catalisadores de Cu-Co-suportados que, em temperaturas acima de $800 \mathrm{~K}$, somente levaram à formação de $\mathrm{N}_{2}$ e $\mathrm{CO}_{2}{ }^{(5)}$, mas a estabilidade destes catalisadores é muito baixa. A presença de vapor d'água também é prejudicial ao catalisador levando à desativação.

Óxidos de cobre suportados em sílica, em alumina e em titânia também foram estudados. As amostras fortemente reduzidas mostraram-se mais ativas para a reação NO - CO que as moderadamente reduzidas, mas não há evidências de que o cobre metálico seja o sítio ativo para a reação 
${ }^{(33)}$. A atividade foi comparada à dos metais nobres ${ }^{(5)}$. Estes catalisadores se apresentaram ativos na ausência de oxigênio e em presença de pequenas quantidades de vapor d'água (3\% em volume).

P. Lin et al. ${ }^{(34)}$ relataram que catalisadores contendo cobalto suportados em $\mathrm{Al}_{2} \mathrm{O}_{3}$ e com $\mathrm{Pt} / \mathrm{Rh}$ como promotores em pequena quantidade apresentaram boa atividade para a redução de NO e oxidação de $\mathrm{CO}$ e propeno, com desempenho comparável ao catalisador de três vias, sendo que o mesmo não foi observado para catalisadores contendo cobre suportados. Ambos os catalisadores ( $\mathrm{Co}$ e $\mathrm{Cu}$ ) apresentaram atividade comparável à do catalisador de três vias quando a quantidade de metais nobres adicionados foi maior, mas ainda cerca de $25 \%$ da quantidade utilizada no catalisador comercial ${ }^{(34)}$.

N. Mizuno et al. ${ }^{(35)}$ prepararam $\mathrm{La}_{2} \mathrm{CuO}_{4}$ disperso em $\mathrm{ZrO}_{2}$ e obtiveram com este catalisador alta atividade catalítica para a reação entre $\mathrm{NO}$ e $\mathrm{CO}$, com grande seletividade para $\mathrm{N}_{2}$ e $\mathrm{CO}_{2}$. Devido à maior área específica do suporte $\mathrm{ZrO}_{2}\left(22 \mathrm{~m}^{2} \mathrm{~g}^{-1}\right)$ em relação ao $\mathrm{La}_{2} \mathrm{CuO}_{4}$ (normalmente cerca de $1 \mathrm{~m}^{2} \mathrm{~g}^{-1}$ ), este composto suportado apresentou área superficial de $12,7 \mathrm{~m}^{2} \mathrm{~g}^{-1(35)}$.

\subsection{Perovskitas}

Perovskitas são óxidos, com fórmula geral $\mathrm{ABO}_{3}$. Elas são uma importante categoria de materiais catalíticos e têm sido estudadas em reações de oxidação de hidrocarbonetos, decomposições diretas de NO, redução de $\mathrm{NO}$ por $\mathrm{CO}, \mathrm{H}_{2}$ e hidrocarbonetos, reações de reforma, etc. ${ }^{(36)}$. 
Nos óxidos tipo perovskitas, $\mathrm{ABO}_{3}, \mathrm{~A}$ é um cátion, geralmente um metal de terras raras ou um metal alcalino terroso e B é um cátion, usualmente um metal de transição ( $3 d, 4 d$ ou $5 d)$. Nesta estrutura, o cátion B ocupa um sítio octaédrico rodeado por seis oxigênios. O cátion $A$, que é mais volumoso, está rodeado por 12 oxigênios e ocupa um sítio dodecaédrico, cavidade esta gerada pelo octaedro $\mathrm{BO}_{6}{ }^{(8,37-38)}$ (Figura 2).

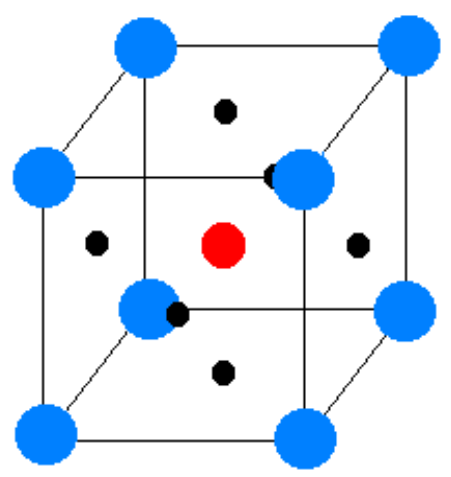

\section{Oxigênio}

Metal B

Metal A

Figura 2: Estrutura da Perovskita $\mathrm{ABO}_{3}$.

Perovskitas são conhecidas como catalisadores ativos para 0 tratamento do gás de exaustão automotivo. Sua alta estabilidade térmica, até mais de $1000^{\circ} \mathrm{C}$ e o grande número de íons metálicos que podem ser incorporados à estrutura $\mathrm{ABO}_{3}$ possibilitam o estudo de várias espécies destes óxidos ${ }^{(33)}$.

A substituição parcial de A ou B por outros metais com diferentes estados de oxidação leva a modificações das propriedades catalíticas, aumenta o estado de oxidação do cátion B ou pode produzir defeitos estruturais (vacâncias aniônicas ou catiônicas) as quais são geralmente associadas com as propriedades físico-químicas do material. Alguns 
trabalhos que têm sido relatados sobre perovskitas com substituição parcial do cátion $A$, afirmam que a substituição pode levar a um aumento de estabilidade térmica e de atividade ${ }^{(8)}$.

Usualmente, para a reação de NO com CO sobre perovskitas, é admitido que o NO é adsorvido e dissociado numa vacância de oxigênio e os átomos de nitrogênio adsorvidos se recombinam e dessorvem como $\mathrm{N}_{2}$. Para regenerar a superfície ativa do catalisador, é necessário CO para eliminar oxigênio com formação de $\mathrm{CO}_{2}$. Provavelmente há competição entre adsorção de $\mathrm{NO}$ e de $\mathrm{CO}$ nos sítios ativos e, em alguns casos, a redução da superfície ocorre em maior taxa ${ }^{(6,33)}$.

Um outro composto conhecido e estudado como catalisador para a reação de redução de $\mathrm{NO}$ com $\mathrm{CO}$ é o $\mathrm{La}_{2} \mathrm{CuO}_{4}$, que tem uma estrutura ortorrômbica, sendo esta uma distorção da estrutura tipo $\mathrm{K}_{2} \mathrm{NiF}_{4}{ }^{(38-40)}$. Essa estrutura, apresentada na Figura 3, pode ser descrita como contendo camadas alternadas de perovskita $\mathrm{ABO}_{3}$ e sal $\mathrm{AO}{ }^{(39)}$.

Segundo S. D. Peter et al. ${ }^{(33)}$, o $\mathrm{La}_{2} \mathrm{CuO}_{4}$, sob a mistura $\mathrm{NO}+\mathrm{CO}$, é reduzido mesmo em condições oxidantes (NO em maior concentração) e os óxidos dos metais separados (La e Cu) têm melhor atividade para a reação de redução de $\mathrm{NO}$ com $\mathrm{CO}$ que $\mathrm{La}_{2} \mathrm{CuO}_{4}$, mas não há evidências experimentais que Cu metálico seja o sítio ativo. Segundo eles, o catalisador $\mathrm{La}_{2} \mathrm{CuO}_{4}$ é reduzido pelo $\mathrm{CO}$ durante a reação ${ }^{(7,33)}$. 


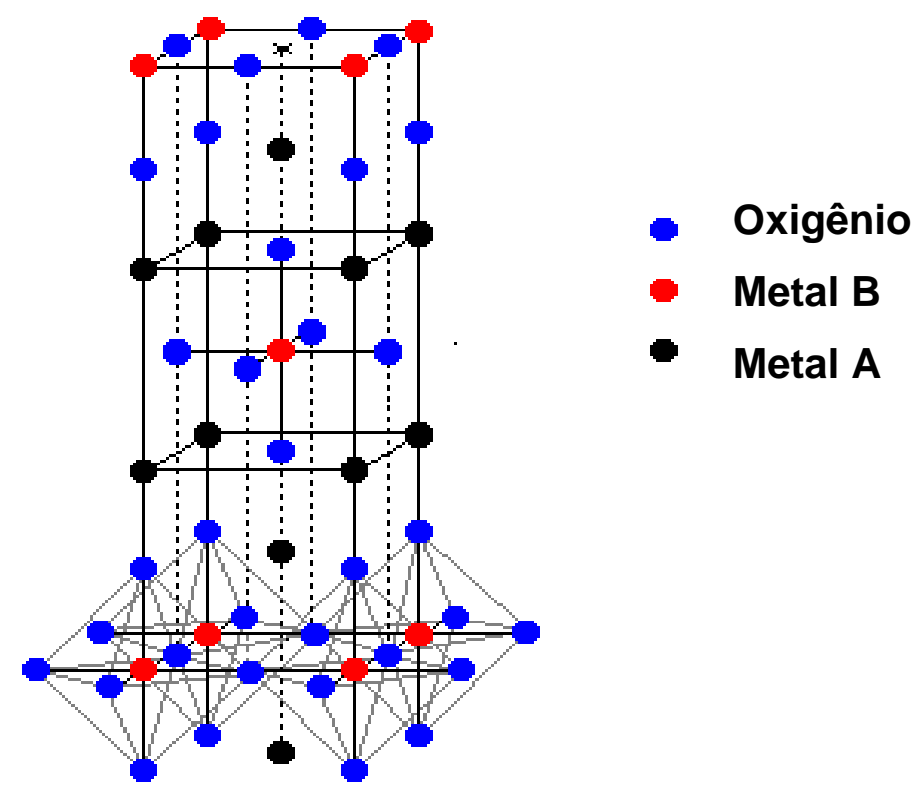

Figura 3: Estrutura $\mathrm{K}_{2} \mathrm{NiF}_{4}$ tetragonal $^{(39,41)}$.

Y. Teraoka et al. ${ }^{(42)}$ investigaram a atividade de catalisadores tipo perovskitas e do tipo $\mathrm{K}_{2} \mathrm{NiF}_{4}$ para a remoção simultânea de $\mathrm{NO}_{x}$ e material particulado de gases de exaustão automotivos e observaram que estes tipos de catalisadores são mais seletivos para a redução de $\mathrm{NO}_{x}$ que os óxidos dos metais e que $\mathrm{Pt} / \mathrm{Al}_{2} \mathrm{O}_{3}{ }^{(42)}$.

Y. Yokoi e H. Uchida (23) estudaram $\mathrm{LaCoO}_{3}$ e $\mathrm{LaNiO}_{3}$ como catalisadores para a decomposição direta de NO e observaram que houve a formação tanto de $\mathrm{N}_{2} \mathrm{O}$ quanto de $\mathrm{NO}_{2}$.

L. Simonot et al. ${ }^{(29)}$ observaram que, com $\mathrm{LaCoO}_{3}$ como catalisador, em temperaturas menores que $360^{\circ} \mathrm{C}$, parece não haver a reação de $\mathrm{NO}$ com CO diretamente. Em torno de $320^{\circ} \mathrm{C}$ a produção de $\mathrm{N}_{2} \mathrm{O}$ é máxima e representa cerca de $30 \%$ do NO convertido (Equações 3.26 e 3.27). 


$$
\begin{aligned}
4 \mathrm{NO}+2 \mathrm{CO} & \rightarrow 2 \mathrm{~N}_{2} \mathrm{O}+2 \mathrm{CO}_{2} \\
2 \mathrm{NO} & \rightarrow \mathrm{N}_{2} \mathrm{O}+\mathrm{O}_{\text {ads }}
\end{aligned}
$$

A temperaturas mais altas a reação de $\mathrm{NO}$ com $\mathrm{CO}$ acontece, com maior seletividade para a formação de $\mathrm{N}_{2}{ }^{(29)}$ (Equação 3.17, reapresentada abaixo).

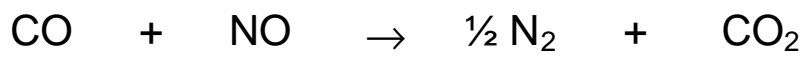

Em temperatura baixa a reação é controlada pelo $\mathrm{O}_{2}$ formado pela decomposição do NO. Esse oxigênio mantém a superfície oxidada, competindo com o NO pelo sítio ativo ${ }^{(5)}$.

Perovskitas de La-Ce-Co apresentaram boa atividade, tanto para oxidação de CO com o oxigênio do ar, quanto para redução de NO com CO e podem representar um bom catalisador para despoluição de gases de exaustão automotiva ${ }^{(27)}$.

\section{- Métodos para Preparação de Perovskitas}

Perovskitas podem ser obtidas pela reação de estado sólido entre óxidos dos metais. Este processo requer alta temperatura $\left(900-1000^{\circ} \mathrm{C}\right)$, o que leva à síntese de um sólido com área específica muito baixa, devido à sinterização $^{(7,43)}$.

A atividade de um catalisador depende de sua composição e do método de preparo ${ }^{(44)}$. Métodos envolvendo co-precipitação, normalmente 
deixam impurezas no catalisador, que influenciam em sua atividade. Métodos que partem dos citratos dos metais apresentam uma possibilidade de obtenção de compostos com áreas específicas maiores, principalmente se envolverem etapas de polimerização ${ }^{(29)}$.

L. Simonot et al. (28) prepararam $\mathrm{LaCoO}_{3}$ por co-precipitação e obtiveram uma perovskita de área específica $3,2 \mathrm{~m}^{2} \mathrm{~g}^{-1}$, tendo potássio como impureza.

S. D. Peter et al. ${ }^{(33)}$ prepararam $\mathrm{La}_{2} \mathrm{CuO}_{4}$ diretamente a partir da decomposição dos nitratos dos metais, obtendo primeiro os óxidos separados e depois a estrutura desejada. Obtiveram um sólido de área específica de $0,6 \mathrm{~m}^{2} \mathrm{~g}^{-1}$, o que corresponde ao esperado devido à alta temperatura de calcinação $\left(1000^{\circ} \mathrm{C} / 48\right.$ horas $)$.

N. Mizuno et al. ${ }^{(6,45)}$ prepararam $\mathrm{La}_{2} \mathrm{CuO}_{4}$ partido de uma solução dos acetatos dos metais, preparando também estruturas com metais parcialmente substituídos. Os compostos obtidos por N. Mizuno et al. ${ }^{(6,45)}$ não apresentaram área específica maior que $4,2 \mathrm{~m}^{2} \mathrm{~g}^{-1}$, sendo que $\mathrm{La}_{2} \mathrm{CuO}_{4}$ foi obtido com área de $1,2 \mathrm{~m}^{2} \mathrm{~g}^{-1}$. Eles observaram que numa substituição parcial do lantânio por cério em 5 e 10\% o cério é incorporado à estrutura ortorrômbica $\mathrm{K}_{2} \mathrm{NiF}_{4}$ do $\mathrm{La}_{2} \mathrm{CuO}_{4}$, e que, na maior porcentagem de cério, existe a formação de pequena quantidade de $\mathrm{CuO}{ }^{(6)}$.

L. Forni et al. ${ }^{(27)}$ prepararam $\mathrm{La}_{(1-\mathrm{x})} \mathrm{Ce}_{\mathrm{x}} \mathrm{CoO}_{3}$ pelo método do citrato. Uma solução de ácido cítrico e etileno glicol foi adicionada a uma solução dos nitratos dos metais (La, Ce e Co) na proporção desejada. A mistura foi evaporada até a formação de um polímero, seco posteriormente em estufa para eliminar resíduos líquidos. O pó resultante foi aquecido por 6 horas a 
$300^{\circ} \mathrm{C}$ para eliminar a matéria orgânica e, depois, calcinada a $950^{\circ} \mathrm{C}$ por 30 horas em atmosfera oxidante. A área específica obtida para o $\mathrm{LaCoO}_{3}$ foi $1,3 \mathrm{~m}^{2} \mathrm{~g}^{-1}$, sem impurezas.

O método do citrato também foi utilizado por Z. Zhao et al. ${ }^{(38)}$ para a preparação de $\mathrm{LaNiO}_{3}$ e $\mathrm{La}_{2} \mathrm{NiO}_{4}$, com pré-calcinação a $600^{\circ} \mathrm{C}$ por 1 hora e calcinação a $950^{\circ} \mathrm{C}$ por 12 horas, levando a um composto com área específica de cerca de $5 \mathrm{~m}^{2} \mathrm{~g}^{-1}$, e por I. Rodriguez-Ramos et al. ${ }^{(46)}$ para a preparação de $\operatorname{LaMn}_{(1-x)} \mathrm{Cu}_{x} \mathrm{O}_{3}$, com calcinação a $700^{\circ} \mathrm{C}$ por 5 horas, obtendo compostos com área específica de até $28 \mathrm{~m}^{2} \mathrm{~g}^{-1}$.

A performance catalítica de óxidos tipo perovskitas é, assim como acontece em outros catalisadores, dependente da área superficial específica ${ }^{(43)}$. V. R. Choudhary et al. ${ }^{(43)}$ estudaram o aumento da área específica de $\mathrm{LaCoO}_{3}$ e $\mathrm{LaMnO}_{3}$ e de suas atividades catalíticas através de um tratamento hidrotérmico. A área superficial do $\mathrm{LaCoO}_{3}$ aumentou de 0,9 $\mathrm{m}^{2} \mathrm{~g}^{-1}$ para $16 \mathrm{~m}^{2} \mathrm{~g}^{-1}$, enquanto a atividade catalítica para a combustão de $\mathrm{CH}_{4}$ subiu de 20 para $64 \%$. 


\section{MATERIAIS E MÉTODOS}

Os materiais e métodos utilizados desde a preparação dos catalisadores até as caracterizações são apresentados a seguir.

\subsection{Reagentes e Gases}

Os reagentes utilizados para a preparação dos catalisadores foram:

$\begin{array}{ll}\mathrm{Cu}\left(\mathrm{NO}_{3}\right)_{2} \cdot 3 \mathrm{H}_{2} \mathrm{O} & \text { - Nitrato de Cobre } \\ \mathrm{La}\left(\mathrm{NO}_{3}\right)_{3} \cdot 5 \mathrm{H}_{2} \mathrm{O} & - \text { Nitrato de Lantânio } \\ \mathrm{Co}\left(\mathrm{NO}_{3}\right)_{2} \cdot 6 \mathrm{H}_{2} \mathrm{O} & - \text { Nitrato de Cobalto } \\ \mathrm{Ni}\left(\mathrm{NO}_{3}\right)_{2} \cdot 6 \mathrm{H}_{2} \mathrm{O} & - \text { Nitrato de Níquel } \\ \mathrm{Ce}\left(\mathrm{NO}_{3}\right)_{3} \cdot 6 \mathrm{H}_{2} \mathrm{O} & - \text { Nitrato de Cério III } \\ \left(\mathrm{NH}_{4}\right) \mathrm{Mo}_{7} \mathrm{O}_{24} \cdot 4 \mathrm{H}_{2} \mathrm{O} & - \text { Heptamolibdato de Amônio } \\ \mathrm{C}_{2} \mathrm{H}_{6} \mathrm{O}_{2} & - \text { Etileno Glicol } \\ \mathrm{C}_{6} \mathrm{H}_{8} \mathrm{O}_{7} \cdot \mathrm{H}_{2} \mathrm{O} & - \text { Ácido Cítrico }\end{array}$

Os gases utilizados para o ensaio catalítico foram:

NO $0,96 \%$ em He;

CO 1,0\% em He;

$\mathrm{N}_{2} 99,99 \%$. 
Os gases utilizados para as análises no cromatógrafo foram:

He 99,99\%;

Ar sintético.

\subsection{Preparação dos Catalisadores}

Os catalisadores foram preparados pelo método do citrato, pois, segundo já foi demonstrado na literatura $(5,27,38,46)$, este método leva à obtenção de perovskitas com áreas superficiais maiores e sem o risco de impurezas, normalmente observadas quando são utilizados métodos como o de co-precipitação ${ }^{(28)}$.

\subsubsection{Método do Citrato}

Foram preparadas soluções dos nitratos dos metais que irão compor o catalisador, em proporções estequiométricas em relação ao catalisador desejado e uma solução de ácido cítrico, na razão de 1 mol de ácido para cada mol de metal.

Para o caso do catalisador de lantânio e molibdênio, as soluções de nitrato de lantânio e heptamolibdato de amônio foram preparadas em relação a estequiometria do mecanismo para a formação de $\mathrm{La}_{2}\left(\mathrm{MoO}_{4}\right)_{3}$, proposto por G. P. Gonzalez-Rojas et al. ${ }^{(47)}$ (Equação 4.1), ou seja, na razão 1:1 para primeiro haver a formação de $\mathrm{LaMoO}_{3}$ e a partir da decomposição deste haver a formação de $\mathrm{La}_{2}\left(\mathrm{MoO}_{4}\right)_{3}$ : 


$$
6 \mathrm{LaMoO}_{3}+4,5 \mathrm{O}_{2} \rightarrow 2 \mathrm{La}_{2}\left(\mathrm{MoO}_{4}\right)_{3}+\mathrm{La}_{2} \mathrm{O}_{3}
$$

As soluções dos metais foram misturadas e, sob agitação, aquecidas até cerca de $60^{\circ} \mathrm{C}$. A essa solução dos nitratos dos metais a $60^{\circ} \mathrm{C}$ foi adicionada a solução de ácido cítrico e o sistema foi mantido a essa temperatura sob agitação por 15 minutos para garantir a homogeneização. Ainda mantendo a agitação e a temperatura de $60^{\circ} \mathrm{C}$, foi adicionado ao sistema etileno glicol em excesso de 5:1 em relação à menor concentração de metal na solução. Após mais 15 minutos de agitação a $60^{\circ} \mathrm{C}$ o sistema foi colocado em banho de areia a $110^{\circ} \mathrm{C}$ por 24 horas, para a eliminação da água e para a formação do polímero precursor. O mecanismo das reações pode ser visualizado na Figura 4.

O polímero formado foi mecanicamente quebrado para eliminar a água restante e aquecido em estufa a $110^{\circ} \mathrm{C}$ por cerca de 12 horas para a secagem completa do material. Após seco o polímero foi pré-calcinado a $600^{\circ} \mathrm{C}$ por 3 horas em atmosfera oxidante, para a eliminação da matéria orgânica e a formação dos óxidos dos metais que, posteriormente, na etapa de calcinação, através de uma reação de estado sólido dariam origem às perovskitas. 


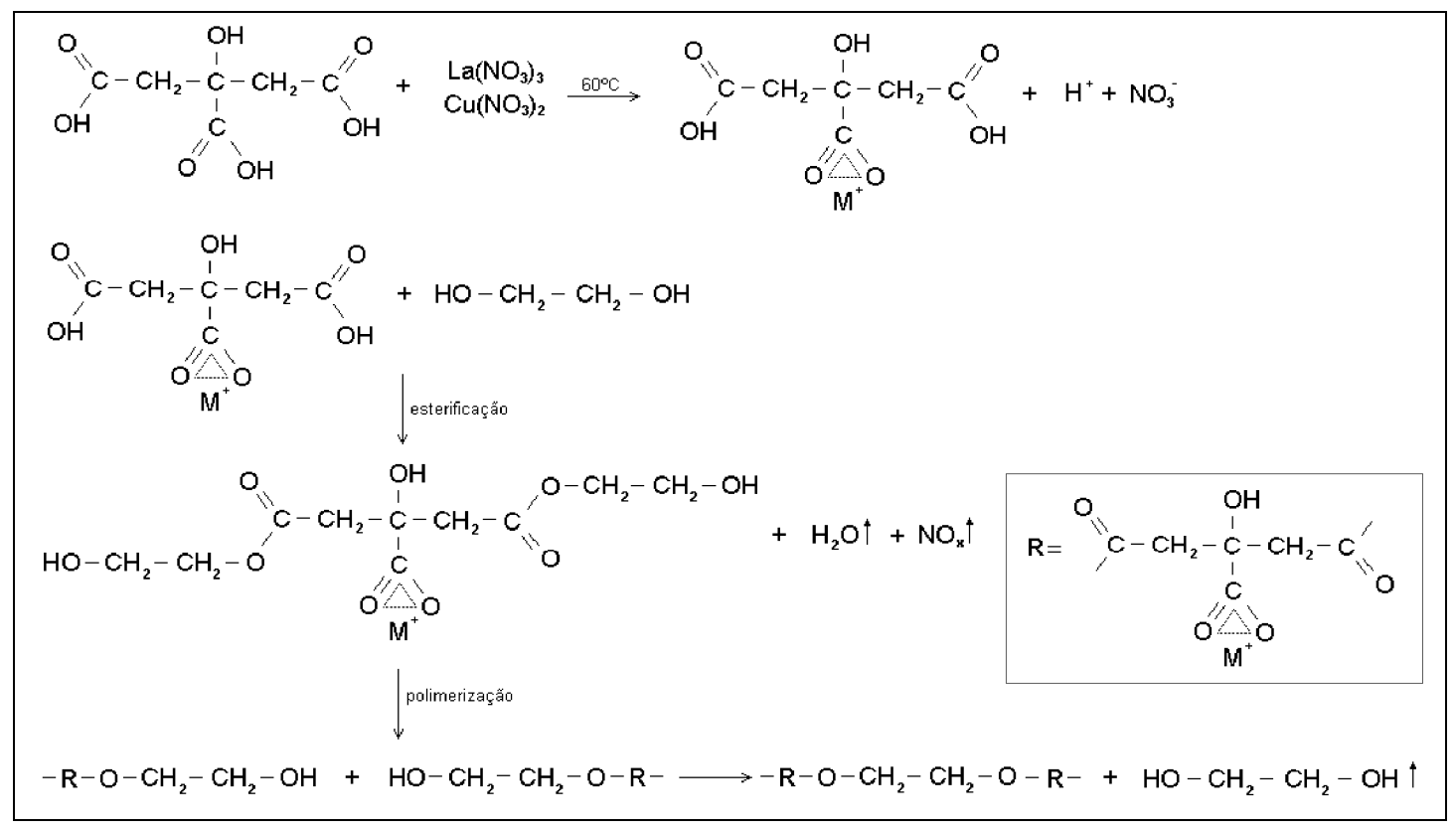

Figura 4: Mecanismo de formação do polímero precursor ${ }^{(48)}$.

Foi feita a calcinação dos catalisadores, em atmosfera oxidante, em 800 ou $900^{\circ} \mathrm{C}$ para estudar a diferença na estrutura e na atividade das perovskitas formadas. Como foi comentado na seção 3.2.4.1.3, a alta temperatura de calcinação, necessária para a obtenção da perovskita, leva à formação de um composto com baixa área específica, e a preparação dos catalisadores em temperaturas mais baixas poderia aumentar a área superficial do catalisador e assim melhorar a sua atividade.

Os catalisadores foram nomeados como mostra a Tabela 1: 
Tabela 1: Nome das amostras e temperaturas de calcinação.

\begin{tabular}{c|c|c|c|c}
\hline \multirow{2}{*}{ Amostra } & \multirow{2}{*}{ Metais } & Razão & \multicolumn{2}{c}{ Calcinação } \\
& & dos & \multicolumn{2}{c}{ (Atmosfera oxidante) } \\
\cline { 3 - 5 } & & metais & temperatura & Tempo \\
\hline \hline A1 & $\mathrm{La} / \mathrm{Cu}$ & $2: 1$ & $900^{\circ} \mathrm{C}$ & 10 horas \\
\hline A2 & $\mathrm{La} / \mathrm{Cu}$ & $2: 1$ & $800^{\circ} \mathrm{C}$ & 10 horas \\
\hline B1 & $\mathrm{La} / \mathrm{Ce} / \mathrm{Cu}$ & $1,4: 0,6: 1$ & $900^{\circ} \mathrm{C}$ & 10 horas \\
\hline B2 & $\mathrm{La} / \mathrm{Ce} / \mathrm{Cu}$ & $1,4: 0,6: 1$ & $800^{\circ} \mathrm{C}$ & 10 horas \\
\hline C1 & $\mathrm{La} / \mathrm{Mo}$ & $1: 1$ & $900^{\circ} \mathrm{C}$ & 10 horas \\
\hline C2 & $\mathrm{La} / \mathrm{Mo}$ & $1: 1$ & $800^{\circ} \mathrm{C}$ & 10 horas \\
\hline D1 & $\mathrm{La} / \mathrm{Co}$ & $1: 1$ & $900^{\circ} \mathrm{C}$ & 10 horas \\
\hline D2 & $\mathrm{La} / \mathrm{Co}$ & $1: 1$ & $800^{\circ} \mathrm{C}$ & 10 horas \\
\hline E1 & $\mathrm{La} / \mathrm{Ni}$ & $1: 1$ & $900^{\circ} \mathrm{C}$ & 10 horas \\
\hline E2 & $\mathrm{La} / \mathrm{Ni}$ & $1: 1$ & $800^{\circ} \mathrm{C}$ & 10 horas \\
\hline F1 & $\mathrm{La} / \mathrm{Ni} / \mathrm{Cu}$ & $3: 1: 1$ & $900^{\circ} \mathrm{C}$ & 10 horas \\
\hline F2 & $\mathrm{La} / \mathrm{Ni} / \mathrm{Cu}$ & $3: 1: 1$ & $800^{\circ} \mathrm{C}$ & 10 horas \\
\hline \hline
\end{tabular}

\subsection{Caracterização dos Catalisadores}

Algumas propriedades são importantes para catalisadores, como por exemplo, área superficial e estados de oxidação dos metais.

Com objetivo de analisar estas e outras características os catalisadores foram caracterizados por Difração de Raios-X, Redução a Temperatura Programada, Fisissorção de Nitrogênio (B.E.T.), Espectrometria de Emissão Atômica por Plasma Induzido ou Espectrofotometria de Absorção Atômica por Atomização por Chama e através do Ensaio Catalítico frente a reação de redução de NO em presença de CO. 


\subsubsection{Fisissorção de Nitrogênio (B.E.T.)}

Através da fisissorção de nitrogênio é possível determinar a superfície específica do composto, característica importante para a atividade catalítica.

O método de determinação de área superficial foi elaborado em 1938 por Brunauer, Emmett e Teller (B.E.T.) e baseia-se na quantidade de nitrogênio adsorvido, através de adsorções e dessorções, a diversas pressões relativas $P / P_{0}$ na temperatura do nitrogênio líquido ${ }^{(49-50)}$.

Através da equação de B.E.T., apresentada pela Equação 4.2, podese determinar o valor do volume da monocamada adsorvida:

$$
\frac{P}{V\left(P_{0}-P\right)}=\frac{1}{C V_{m}}+\frac{(C-1)}{C V_{m}} \cdot \frac{P}{P_{0}}
$$

Sendo:

$V=$ Volume de $\mathrm{N}_{2}$ adsorvido à pressão relativa $P / P_{0}$;

$V_{m}=$ Volume de $\mathrm{N}_{2}$ para cobrir o adsorbato com uma monocamada;

$P_{0}=$ Pressão de saturação do $\mathrm{N}_{2}$ líquido;

$C$ = Constante do sistema gás-sólido;

$P / P_{0}$ varia de 0,0 a 0,3

A partir da curva de $(1 / V) \cdot\left[P /\left(P_{0}-P\right)\right]$ versus $P / P_{0}$ obtém-se os coeficientes linear, $1 / C V_{m}$, e angular, $(C-1) / C V_{m}$, e, a partir deles o valor de $V_{m}$ e da constante $C$. 
A área superficial específica $\left(S_{g}\right)$ pode ser calculada pela Equação 4.3:

$S_{g}=n \cdot \sigma \cdot V_{m} / M_{a}$

Sendo:

$$
\begin{aligned}
& n=\frac{6,023 \cdot 10^{23}}{22,414} \text { moléculas } / \mathrm{cm}^{3} ; \\
& M_{a}=\text { Massa da amostra em gramas; } \\
& \sigma=\text { Área de cobertura de uma molécula de } \mathrm{N}_{2} \text { adsorvida }\left(16 \AA^{2}\right)
\end{aligned}
$$

\subsubsection{Redução à Temperatura Programada (RTP)}

Esta técnica tem como objetivo estudar a temperatura de redução dos compostos. Ela tem sido aplicada, com bastante sucesso, na caracterização de catalisadores metálicos.

Um detector de condutividade térmica responde à diferença na concentração de hidrogênio, que, ao passar pela amostra, reage com oxigênio, formando água e reduzindo a amostra. Um forno, com taxa de aquecimento programada, aquece a amostra e, de acordo com a temperatura que a redução acontece, é possível identificar as espécies presentes no composto e em que quantidade. Através de uma calibração feita com um composto conhecido, a partir da área do pico é possível determinar a quantidade de moles de $\mathrm{H}_{2}$ que reagiu para reduzir a espécie. 
O perfil de RTP consiste em um ou uma série de picos, sendo cada pico um processo de redução, envolvendo uma espécie particular presente no sólido. Os fatores que mais influenciam na curva de RTP são velocidade de aquecimento, vazão da mistura redutora, massa da amostra contida no reator e a concentração do gás na mistura ${ }^{(49)}$.

A amostra foi colocada num reator de quartzo, localizado dentro de um forno com velocidade de aquecimento controlada, e com fluxo contínuo de $\mathrm{H}_{2}$. As condições das análises foram as seguintes:

Massa de amostra: $10 \mathrm{mg}$;

Velocidade de Aquecimento: $10^{\circ} \mathrm{C} \min ^{-1}$, até $1000^{\circ} \mathrm{C}$;

Gás redutor: $\mathrm{H}_{2} 5 \%$ em $\mathrm{N}_{2}$ (em volume);

Fluxo do gás redutor: $30 \mathrm{~mL} \mathrm{~min}^{-1}$.

Para as amostras de lantânio e molibdênio (amostras C1 e C2), depois que a temperatura chegou em $1000^{\circ} \mathrm{C}$, esta foi mantida por 20 minutos, para a redução do composto se completasse.

O equipamento utilizado possuía um detector de condutividade térmica, sendo a diferença de concentração de $\mathrm{H}_{2}$ registrada num computador e, através da área de cada pico, foi possível determinar o número de moles de $\mathrm{H}_{2}$ consumidos para reduzir cada espécie e, assim, quantificar as espécies presentes na amostra. A calibração para este procedimento é apresentada no Anexo A. 


\subsubsection{Difração de Raios-X pelo Método do Pó}

É a técnica mais utilizada para a caracterização de catalisadores e de estruturas cristalinas. Através do ângulo de reflexão de raios-X emitidos por uma fonte de radiação é possível identificar as espécies presentes no composto.

A amostra a ser analisada é reduzida a um fino pó e submetida a um feixe de raios-X monocromático. Se a amostra for cristalina, cada partícula de pó será um pequeno cristal ou um conjunto de pequenos cristais orientados randomicamente em relação ao feixe incidente. Desse modo, todo conjunto de planos cristalográficos será capaz de reflexão, ou seja,

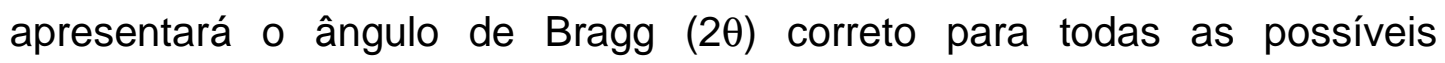
orientações ao redor do feixe incidente.

Os raios-X emitidos são difratados e depois detectados de acordo com o ângulo de difração $2 \theta$ (Figura 5).

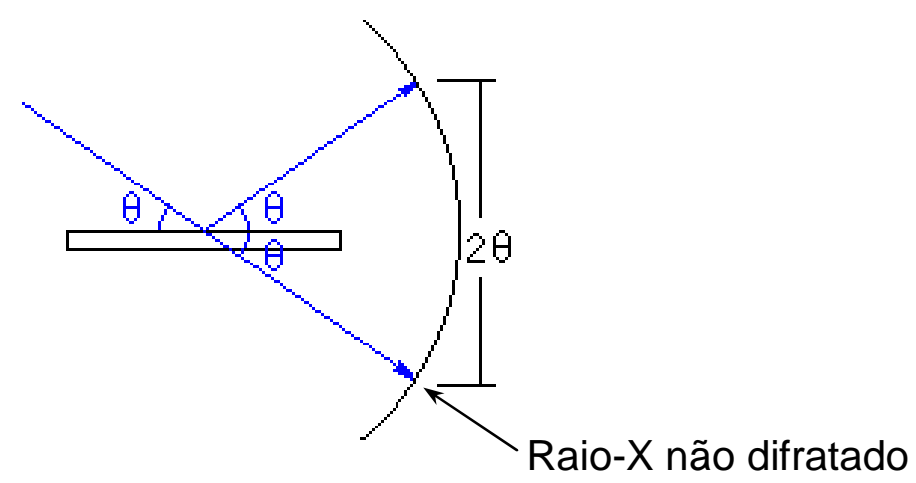

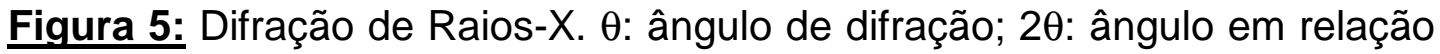
à referência. 
A radiação refletida é registrada, sendo apresentada por um gráfico

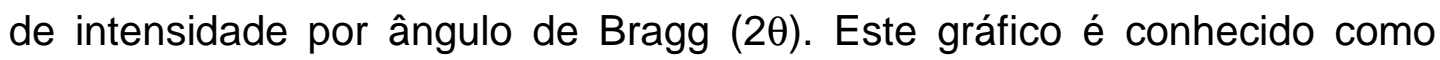
difratograma e nele uma série de picos característicos de cada substância aparece, possibilitando sua identificação.

Através da Lei de Bragg (Equação 4.4) é possível determinar o valor da distância entre os planos do cristal estudado (d) e, por comparação com valores conhecidos, identificar a composição da amostra.

$\mathrm{n} \lambda=2 \mathrm{~d} \operatorname{sen} \theta$

$\rightarrow$ Lei de Bragg

(Equação 4.4)

Sendo:

$\lambda=$ Comprimento de onda (conhecido pelo tubo utilizado como fonte de radiação);

$\theta=$ Ângulo de reflexão (determinado experimentalmente);

d = Distância entre os planos (calculado a partir da Lei de Bragg).

A dedução da Lei de Bragg é apresentada no Apêndice C.

As amostras foram reduzidas a um pó fino e compactadas no portaamostra. As condições de análise foram:

Tubo de Cu: $\lambda \mathrm{K} \alpha=1,5406 \AA$;

Intervalo de varredura: $2 \theta=$ de $3^{\circ}$ a $80^{\circ}$;

Velocidade de varredura: $2^{\circ} \mathrm{min}^{-1}$ 
Com os valores de $2 \theta$, através da Lei de Bragg (Equação 4.4) foi possível obter os valores de "d" para cada composto e a identificação foi feita por comparação com dados da literatura ${ }^{(51)}$.

\subsubsection{Análise da Composição dos Sólidos}

Foram utilizadas duas técnicas para a caracterização química das amostras. Cobre, níquel e cobalto foram analisados por espectrofotometria de absorção atômica, com atomização por chama. As concentrações de lantânio, cério e molibdênio foram determinadas por espectrometria de emissão atômica por plasma induzido.

Como as amostras calcinadas em 900 e $800^{\circ} \mathrm{C}$ foram preparadas em uma única etapa, somente sendo separadas para a calcinação, as análises de concentração dos metais foram feitas com as amostras pré-calcinadas, já que na etapa de calcinação não se esperava perda de massa ou de metais por somente ocorrer reação do estado sólido entre os óxidos para a formação da perovskita.

Para a determinação das concentrações dos metais neste estudo, as amostras foram primeiramente abertas com cerca de $5 \mathrm{~mL}$ de "água-régia" e diluídas com água para um volume de $100 \mathrm{~mL}$ e esta solução foi submetida às análises. 


\subsubsection{Espectrometria de Emissão Atômica por Plasma} Induzido

O plasma é produzido pelo efeito do campo de radiofreqüência no gás fluente. Argônio flui através de um tubo de quartzo, envolto por uma espiral de cobre. A espiral é energizada por um gerador de radiofreqüência criando um campo magnético no gás dentro do tubo. Isso induz uma corrente circular no gás condutor, que o aquece. Argônio não é condutor a temperatura ambiente, mas pode se tornar condutor elétrico se aquecido. $\mathrm{O}$ argônio é rapidamente aquecido pela descarga da espiral de cobre, produzindo um plasma bastante estável, com temperatura entre 9000 e $10000 \mathrm{~K}$.

A amostra é levada para dentro do plasma por argônio e pode estar na forma de aerosol, vapor ou um pó fino ${ }^{(52)}$.

O aquecimento promove nos átomos da amostra a passagem dos elétrons mais externos (mais distantes do núcleo) do seu estado fundamental para estados excitados. Depois de um microssegundo ou menos, os átomos excitados retornam a seu estado fundamental e liberam essa energia como fótons de radiação visível ou ultravioleta.

\subsubsection{Espectrofotometria de Absorção Atômica com} Atomização por Chama

A maioria dos átomos livres presentes nas chamas normalmente usadas está no estado fundamental, já que a chama não tem energia 
suficiente para excitar os átomos a níveis mais altos (exceto elementos do grupo I - Alcalinos). Uma fonte de luz que emita uma linha espectral suficientemente estreita e de energia característica é usada para excitar estes átomos no estado fundamental formados na chama. A diminuição da energia desta fonte (absorção) é então observada ${ }^{(53)}$.

A absorção é proporcional à concentração dos átomos livres presentes na chama, obedecendo à lei de Lambert-Beer (Equação 4.5).

Absorbância $=\log \mathrm{I}_{0} / \mathrm{I}_{\mathrm{t}}=\mathrm{K} \times \mathrm{C} \times \mathrm{L}$

(Equação 4.5)

Sendo:

$\mathrm{I}_{0}=$ Intensidade da radiação incidente emitida pela fonte de luz;

$\mathrm{I}_{\mathrm{t}}=$ Intensidade da radiação transmitida (quantidade não absorvida);

C = Concentração da amostra (átomos livres);

$\mathrm{K}=$ Constante de proporcionalidade (determinada experimentalmente);

$\mathrm{L}=$ Caminho ótico.

Em termos práticos, a lei de Lambert-Beer pode ser reduzida a (Equação 4.6) ${ }^{(53)}$ :

Absorbância $=\log \mathrm{I}_{0} / \mathrm{I}_{\mathrm{t}}=\mathrm{C}$

pois o equipamento é calibrado com padrões e as concentrações das amostras são obtidas por interpolação nas mesmas condições experimentais. O método não é absoluto, mas comparativo. 


\subsubsection{Ensaio catalítico}

Para estudar o comportamento dos catalisadores frente à reação química é realizado um ensaio catalítico.

Para este procedimento é utilizada uma linha de ensaios, que é alimentada continuamente com fluxo controlado dos gases que participarão da reação, normalmente diluídos em gases inertes. O catalisador é colocado em um reator e este é aquecido por um forno até a temperatura em que se deseja estudar a reação. Este sistema é ligado em linha a um cromatógrafo a gás que continuamente analisa os produtos da reação. Com os resultados obtidos pela cromatografia para as condições de reação (massa de catalisador, fluxo de alimentação e temperatura de reação), é possível avaliar a atividade e seletividade do catalisador.

A cromatografia gasosa é a técnica normalmente utilizada para separar, identificar e quantificar os componentes do gás de saída do reator. Conhecendo a composição do gás de entrada no ensaio, com a análise do gás de saída, obtida pela cromatografia gasosa, é possível identificar as reações que ocorreram no reator, sob influência do catalisador e, assim, determinar a atividade e seletividade do catalisador.

Para este estudo, as amostras foram colocadas num reator tubular de vidro com leito fixo, posicionado verticalmente dentro de um forno com aquecimento controlado, alimentado por um fluxo contínuo da mistura $\mathrm{NO}+\mathrm{CO}$ em He, e ligado a um cromatógrafo gasoso. Um esquema da linha de ensaios é apresentado na Figura 6. 
O vaporizador indicado na Figura 6 não foi utilizado, já que a mistura reagente era gasosa.

Como a maioria dos estudos realizados envolvendo redução de NO com CO utiliza uma mistura reagente $1: 1$ de $\mathrm{NO}$ e $\mathrm{CO}$ em He ${ }^{(6,29,33,35)}$, com concentração em torno de 2000ppm de cada, para este estudo optou-se por utilizar uma mistura equimolar de $\mathrm{NO}$ e $\mathrm{CO}$ em $\mathrm{He}$, com 0,5\% cada $(\mathrm{NO} 1 \% / \mathrm{He}+\mathrm{CO} 1 \% / \mathrm{He})$. Para a determinação da concentração da mistura reagente o fator limitante foi a sensibilidade do cromatógrafo utilizado.

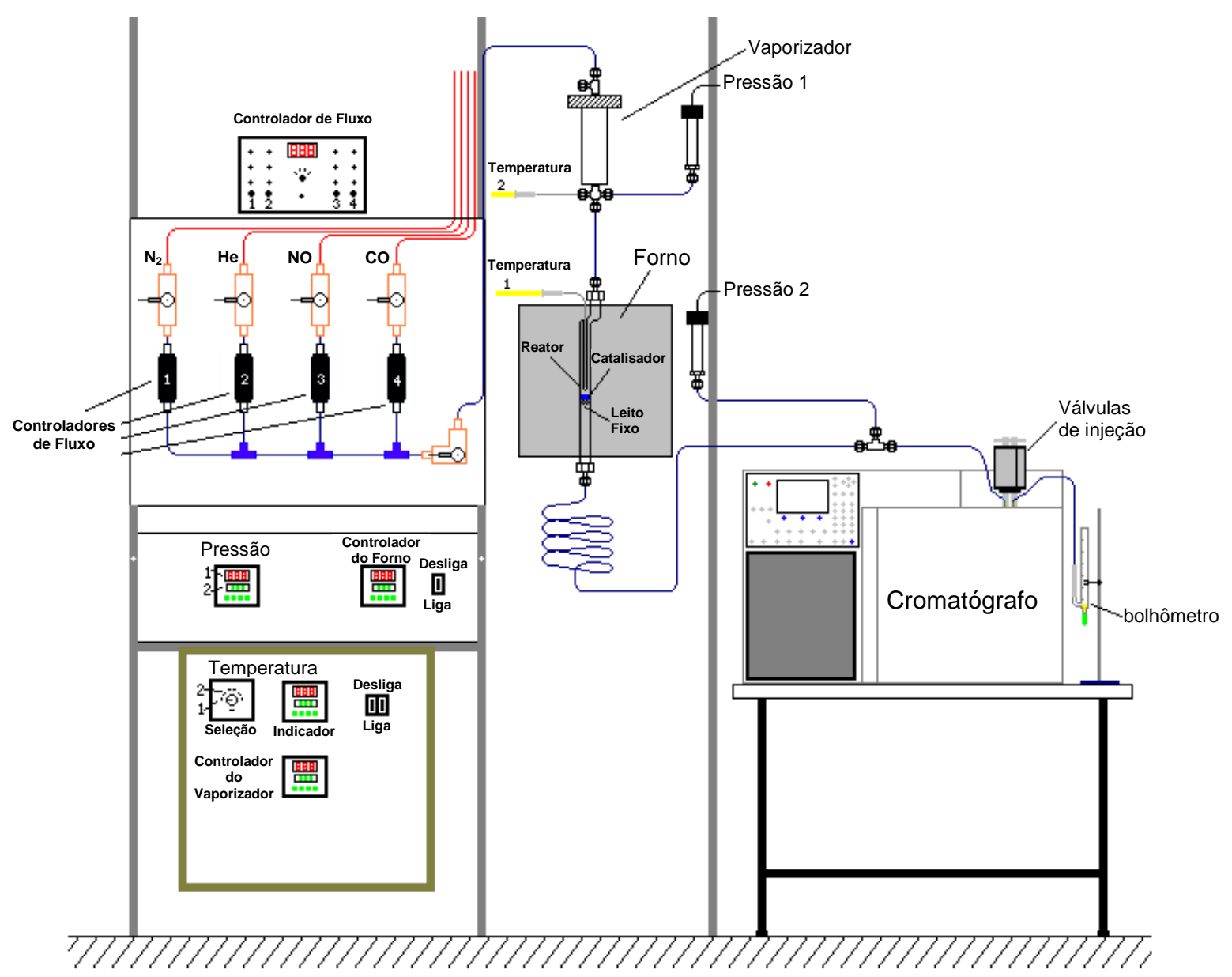

Figura 6: Linha de ensaios catalíticos. 
As condições dos ensaios catalíticos foram as seguintes:

Massa de catalisador: $150 \mathrm{mg}$;

Fluxo de alimentação: $25 \mathrm{~mL} \mathrm{~min}^{-1}$ de $\mathrm{NO} / \mathrm{He}+25 \mathrm{~mL} \mathrm{~min}^{-1}$ de $\mathrm{CO} / \mathrm{He}$; $W / F: 3,0 \mathrm{mg}_{\text {cat. }}$ min $\mathrm{mL}_{\text {mist. }}{ }^{-1}$

Temperatura da reação: $500^{\circ} \mathrm{C}$;

Taxa de aquecimento do forno: $10^{\circ} \mathrm{C} \mathrm{min}^{-1}$;

Tempo de ensaio: 6 horas.

O fluxo de alimentação era mantido através de controladores de fluxo mássico, indicado na Figura 6. A temperatura no interior do reator era indicada através de um termopar localizado no interior do leito do reator, dentro de uma bainha. Este sistema pode ser melhor visualizado na Figura 7.

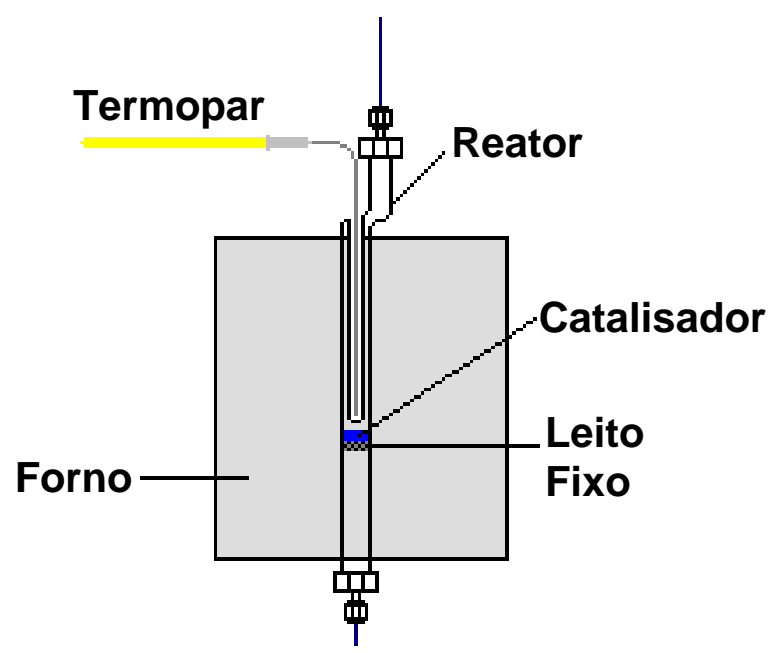

Figura 7: Reator de vidro utilizado para os ensaios catalíticos. 
A análise dos produtos foi feita em um cromatógrafo gasoso, equipado com duas colunas ligadas em série, sendo a primeira uma coluna empacotada Porapak N e a segunda uma Peneira Molecular 13X, com hélio como gás de arraste. As injeções eram feitas por válvulas com acionamento pneumático.

A coluna Porapak $\mathrm{N}$ foi utilizada com a finalidade de separar $\mathrm{CO}_{2} \mathrm{e}$ $\mathrm{N}_{2} \mathrm{O}$, e a Peneira Molecular $13 \mathrm{X}$ para separar $\mathrm{O}_{2}, \mathrm{~N}_{2}, \mathrm{NO}$ e $\mathrm{CO}$.

Antes de cada ensaio, a temperatura ambiente par garantir que não ocorresse reação entre os reagentes, foram feitas injeções no cromatógrafo para conhecimento da área máxima do pico cada reagente. Esta área era a área máxima de cada reagente, ou correspondente a $0 \%$ de conversão.

Após o início dos ensaios, a partir da área observada em cada pico (A) foi calculada a conversão dos reagentes da seguinte forma (Equações 4.7 e 4.8):

$$
\begin{aligned}
& R_{\text {saída }}=A \cdot 100 \% / A_{\text {máx }} \\
& \text { Conversão }_{\text {reagente }}=100 \%-R_{\text {saída }}
\end{aligned}
$$

Sendo:

$R_{\text {saída }}=$ Concentração do reagente na saída (\%);

$A \quad=$ Área do pico (u.a.);

$A_{\text {máx }}=$ Área máxima do reagente (u.a.);

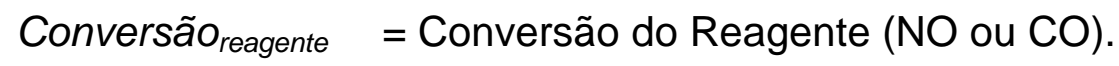


$\mathrm{O}$ cálculo do rendimento em $\mathrm{N}_{2}$ foi feito da mesma forma (Equação 4.9), sendo considerada a área máxima de $N_{2}$, ou $100 \%$ de rendimento, a área observada no ensaio da amostra $\mathbf{B}_{2}$ (ver seção 5.5).

Rendimento $N_{2}=A\left(N_{2}\right) \cdot 100 \% / A_{\operatorname{máx}(B 2)}$

(Equação 4.9)

Sendo:

Rendimento $\mathrm{N}_{2} \quad$ = Rendimento em N (\%);

$A\left(N_{2}\right)=$ Área do pico de $\mathrm{N}_{2}$ (u.a.);

$A_{\text {máx(B2) }}=$ Área máxima de $\mathrm{N}_{2}$ / área máxima da amostra B2 (u.a.).

Com estes valores de conversão ou rendimento foram construídos os gráficos para cada uma das amostras estudadas. 


\section{RESULTADOS E DISCUSSÃO}

Os catalisadores preparados foram caracterizados por difração de raios-X, redução a temperatura programada (RTP), análise química e área específica, além de terem sido testado frente a reação de redução de NO com CO.

\subsection{Difração de Raios-X}

Os difratogramas das amostras de lantânio e cobre são apresentados na Figura 8 e foram comparados com a literatura ${ }^{(51)}$ para caracterização da fase cristalina.

A amostra pré-calcinada em $600^{\circ} \mathrm{C}$ por 3 horas e depois calcinada em $900^{\circ} \mathrm{C}$ por 10 horas (A1) apresentou picos referentes à estrutura ortorrômbica do $\mathrm{La}_{2} \mathrm{CuO}_{4}$, com apenas dois pequenos picos (intensidade $3 \%$ ) que fazem referência à presença de $\mathrm{CuO}$.

Já no difratograma da amostra pré-calcinada em $600^{\circ} \mathrm{C}$ por 3 horas e depois calcinada em $800^{\circ} \mathrm{C}$ por 10 horas (A2), além dos picos correspondentes ao $\mathrm{La}_{2} \mathrm{CuO}_{4}$ ortorrômbico, também é possível observar picos que podem indicar a presença de pequena quantidade de $\mathrm{CuO}, \mathrm{La}_{2} \mathrm{O}_{3}$ e $\mathrm{La}_{2} \mathrm{CuO}_{4}$ tetragonal, também observado por N. Guilhaume et al. ${ }^{(7)}$. 


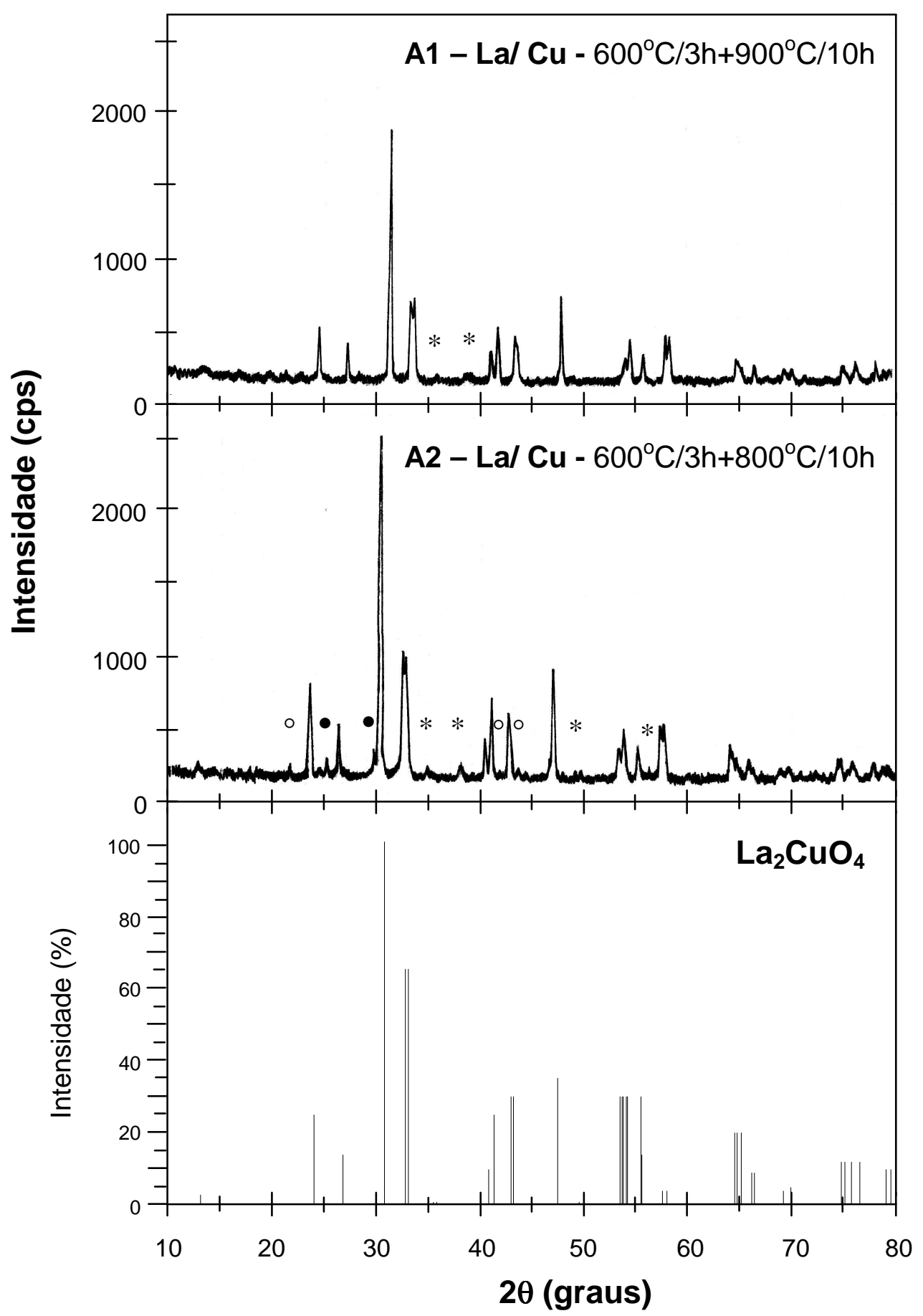

Figura 8: Difratogramas das amostras A1, A2 e padrão de $\mathrm{La}_{2} \mathrm{CuO}_{4}$ (ortorrômbico) ${ }^{(51)}$. A1 - amostra de La/ Cu pré-calcinada em $600^{\circ} \mathrm{C}$ e calcinada em $900^{\circ} \mathrm{C}$; $\mathbf{A} 2$ - amostra de La/ Cu pré-calcinada em $600^{\circ} \mathrm{C}$ e calcinada em $800^{\circ} \mathrm{C}$. * $-\mathrm{CuO} ;{ }^{\circ}-\mathrm{La}_{2} \mathrm{O}_{3} ;{ }^{\bullet-} \mathrm{La}_{2} \mathrm{CuO}_{4}$ tetragonal ${ }^{(7)}$. 
A existência de uma estrutura de $\mathrm{La}_{2} \mathrm{CuO}_{4}$ tetragonal do tipo $\mathrm{K}_{2} \mathrm{NiF}_{4}$ em temperaturas menores que $900^{\circ} \mathrm{C}$ foi reportada por J. M. Longo e P. M. Raccah ${ }^{(39)}$. Eles observaram que $0 \mathrm{La}_{2} \mathrm{CuO}_{4}$ ortorrômbico se transforma em tetragonal em $260^{\circ} \mathrm{C}$ e somente retorna completamente à estrutura ortorrômbica por volta de $990^{\circ} \mathrm{C}$, sendo possível observar em $800^{\circ} \mathrm{C}$ uma mistura das fases ortorrômbica e tetragonal.

É possível notar na Figura 8 que a intensidade dos picos do difratograma da amostra A2 é maior, indicando que, apesar de não ter se formado um cristal puro, de única fase, a fase ortorrômbica é mais cristalina nesta amostra.

Nas amostras com substituição de $30 \%$ do lantânio por cério (amostras B1 e B2) foi possível observar que os picos mais intensos do difratograma correspondem ao $\mathrm{CeO}_{2}$, indicando a provável formação de uma fase óxido de cério. Além de $\mathrm{CeO}_{2}$ também é possível observar a presença de $\mathrm{CuO}$ e de uma fase de $\mathrm{La}_{2} \mathrm{CuO}_{4}$, mas não é possível afirmar que parte do cério tenha se incorporado à estrutura do $\mathrm{La}_{2} \mathrm{CuO}_{4}$, já que, segundo N. Mizuno et al. ${ }^{(6)}$, a estrutura cristalina continua a mesma no caso desta substituição, não sendo observada mudança no difratograma. Não houve grande variação no difratograma das duas temperaturas de calcinação estudadas, exceto pela intensidade observada: a amostra calcinada em $900^{\circ} \mathrm{C}$ apresenta picos mais intensos, o que indica que é mais cristalina que a amostra calcinada em $800^{\circ} \mathrm{C}$. Os difratogramas são apresentados na Figura 9. 


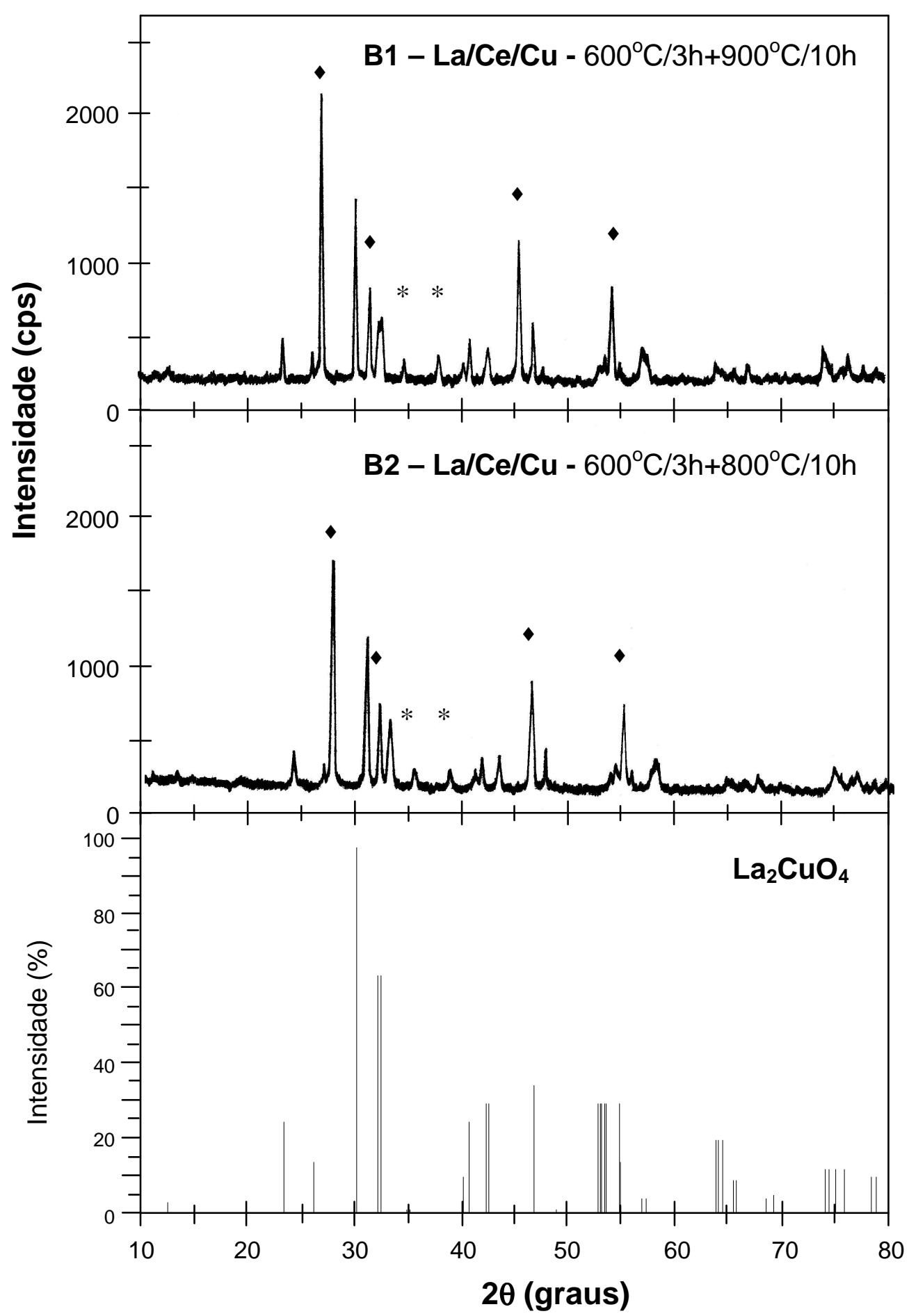

Figura 9: Difratogramas das amostras B1, B2 e padrão de $\mathrm{La}_{2} \mathrm{CuO}_{4}{ }^{(51)}$. B1 - amostra de $\mathrm{La} / \mathrm{Ce} / \mathrm{Cu}$ pré-calcinada em $600^{\circ} \mathrm{C}$ e calcinada em $900^{\circ} \mathrm{C}$; B2 - amostra de La/Ce/Cu pré-calcinada em $600^{\circ} \mathrm{C}$ e calcinada em $800^{\circ} \mathrm{C}$. $*$ - $\mathrm{CuO} ;-\mathrm{CeO}_{2}$ 
As amostras de lantânio e molibdênio (amostras $\quad$ C1 e C2) apresentaram uma fase cristalina mais próxima do $\mathrm{La}_{2} \mathrm{Mo}_{2} \mathrm{O}_{9}$, e não $\mathrm{La}_{2}\left(\mathrm{MoO}_{4}\right)_{3}$ como esperado. O difratograma obtido corresponde àquele observado por G. P. Gonzalez-Rojas et al. ${ }^{(47)}$, mas segundo o JCPDS, os picos correspondem ao $\mathrm{La}_{2} \mathrm{Mo}_{2} \mathrm{O}_{9}$, e não $\mathrm{La}_{2}\left(\mathrm{MoO}_{4}\right)_{3}$ como dito por Gonzalez-Rojas et al. ${ }^{(47)}$. Este composto $\left(\mathrm{La}_{2} \mathrm{Mo}_{2} \mathrm{O}_{9}\right)$ tem um sistema cúbico, sendo uma mistura de fases de $\mathrm{La}_{2} \mathrm{O}_{3}$ e $\mathrm{MoO}_{3}\left(\mathrm{La}_{2} \mathrm{O}_{3}\right.$ * $\left.2 \mathrm{MoO}_{3}\right)$. A amostra calcinada a $900^{\circ} \mathrm{C}$ por 10 horas (amostra $\mathbf{C 1}$ ) mostrou-se mais cristalina que a amostra calcinada a $800^{\circ} \mathrm{C}$ por 10 horas (amostra C2), o que pode ser concluído devido à maior intensidade dos picos no difratograma da amostra C1. Os difratogramas das amostras $\mathbf{C} 1$ e $\mathbf{C 2}$ e o padrão de $\mathrm{La}_{2} \mathrm{Mo}_{2} \mathrm{O}_{9}$ são apresentados na Figura 10.

Para o caso das amostras de La/Co e La/Ni aquelas calcinadas a $800^{\circ} \mathrm{C}$ (amostras D2 e E2, respectivamente) por 10 horas foram mais cristalinas que as calcinadas a $900^{\circ} \mathrm{C}$ por 10 horas (amostras D1 e E1, respectivamente).

As amostras de lantânio e cobalto (amostras D1 e D2) apresentaram a estrutura da perovskita $\mathrm{LaCoO}_{3}$. Os difratogramas das amostras D1 e D2 e do padrão de $\mathrm{LaCoO}_{3}$ podem ser vistos na Figura 11.

A estrutura de $\mathrm{LaNiO}_{3}$ pode ser observada nas amostras de lantânio e níquel (amostras E1 e E2). O padrão de $\mathrm{LaNiO}_{3}$ e os difratogramas das amostras E1 e E2 estão na Figura 12.

As amostras de lantânio, cobre e níquel (amostras F1 e F2) apresentaram em sua estrutura uma mistura das fases $\mathrm{LaNiO}_{3}$ e $\mathrm{La}_{2} \mathrm{CuO}_{4}$, 
como esperado.Os padrões de $\mathrm{LaNiO}_{3}$ e de $\mathrm{La}_{2} \mathrm{CuO}_{4}$ e os difratogramas das amostras F1 e F2 são apresentados na Figura 13.

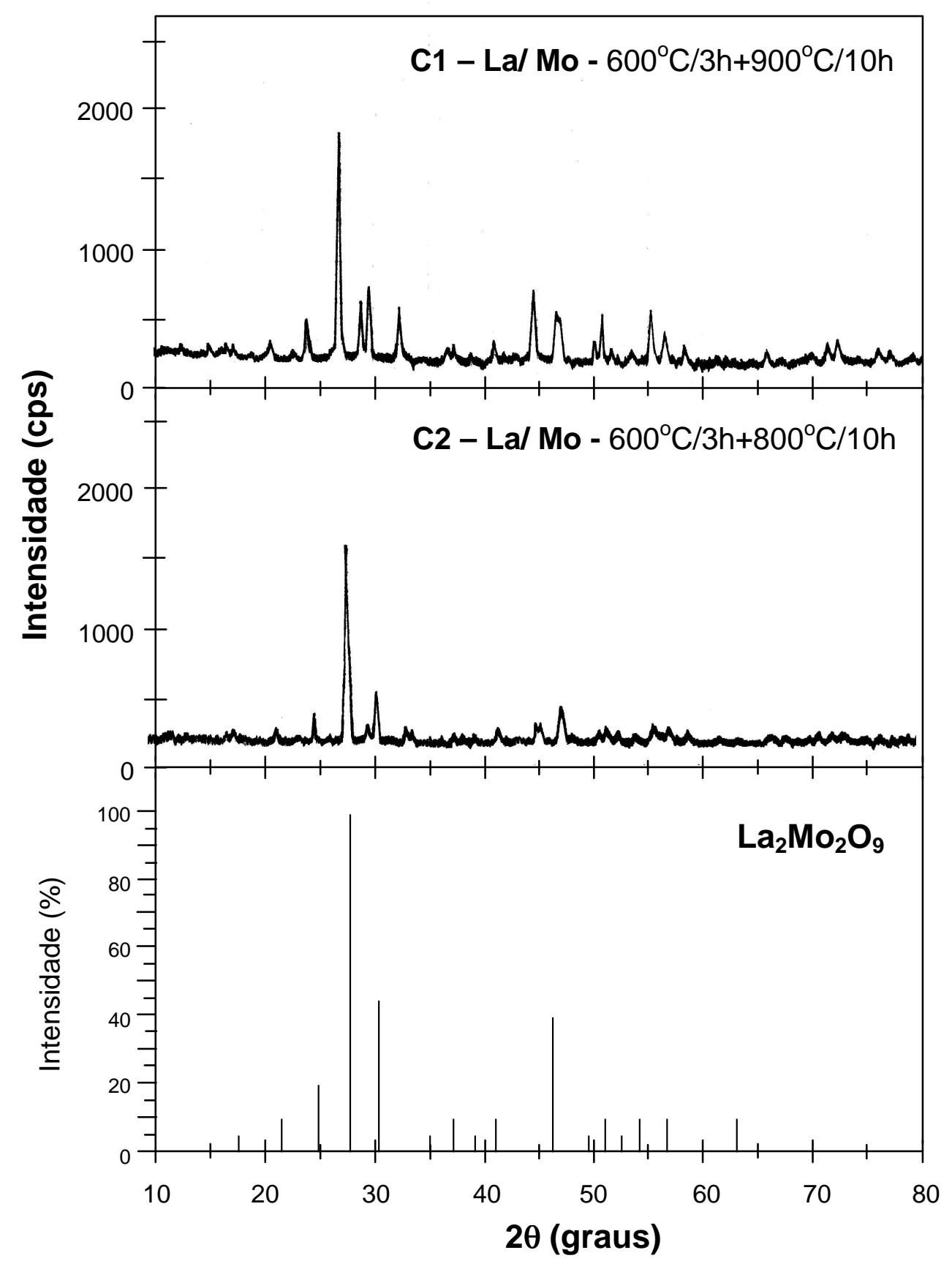

Figura 10: Difratogramas das amostras C1, C2 e padrão de $\mathrm{La}_{2} \mathrm{Mo}_{2} \mathrm{O}_{9}{ }^{\left({ }^{(51)}\right.}$. C1 - amostra de La/ Mo pré-calcinada em $600^{\circ} \mathrm{C}$ e calcinada em $900^{\circ} \mathrm{C}$; C2 - amostra de La/ Mo pré-calcinada em $600^{\circ} \mathrm{C}$ e calcinada em $800^{\circ} \mathrm{C}$. 


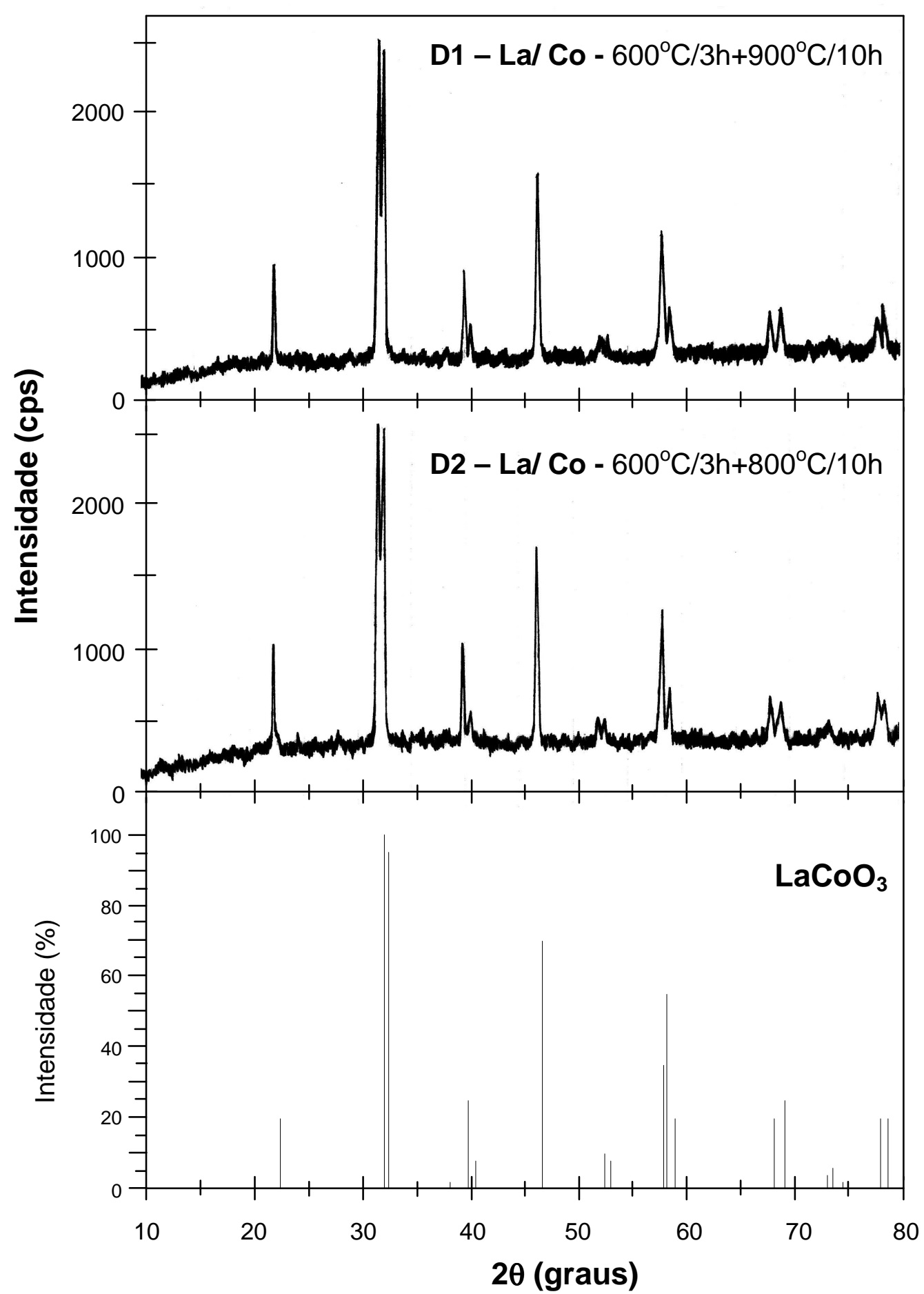

Figura 11: Difratogramas das amostras D1, D2 e padrão de $\mathrm{LaCoO}_{3}{ }^{(51)}$. D1 - amostra de La/ Co pré-calcinada em $600^{\circ} \mathrm{C}$ e calcinada em $900^{\circ} \mathrm{C}$; D2 - amostra de La/ Co pré-calcinada em $600^{\circ} \mathrm{C}$ e calcinada em $800^{\circ} \mathrm{C}$. 


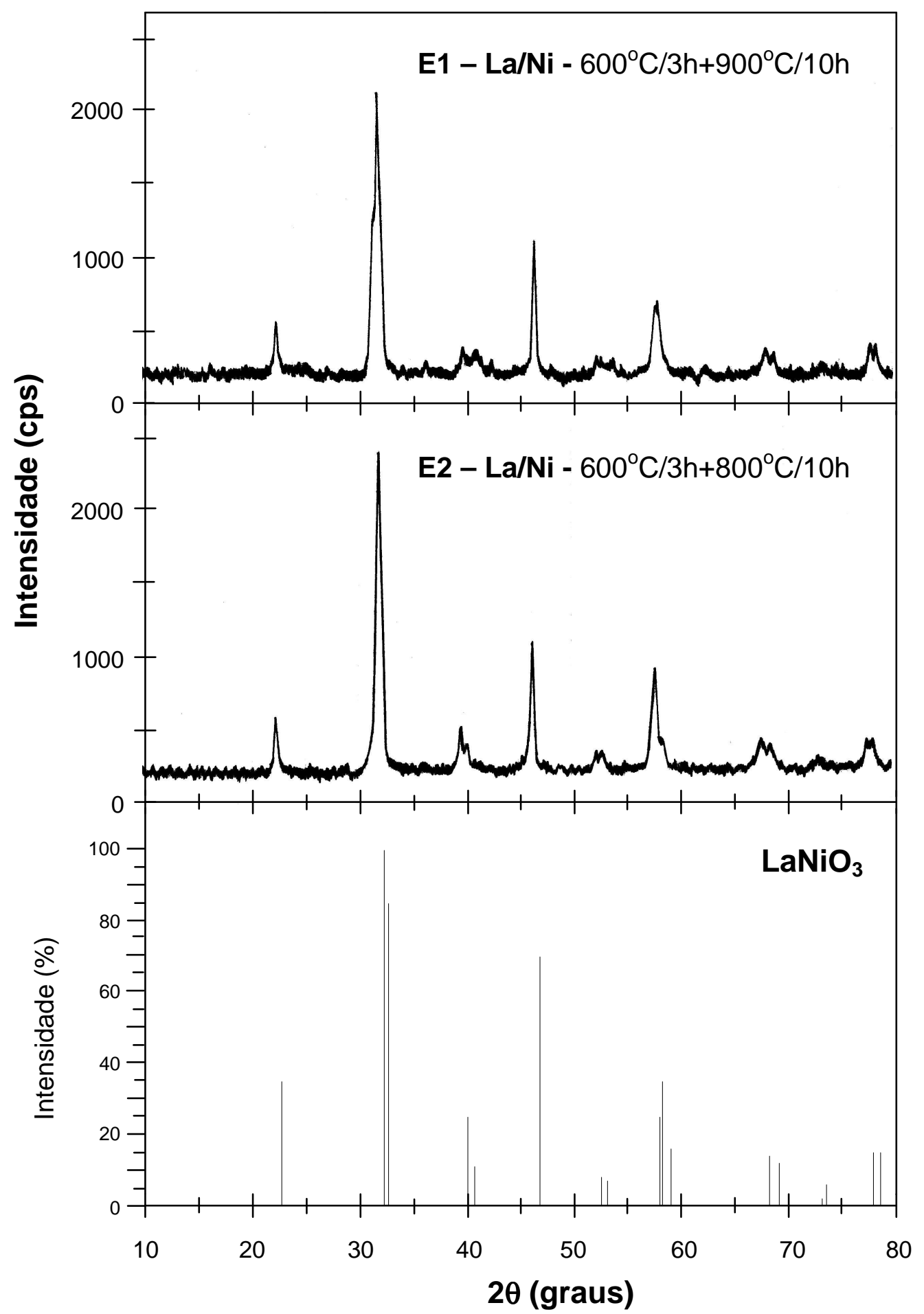

Figura 12: Difratogramas das amostras E1, E2 e padrão de $\mathrm{LaNiO}_{3}{ }^{(51)}$. E1 - amostra de La/Ni, pré-calcinada em $600^{\circ} \mathrm{C}$ e calcinada em $900^{\circ} \mathrm{C}$; E2 - amostra de La/Ni, pré-calcinada em $600^{\circ} \mathrm{C}$ e calcinada em $800^{\circ} \mathrm{C}$. 


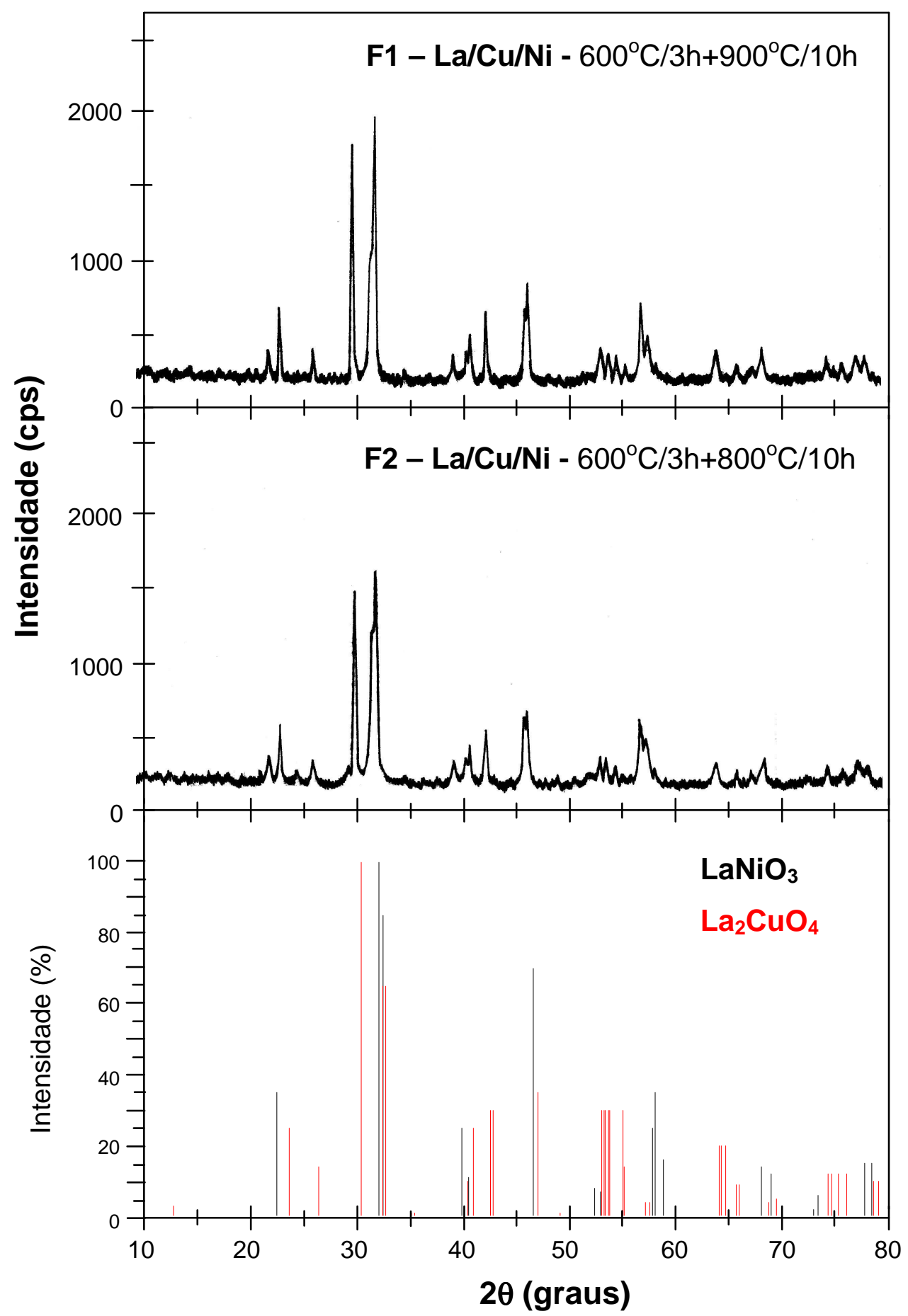

Figura 13: Difratogramas das amostras F1, F2 e padrões de $\mathrm{La}_{2} \mathrm{CuO}_{4} \mathrm{e}$ $\mathrm{LaNiO}_{3}{ }^{(51)}$. F1 - amostra de $\mathrm{La} / \mathrm{Cu} / \mathrm{Ni}$, pré-calcinada em $600^{\circ} \mathrm{C}$ e calcinada em $900^{\circ} \mathrm{C}$; $\mathbf{F} 2$ - amostra de $\mathrm{La} / \mathrm{Cu} / \mathrm{Ni}$, pré-calcinada em $600^{\circ} \mathrm{C}$ e calcinada em $800^{\circ} \mathrm{C}$. 


\subsection{Redução a Temperatura Programada (RTP)}

As curvas de RTP das amostras de lantânio e cobre (amostras A1 e A2) mostram um pico por volta de $350^{\circ} \mathrm{C}$, que pode ser atribuído à soma da redução do oxigênio restante na estrutura do óxido e de uma pequena quantidade de $\mathrm{CuO}$, também observada no DRX. A presença de excesso de oxigênio também foi observada por S. D. Peter et al. ${ }^{(54)}$. Outros dois picos aparecem um na região de $375-420^{\circ} \mathrm{C}$ (dependendo da temperatura de calcinação) e outro na região de $550^{\circ} \mathrm{C}$. Como o cobre está presente na estrutura $\mathrm{La}_{2} \mathrm{CuO}_{4}$ na forma $\mathrm{Cu}^{2+}{ }^{(6)}$, estes picos podem ser atribuídos, o primeiro à soma das reduções completa $\left(\mathrm{Cu}^{+2} \rightarrow \mathrm{Cu}^{0}\right)$ e parcial $\left(\mathrm{Cu}^{2+} \rightarrow \mathrm{Cu}^{+1}\right)$ do cobre, Equações 5.1 e 5.2 , e o segundo a outra redução parcial do cobre $\left(\mathrm{Cu}^{+1} \rightarrow \mathrm{Cu}^{0}\right)$, apresentada pela Equação 5.3.

$$
\begin{aligned}
\mathrm{La}_{2} \mathrm{CuO}_{4} & +\mathrm{H}_{2} \rightarrow \mathrm{La}_{2} \mathrm{O}_{3}+\mathrm{Cu}^{0}+\mathrm{H}_{2} \mathrm{O} \\
2 \mathrm{La}_{2} \mathrm{CuO}_{4}+\mathrm{H}_{2} & \rightarrow 2 \mathrm{La}_{2} \mathrm{O}_{3}+\mathrm{Cu}_{2} \mathrm{O}+\mathrm{H}_{2} \mathrm{O} \\
\mathrm{Cu}_{2} \mathrm{O}+\mathrm{H}_{2} & \rightarrow 2 \mathrm{Cu}^{0}+\mathrm{H}_{2} \mathrm{O}
\end{aligned}
$$

O perfil de RTP da amostra A1 é apresentado na Figura 14 e o da amostra A2 na Figura 15. O dados de temperatura dos picos, suas respectivas áreas e consumo de $\mathrm{H}_{2}$ para a redução são apresentados nas Tabelas 2 (amostra A1) e 3 (amostra A2). 


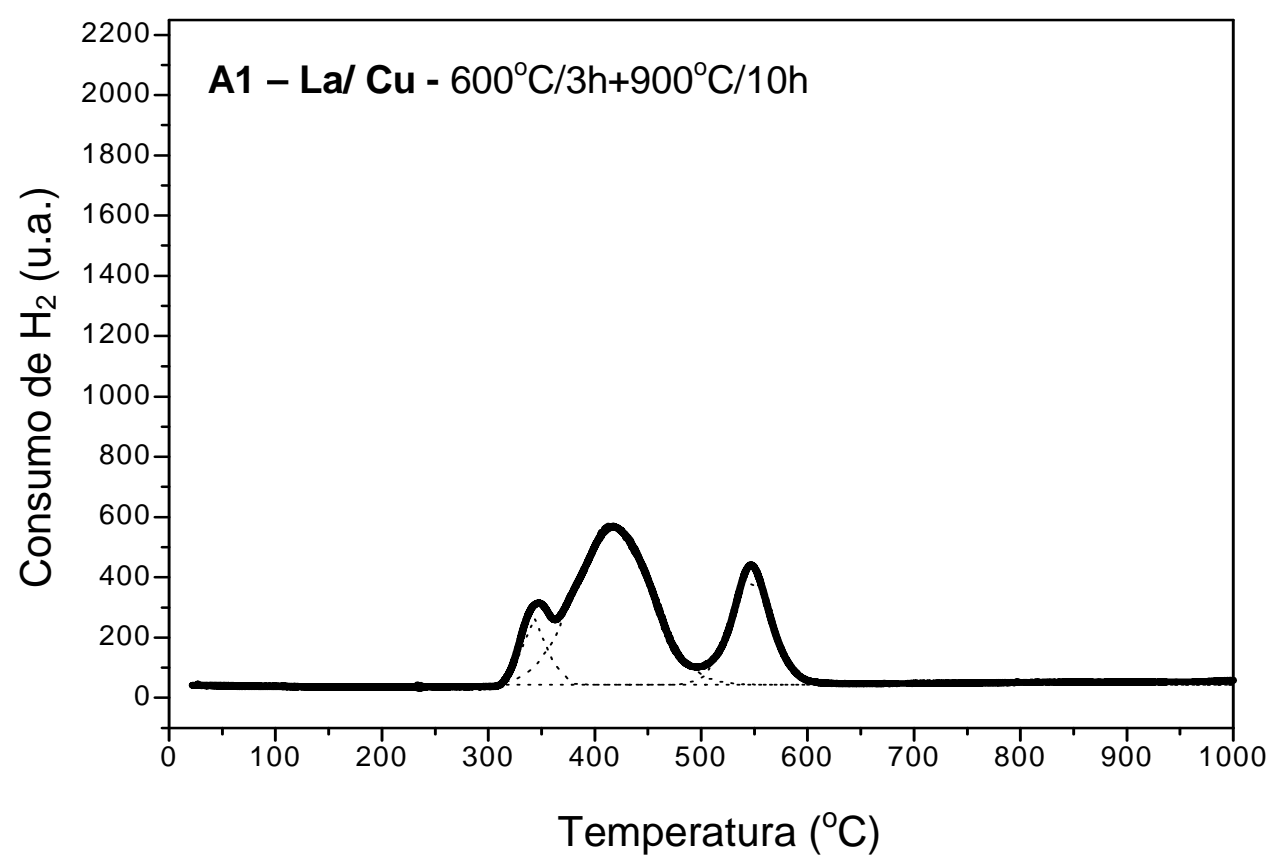

Figura 14: Perfil de RTP da amostra A1. A1 - amostra de La/ Cu précalcinada em $600^{\circ} \mathrm{C}$ e calcinada em $900^{\circ} \mathrm{C}$.

Tabela 2: Temperatura, área e número de moles de $\mathrm{H}_{2}$ consumido em cada pico do perfil de RTP da amostra A1 (Figura 14).

\begin{tabular}{c|c|c}
\hline \hline $\begin{array}{c}\text { Temperatura do } \\
\text { pico }\left({ }^{\circ} \mathrm{C}\right)\end{array}$ & $\begin{array}{c}\text { Área do pico } \\
\text { (u.a.) }\end{array}$ & $\begin{array}{c}\text { Número de moles } \\
\text { de } \mathrm{H}_{2} \text { consumido }\end{array}$ \\
\hline 343,3 & $6,55 \cdot 10^{3}$ & $2,79 \cdot 10^{-6}$ \\
\hline 417,0 & $4,59 \cdot 10^{4}$ & $1,95 \cdot 10^{-5}$ \\
\hline 547,2 & $1,76 \cdot 10^{4}$ & $7,52 \cdot 10^{-6}$ \\
\hline
\end{tabular}

O número de moles de $\mathrm{H}_{2}$ correspondente à redução de $\mathrm{Cu}^{2+} \rightarrow \mathrm{Cu}^{1+}$ no pico em $417,0^{\circ} \mathrm{C}$ é igual ao número de moles de $\mathrm{H}_{2}$ consumido no pico em $547,2^{\circ} \mathrm{C}\left(7,52 \cdot 10^{-6}\right.$ moles de $\left.\mathrm{H}_{2}\right)$, o restante corresponde à redução de $\mathrm{Cu}^{2+} \rightarrow \mathrm{Cu}^{0}\left(1,23 \cdot 10^{-5}\right.$ moles de $\left.\mathrm{H}_{2}\right)$. 
Com estes valores e as Equações 5.1, 5.2 e 5.3 é possível concluir que o número de moles de $\mathrm{Cu}$ presente na perovskita $\mathrm{La}_{2} \mathrm{CuO}_{4}$ é $2,73 \cdot 10^{-5}$, que corresponde ao número de moles de cobre teórico em $10 \mathrm{mg}$ de amostra. Os dados de número de moles de $\mathrm{La}_{2} \mathrm{CuO}_{4}$ esperado e o obtido experimentalmente são apresentados na Tabela 4.

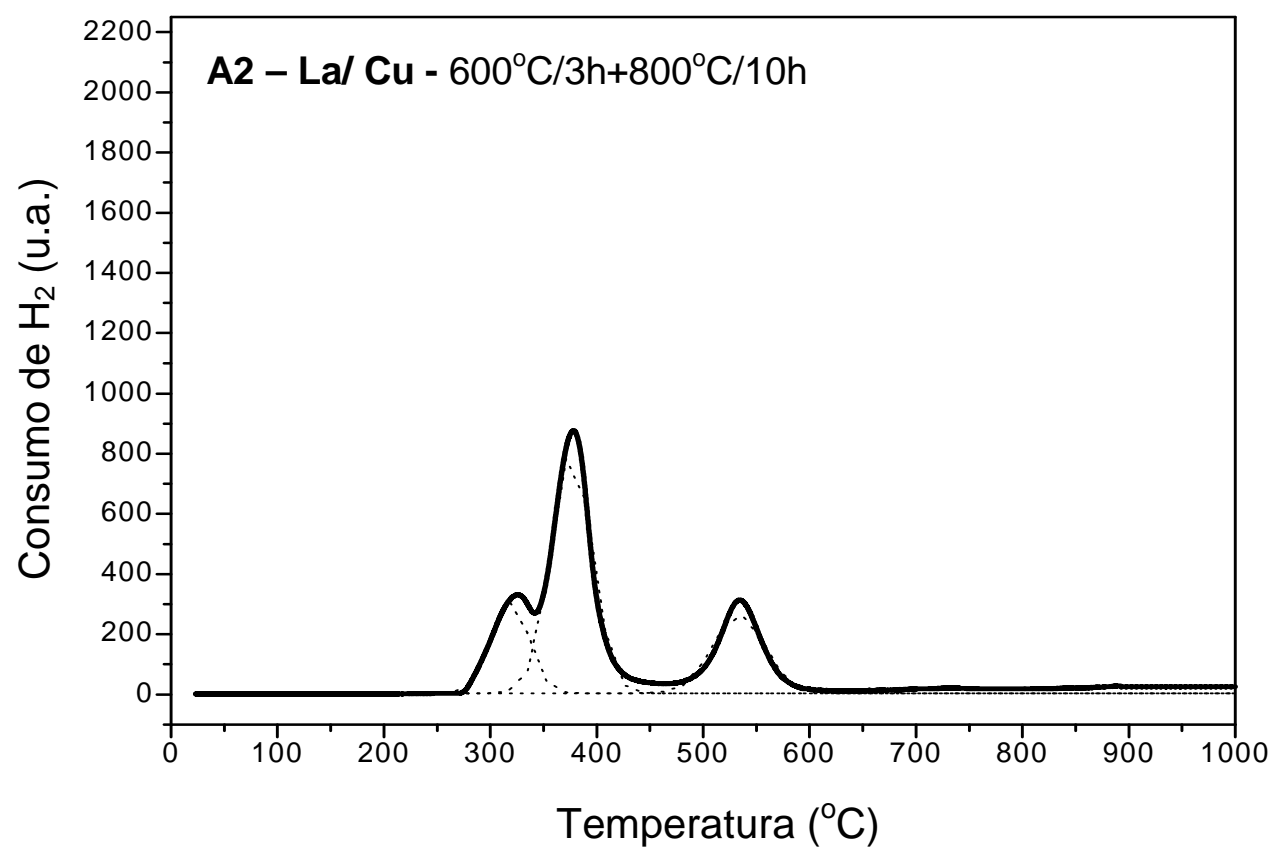

Figura 15: Perfil de RTP da amostra A2. A2 - amostra de La/ Cu précalcinada em $600^{\circ} \mathrm{C}$ e calcinada em $800^{\circ} \mathrm{C}$.

Tabela 3: Temperatura, área e número de moles de $\mathrm{H}_{2}$ consumido em cada pico do perfil de RTP da amostra A2 (Figura 15).

\begin{tabular}{c|c|c}
\hline \hline $\begin{array}{c}\text { Temperatura do } \\
\text { pico }\left({ }^{\circ} \mathbf{C}\right)\end{array}$ & $\begin{array}{c}\text { Área do pico } \\
\text { (u.a.) }\end{array}$ & $\begin{array}{c}\text { Número de moles } \\
\text { de } \mathbf{H}_{2} \text { consumido }\end{array}$ \\
\hline \hline 318,5 & $1,34 \cdot 10^{4}$ & $5,70 \cdot 10^{-6}$ \\
\hline 376,6 & $3,85 \cdot 10^{4}$ & $1,64 \cdot 10^{-5}$ \\
\hline 533,5 & $1,61 \cdot 10^{4}$ & $6,84 \cdot 10^{-6}$ \\
\hline
\end{tabular}


Da mesma forma como observado para a amostra $\mathbf{A 1}$, o número de moles de $\mathrm{H}_{2}$ correspondente à redução de $\mathrm{Cu}^{2+} \rightarrow \mathrm{Cu}^{1+}$ no pico em $376,6^{\circ} \mathrm{C}$ é igual ao número de moles de $\mathrm{H}_{2}$ consumido no pico em $547,5^{\circ} \mathrm{C}$ $\left(6,84 \cdot 10^{-6}\right.$ moles de $\left.\mathrm{H}_{2}\right)$, o restante corresponde à redução de $\mathrm{Cu}^{2+} \rightarrow \mathrm{Cu}^{0}$ $\left(9,56 \cdot 10^{-6}\right.$ moles de $\left.\mathrm{H}_{2}\right)$.

Assim, o número de moles de $\mathrm{Cu}$ presente na perovskita $\mathrm{La}_{2} \mathrm{CuO}_{4}$ na amostra $\mathbf{A} 2$ é $2,32 \cdot 10^{-5}$, que corresponde ao número de moles da $\mathrm{La}_{2} \mathrm{CuO}_{4}$ em $10 \mathrm{mg}$ de amostra. Os dados de número de moles de $\mathrm{La}_{2} \mathrm{CuO}_{4}$ esperado e o obtido experimentalmente são apresentados na Tabela 4.

O menor número de moles de $\mathrm{La}_{2} \mathrm{CuO}_{4}$ obtido para a amostra $\mathbf{A 2}$ confirma o que foi comentado nas análises de difração de raios- $X$, que a amostra A2 tem uma maior quantidade de óxido de cobre, $\mathrm{CuO}$, que a amostra $\mathbf{A 1 .}$

Tabela 4: Número estimado de moles de $\mathrm{La}_{2} \mathrm{CuO}_{4}$ e valores obtidos experimentalmente, correspondentes à massa reduzida nas amostras $\mathbf{A 1}$ e A2.

\begin{tabular}{|c|c|c|c|c|}
\hline $\begin{array}{c}\text { Massa } \\
\text { Molar } \\
\mathrm{La}_{2} \mathrm{CuO}_{4}(\mathrm{~g})\end{array}$ & $\begin{array}{c}\text { Massa } \\
\text { reduzida } \\
\text { no } \operatorname{RTP}(\mathbf{g})\end{array}$ & $\begin{array}{c}\text { № estimado de } \\
\text { moles de } \mathrm{H}_{2} \\
\mathrm{La}_{2} \mathrm{CuO}_{4}\end{array}$ & $\begin{array}{c}\text { № de moles de } \\
\mathrm{Cu} \text { na } \mathrm{La}_{2} \mathrm{CuO}_{4} \\
\text { (Amostra A1) }\end{array}$ & $\begin{array}{l}\text { № de moles de } \\
\mathrm{Cu} \text { na } \mathrm{La}_{2} \mathrm{CuO}_{4} \\
\text { (Amostra } \mathrm{A} 2 \text { ) }\end{array}$ \\
\hline 405,3 & 0,010 & $2,47 \cdot 10^{-5}$ & $2,73 \cdot 10^{-5}$ & $2,32 \cdot 10^{-5}$ \\
\hline
\end{tabular}

As amostras parcialmente substituídas por cério (amostras B1 e B2) apresentaram maior consumo de $\mathrm{H}_{2}$ (Figuras 16 e 17) que as amostras não 
substituídas (amostras A1 e A2), sendo seu pico mais intenso por volta de $350-380^{\circ} \mathrm{C}$. Este pico, juntamente com o pico menor em $385-440^{\circ} \mathrm{C}$, provavelmente refere-se à soma das reduções total $\left(\mathrm{Cu}^{2+} \rightarrow \mathrm{Cu}^{0}\right)$ e parcial $\left(\mathrm{Cu}^{2+} \rightarrow \mathrm{Cu}^{1+}\right)$ do cobre, Equações 5.4 e 5.5 , e às reduções do $\mathrm{CuO}$, do $\mathrm{CeO}_{2}$ (Equação 5.6) e excesso de $\mathrm{O}_{2}$ no sólido, já que o cério tem grande capacidade de armazenar oxigênio ${ }^{(6,20,26)}$, mudando facilmente seu estado de oxidação de $\mathrm{Ce}^{4+} \rightleftarrows \mathrm{Ce}^{3+}$. Este consumo de $\mathrm{H}_{2}$ está de acordo com o estudo realizado por N. Mizuno et al. ${ }^{(6)}$, que observaram que a substituição parcial do $\mathrm{La}^{3+}$ por $\mathrm{Ce}^{4+}$ diminui o número de oxidação do cobre para menos de +2 , e deixa o composto rico em oxigênio. O segundo pico, de menor intensidade, entre 515 e $555^{\circ} \mathrm{C}$, provavelmente corresponde à redução parcial do cobre, $\mathrm{Cu}^{+1} \rightarrow \mathrm{Cu}^{0}$ (Equação 5.3) e à redução de pequena quantidade de $\mathrm{Ce}_{2} \mathrm{O}_{3}$ (Equação 5.7) proveniente do cério presente na estrutura perovskita, como mostrado nas Equações 5.4 e 5.5.

$$
\begin{aligned}
& 2 \mathrm{La}_{1,4} \mathrm{Ce}_{0,6} \mathrm{CuO}_{4}+2 \mathrm{H}_{2} \rightarrow \\
& \rightarrow 1,4 \mathrm{La}_{2} \mathrm{O}_{3}+0,6 \mathrm{Ce}_{2} \mathrm{O}_{3}+2 \mathrm{Cu}^{0}+2 \mathrm{H}_{2} \mathrm{O} \\
& 2 \mathrm{La}_{1,4} \mathrm{Ce}_{0,6} \mathrm{CuO}_{4} \quad+\quad \mathrm{H}_{2} \rightarrow \\
& \rightarrow 1,4 \mathrm{La}_{2} \mathrm{O}_{3}+0,6 \mathrm{Ce}_{2} \mathrm{O}_{3}+\mathrm{Cu}_{2} \mathrm{O}+\mathrm{H}_{2} \mathrm{O} \\
& \mathrm{CeO}_{2}+2 \mathrm{H}_{2} \rightarrow \mathrm{Ce}^{0}+2 \mathrm{H}_{2} \mathrm{O} \\
& \mathrm{Ce}_{2} \mathrm{O}_{3}+3 \mathrm{H}_{2} \rightarrow 2 \mathrm{Ce}^{0}+3 \mathrm{H}_{2} \mathrm{O}
\end{aligned}
$$


O perfil de RTP da amostra B1 é apresentado na Figura 16 e o da amostra B2 na Figura 17. O dados de temperatura dos picos, suas respectivas áreas e consumo de $\mathrm{H}_{2}$ para a redução são apresentados nas Tabelas 5 (amostra B1) e 6 (amostra B2).

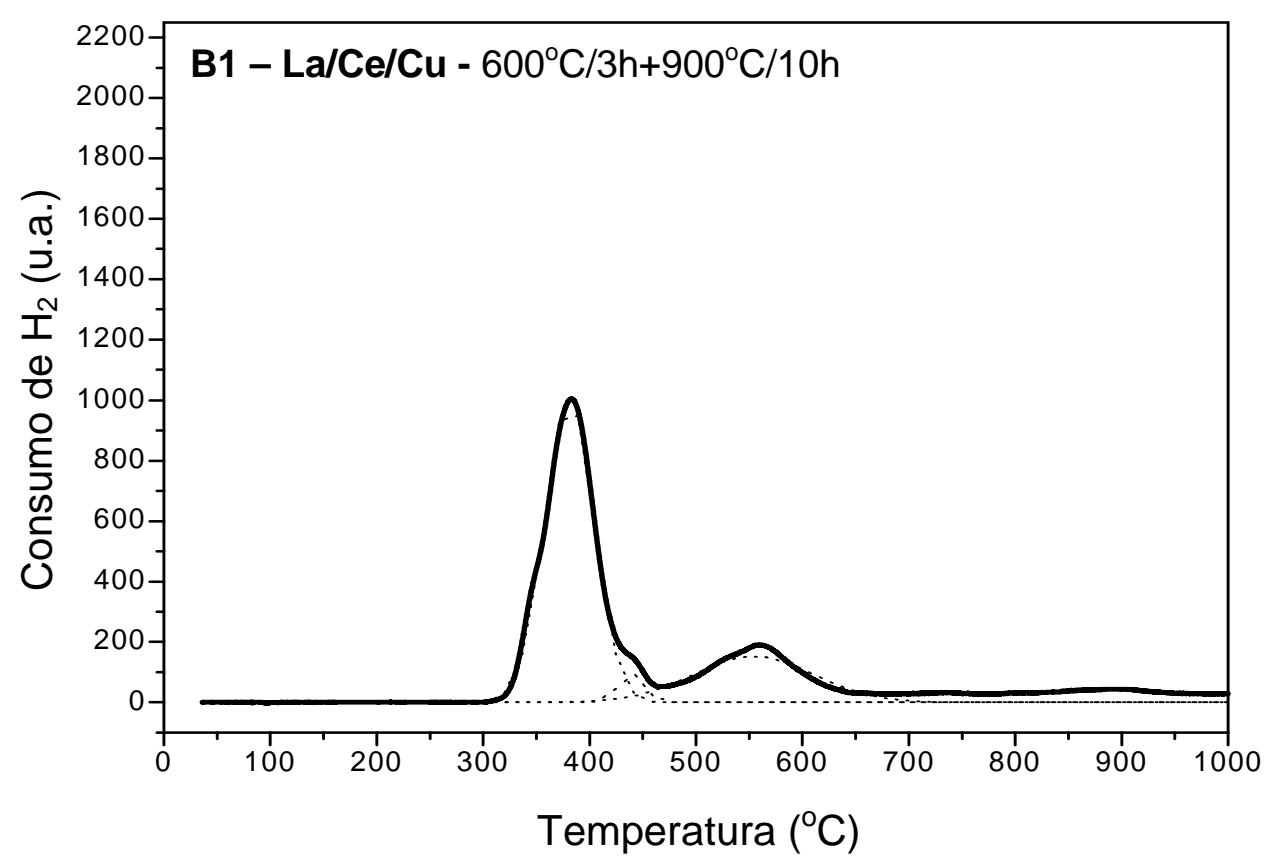

Figura 16: Perfil de RTP da amostra B1. B1 - amostra de La/ Ce/ Cu précalcinada em $600^{\circ} \mathrm{C}$ e calcinada em $900^{\circ} \mathrm{C}$.

Tabela 5: Temperatura, área e número de moles de $\mathrm{H}_{2}$ consumido em cada pico do perfil de RTP da amostra B1 (Figura 16).

\begin{tabular}{c|c|c}
\hline \hline $\begin{array}{c}\text { Temperatura do } \\
\text { pico }\left({ }^{\circ} \mathrm{C}\right)\end{array}$ & $\begin{array}{c}\text { Área do pico } \\
\text { (u.a.) }\end{array}$ & $\begin{array}{c}\text { Número de moles } \\
\text { de } \mathrm{H}_{2} \text { consumido }\end{array}$ \\
\hline 380,9 & $5,78 \cdot 10^{4}$ & $2,46 \cdot 10^{-5}$ \\
\hline 439,3 & $2,85 \cdot 10^{3}$ & $1,21 \cdot 10^{-6}$ \\
\hline 554,2 & $2,16 \cdot 10^{4}$ & $9,20 \cdot 10^{-6}$ \\
\hline
\end{tabular}




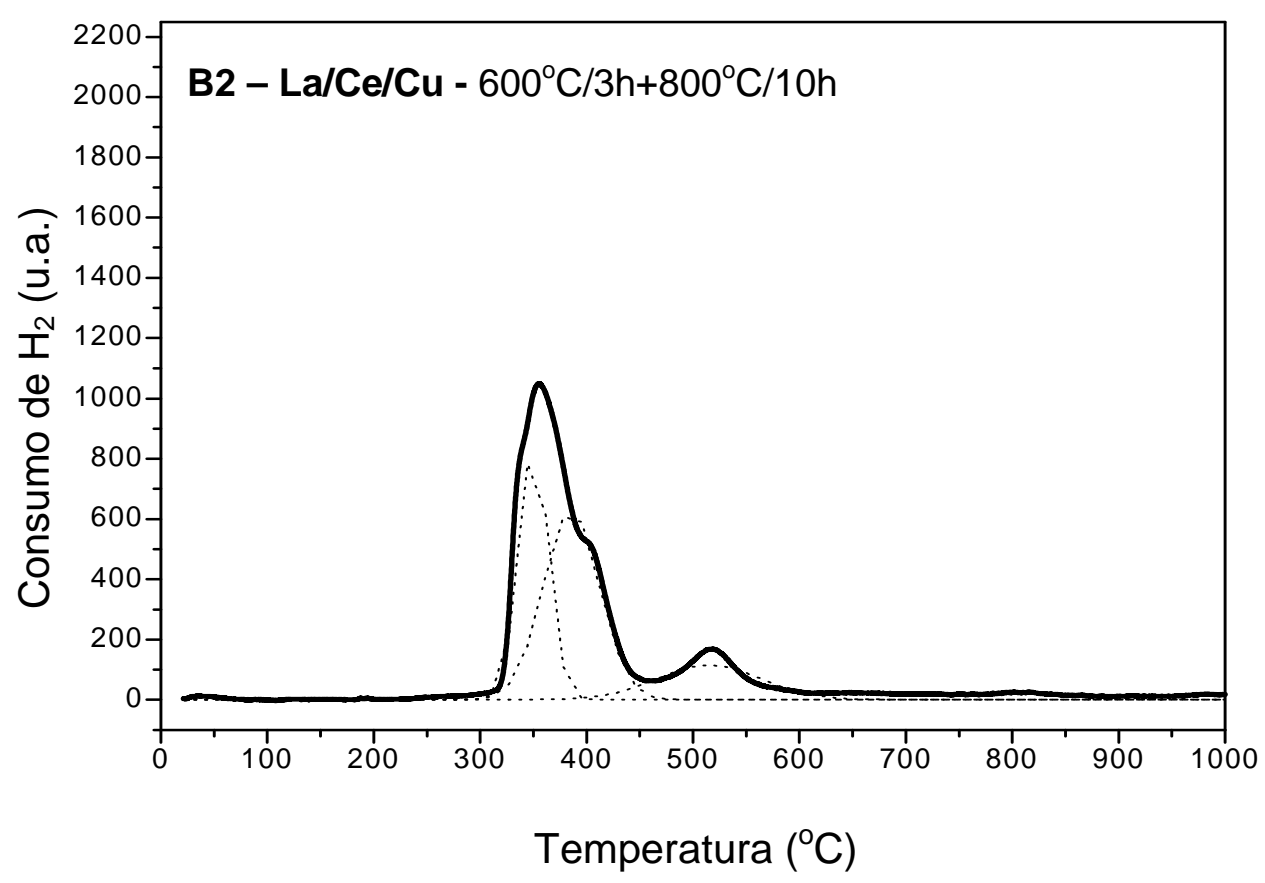

Figura 17: Perfil de RTP da amostra B2. B2 - amostra de La/ Ce/ Cu précalcinada em $600^{\circ} \mathrm{C}$ e calcinada em $800^{\circ} \mathrm{C}$.

Tabela 6: Temperatura, área e número de moles de $\mathrm{H}_{2}$ consumido em cada pico do perfil de RTP da amostra B2 (Figura 17).

\begin{tabular}{c|c|c}
\hline \hline $\begin{array}{c}\text { Temperatura do } \\
\text { pico }\left({ }^{\circ} \mathrm{C}\right)\end{array}$ & $\begin{array}{c}\text { Área do pico } \\
\text { (u.a.) }\end{array}$ & $\begin{array}{c}\text { Número de moles } \\
\text { de } \mathrm{H}_{2} \text { consumido }\end{array}$ \\
\hline 350,2 & $2,98 \cdot 10^{4}$ & $1,27 \cdot 10^{-5}$ \\
\hline 385,8 & $4,13 \cdot 10^{4}$ & $1,76 \cdot 10^{-5}$ \\
\hline 515,1 & $1,40 \cdot 10^{4}$ & $5,97 \cdot 10^{-6}$ \\
\hline
\end{tabular}

Como não há dados suficientes para quantificar o número de moles consumido por cada espécie para redução, como por exemplo a quantidade de cério que está presente na estrutura perovskita, não é possível 
determinar em que quantidade cada espécie está presente nas amostras B1 e B2.

O perfil de RTP observado para as amostras de lantânio e molibdênio (amostras C1 e C2) foi bastante próximo daquele obtido por P. Arnoldy et al. ${ }^{(55)}$ para $\mathrm{MoO}_{3}$, somente com temperaturas mais altas (Figuras 18 e 19). A mudança nas temperaturas de redução pode ser justificada pela diferença na concentração de $\mathrm{H}_{2}$ na mistura redutora ( $P$. Arnoldy et al. ${ }^{(55)}$ utilizaram um gás $67 \%$ de $\mathrm{H}_{2} / \mathrm{Ar}$, enquanto neste estudo o gás redutor utilizado foi $5 \% \mathrm{H}_{2} / \mathrm{N}_{2}$ ) e pela interação da fase $\mathrm{MoO}_{3}$ com a fase $\mathrm{La}_{2} \mathrm{O}_{3}{ }^{(56)}$, ambas observadas no $\mathrm{DRX}$ como uma fase $\mathrm{La}_{2} \mathrm{Mo}_{2} \mathrm{O}_{9}$ $\left(\mathrm{La}_{2} \mathrm{O}_{3} * 2 \mathrm{MoO}_{3}\right)$

Segundo P. Arnoldy et al. ${ }^{(55)}$, a redução de $\mathrm{MoO}_{3}$ a Mo metálico pode ser descrita como uma seqüência de duas reações, sendo $\mathrm{MoO}_{2}$ o único intermediário (Equações 5.8 e 5.9). A redução de $\mathrm{MoO}_{3}$ a $\mathrm{MoO}_{2}$ pode acontecer em 3 etapas, podendo ocorrer a formação não seletiva de vários sub-óxidos de $\mathrm{MoO}_{3}\left(\mathrm{Mo}_{9} \mathrm{O}_{26}, \mathrm{Mo}_{8} \mathrm{O}_{23}\right.$ e $\left.\mathrm{Mo}_{4} \mathrm{O}_{11}\right)$, enquanto a redução de $\mathrm{MoO}_{2}$ a $\mathrm{Mo}^{0}$ acontece em uma etapa.

$$
\begin{aligned}
& \mathrm{MoO}_{3}+\mathrm{H}_{2} \rightarrow \mathrm{MoO}_{2}+\mathrm{H}_{2} \mathrm{O} \\
& \mathrm{MoO}_{2}+2 \mathrm{H}_{2} \rightarrow \mathrm{Mo}^{0}+2 \mathrm{H}_{2} \mathrm{O}
\end{aligned}
$$

Na curva de RTP das amostras C1 e C2 é possível notar a presença de vários picos aglomerados. Os picos que aparecem em temperatura mais baixa podem ser atribuídos à redução parcial do $\mathrm{MoO}_{3}$ a $\mathrm{MoO}_{2}$ e à possível 
formação de $\mathrm{MoN}_{2}$, como sugerido por P. Arnoldy et al. ${ }^{(55)}$, que reportou que a presença de $\mathrm{H}_{2} / \mathrm{N}_{2}$ pode levar à formação de nitreto de molibdênio $\left(\mathrm{MoN}_{2}\right)$ a partir do $\mathrm{MoO}_{3}$ (Equação 5.10), modificando o perfil de RTP.

$\mathrm{MoO}_{3}+3 \mathrm{H}_{2}+\mathrm{N}_{2} \rightarrow \mathrm{MoN}_{2}+3 \mathrm{H}_{2} \mathrm{O}$

(Equação 5.10)

Os picos que aparecem depois da temperatura mantida em $1000^{\circ} \mathrm{C}$, provavelmente correspondem à redução de $\mathrm{MoO}_{2}$ a $\mathrm{Mo}^{0}$ e de algum subóxido de $\mathrm{MoO}_{2}$ a $\mathrm{Mo}^{0}$, o que está de acordo com o observado por $\mathrm{P}$. Arnoldy et al. ${ }^{(55)}$.

É possível notar que as temperaturas de redução da curva de RTP da amostra C2 (Figura 19) são menores, provavelmente devido à menor interação entre as fases $\mathrm{MoO}_{3}$ e $\mathrm{La}_{2} \mathrm{O}_{3}$, já que quanto menor a temperatura de calcinação, menor a estabilidade térmica do composto e menores as temperaturas de redução.

O dados de temperatura dos picos, suas respectivas áreas e consumo de $\mathrm{H}_{2}$ para a redução das amostras $\mathbf{C} 1$ e $\mathbf{C 2}$ são apresentados nas Tabelas 7 e 8 , respectivamente. A Tabela 9 apresenta o número de moles de molibdênio estimado nas amostras $\mathbf{C} 1$ e $\mathbf{C 2}$, o número de moles de $\mathrm{H}_{2}$ que deveria ser consumido e os valores obtidos experimentalmente. 


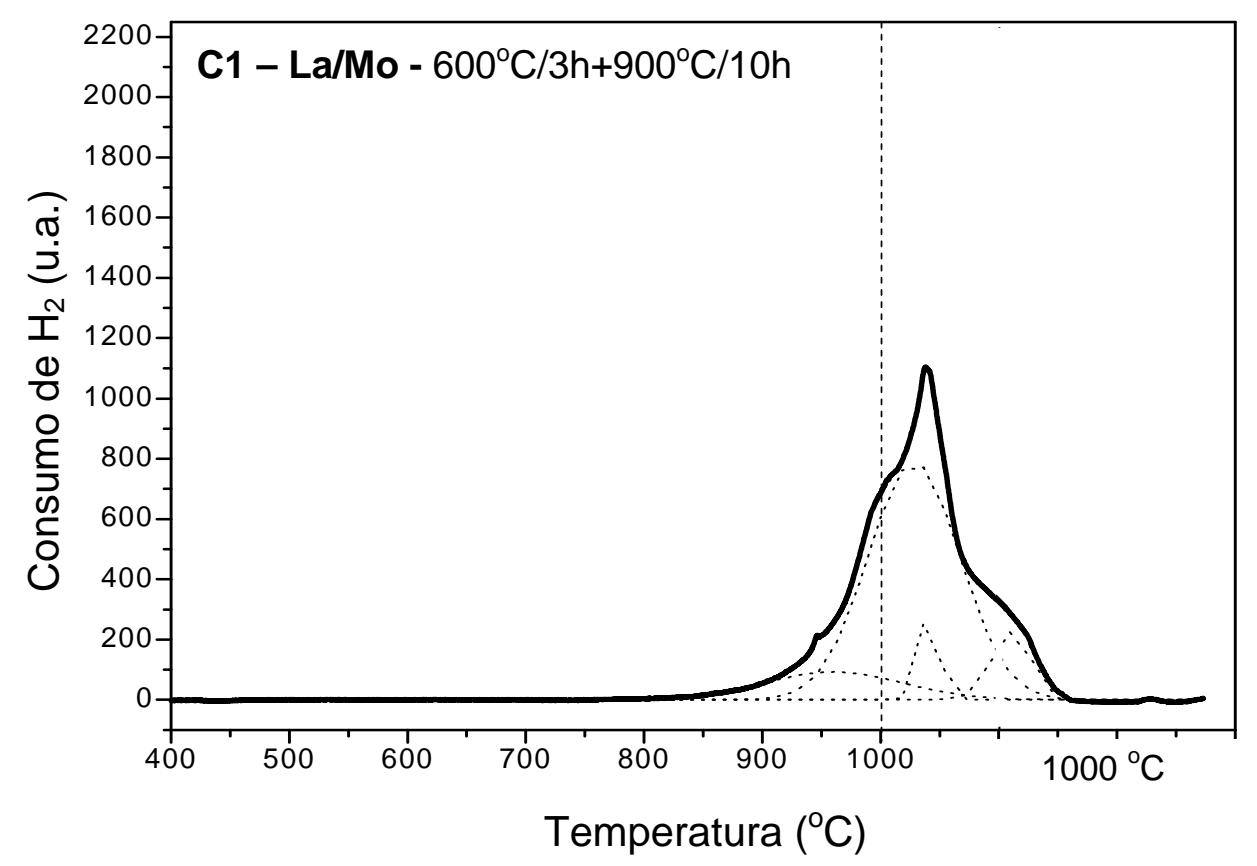

Figura 18: Perfil de RTP da amostra C1. C1 - amostra de La/ Mo précalcinada em $600^{\circ} \mathrm{C}$ e calcinada em $900^{\circ} \mathrm{C}$.

Tabela 7: Temperatura, área e número de moles de $\mathrm{H}_{2}$ consumido em cada pico do perfil de RTP da amostra C1 (Figura 18).

\begin{tabular}{c|c|c}
\hline \hline $\begin{array}{c}\text { Temperatura do } \\
\text { pico }\left({ }^{\circ} \mathrm{C}\right)\end{array}$ & $\begin{array}{c}\text { Área do pico } \\
\text { (u.a.) }\end{array}$ & $\begin{array}{c}\text { Número de moles } \\
\text { de } \mathrm{H}_{2} \text { consumido }\end{array}$ \\
\hline 960,0 & $1,36 \cdot 10^{4}$ & $5,81 \cdot 10^{-6}$ \\
\hline$>1000$ & $7,66 \cdot 10^{4}$ & $3,26 \cdot 10^{-5}$ \\
$>1000$ & $6,48 \cdot 10^{3}$ & $2,76 \cdot 10^{-6}$ \\
\hline$>1000$ & $9,36 \cdot 10^{3}$ & $3,99 \cdot 10^{-6}$ \\
\hline
\end{tabular}




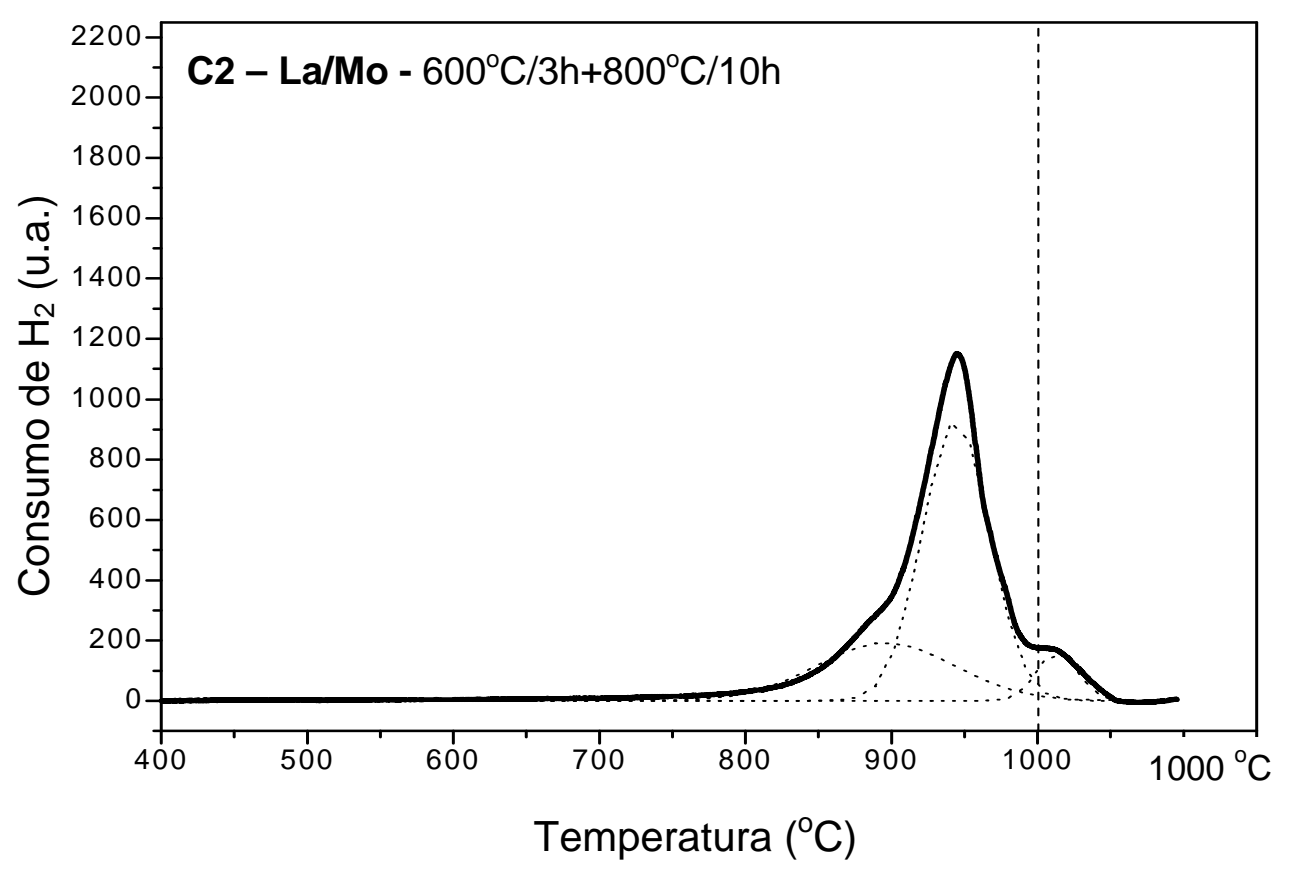

Figura 19: Perfil de RTP da amostra C2. C2 - amostra de La/ Mo précalcinada em $600^{\circ} \mathrm{C}$ e calcinada em $800^{\circ} \mathrm{C}$.

Tabela 8: Temperatura, área e número de moles de $\mathrm{H}_{2}$ consumido em cada pico do perfil de RTP da amostra C2 (Figura 19).

\begin{tabular}{c|c|c}
\hline \hline $\begin{array}{c}\text { Temperatura do } \\
\text { pico }\left({ }^{\circ} \mathrm{C}\right)\end{array}$ & $\begin{array}{c}\text { Área do pico } \\
\text { (u.a.) }\end{array}$ & $\begin{array}{c}\text { Número de moles } \\
\text { de } \mathrm{H}_{2} \text { consumido }\end{array}$ \\
\hline 895,9 & $2,27 \cdot 10^{4}$ & $9,68 \cdot 10^{-6}$ \\
\hline 944,1 & $5,35 \cdot 10^{4}$ & $2,28 \cdot 10^{-5}$ \\
\hline$>1000$ & $5,62 \cdot 10^{3}$ & $2,39 \cdot 10^{-6}$ \\
\hline
\end{tabular}


Tabela 9: Número estimado de moles de $\mathrm{Mo}^{6+}$ nas amostras C1 e C2 correspondente à massa reduzida e valores obtidos experimentalmente.

\begin{tabular}{|c|c|c|c|c|c|}
\hline $\begin{array}{c}\text { Massa } \\
\text { Molar } \\
\mathrm{La}_{2} \mathrm{Mo}_{2} \mathrm{O}_{9} \\
(\mathrm{~g})\end{array}$ & $\begin{array}{c}\text { Massa } \\
\text { reduzida } \\
\text { no RTP } \\
\text { (g) }\end{array}$ & $\begin{array}{c}\text { № } \\
\text { estimado } \\
\text { de moles } \\
\text { de } \mathrm{Mo}^{6+}\end{array}$ & $\begin{array}{c}\text { № de } \\
\text { moles de } \\
\mathrm{H}_{2} \\
\text { consumido } \\
\text { (Teórico) }\end{array}$ & $\begin{array}{c}\text { № de } \\
\text { moles de } \\
\mathrm{H}_{2} \\
\text { consumido } \\
\text { (Amostra C1) }\end{array}$ & $\begin{array}{c}\text { № de } \\
\text { moles de } \\
\mathrm{H}_{2} \\
\text { consumido } \\
\text { (Amostra C2) }\end{array}$ \\
\hline 613,68 & 0,010 & $3,26 \cdot 10^{-5}$ & $9,78 \cdot 10^{-5}$ & $4,52 \cdot 10^{-5}$ & $3,49 \cdot 10^{-5}$ \\
\hline
\end{tabular}

Não é possível quantificar as espécies de molibdênio, pois, em ambas as amostras, quando a temperatura atingiu $1000^{\circ} \mathrm{C}$ a redução não estava completa e, portanto, não se pode afirmar que este consumo de $\mathrm{H}_{2}$ seja correspondente à redução completa de todas as espécies de molibdênio. Como observado nas Equações 5.8, 5.9 e 5.10, cada mol de $\mathrm{Mo}^{6+}$ consome para a sua redução completa ou para formar $\mathrm{MoN}_{2} 6$ moles de $\mathrm{H}_{2}$. Estimavase haver $3,26 \cdot 10^{-5}$ moles de $\mathrm{Mo}^{6+}$ nos $10 \mathrm{mg}$ de amostra reduzidos, o que corresponderia a um consumo de $9,78 \cdot 10^{-5}$ moles de $\mathrm{H}_{2}$, valor bastante acima do consumo real $\left(4,52 \cdot 10^{-5}\right.$ no RTP da amostra $\mathbf{C} 1$ e $3,49 \cdot 10^{-5}$ no da amostra C2).

No estudo de RTP das amostras de lantânio e cobalto (amostras D1 e D2), Figuras 20 e 21, observa-se que a redução do cobalto acontece em três etapas, que podem ser descritas pelas Equações 5.11, 5.12 e 5.13: 


$$
\begin{aligned}
& 2 \mathrm{LaCoO}_{3}+3 \mathrm{H}_{2} \rightarrow \mathrm{La}_{2} \mathrm{O}_{3}+2 \mathrm{Co}^{0}+3 \mathrm{H}_{2} \mathrm{O} \text { (Equação 5.11) } \\
& 2 \mathrm{LaCoO}_{3}+\mathrm{H}_{2} \rightarrow \mathrm{La}_{2} \mathrm{Co}_{2} \mathrm{O}_{5}+\mathrm{H}_{2} \mathrm{O} \quad \text { (Equação 5.12) } \\
& \mathrm{La}_{2} \mathrm{Co}_{2} \mathrm{O}_{5}+2 \mathrm{H}_{2} \rightarrow \mathrm{La}_{2} \mathrm{O}_{3}+2 \mathrm{Co}^{0}+2 \mathrm{H}_{2} \mathrm{O} \text { (Equação 5.13) }
\end{aligned}
$$

O primeiro pico, por volta de $424-442^{\circ} \mathrm{C}$, provavelmente corresponde à redução completa do cobalto $\left(\mathrm{Co}^{3+} \rightarrow \mathrm{Co}^{0}\right)$, seguindo a Equação 5.11. O segundo pico, que aparece na região de $485-502^{\circ} \mathrm{C}$, pode ser atribuído à redução parcial do cobalto $\left(\mathrm{Co}^{3+} \rightarrow \mathrm{Co}^{2+}\right)$, como apresentado pela Equação 5,12. O terceiro pico, mais intenso, observado entre $627-648^{\circ} \mathrm{C}$, é referente à redução de $\mathrm{Co}^{2+} \rightarrow \mathrm{Co}^{0}$ (Equação 5.13). Esta etapa requer o dobro do $\mathrm{H}_{2}$ consumido pelo segundo pico, o que realmente foi observado.

Os valores das áreas dos picos e os respectivos consumos de $\mathrm{H}_{2}$ são apresentados nas Tabelas 10 e 11, para as amostras D1 e D2 respectivamente. 


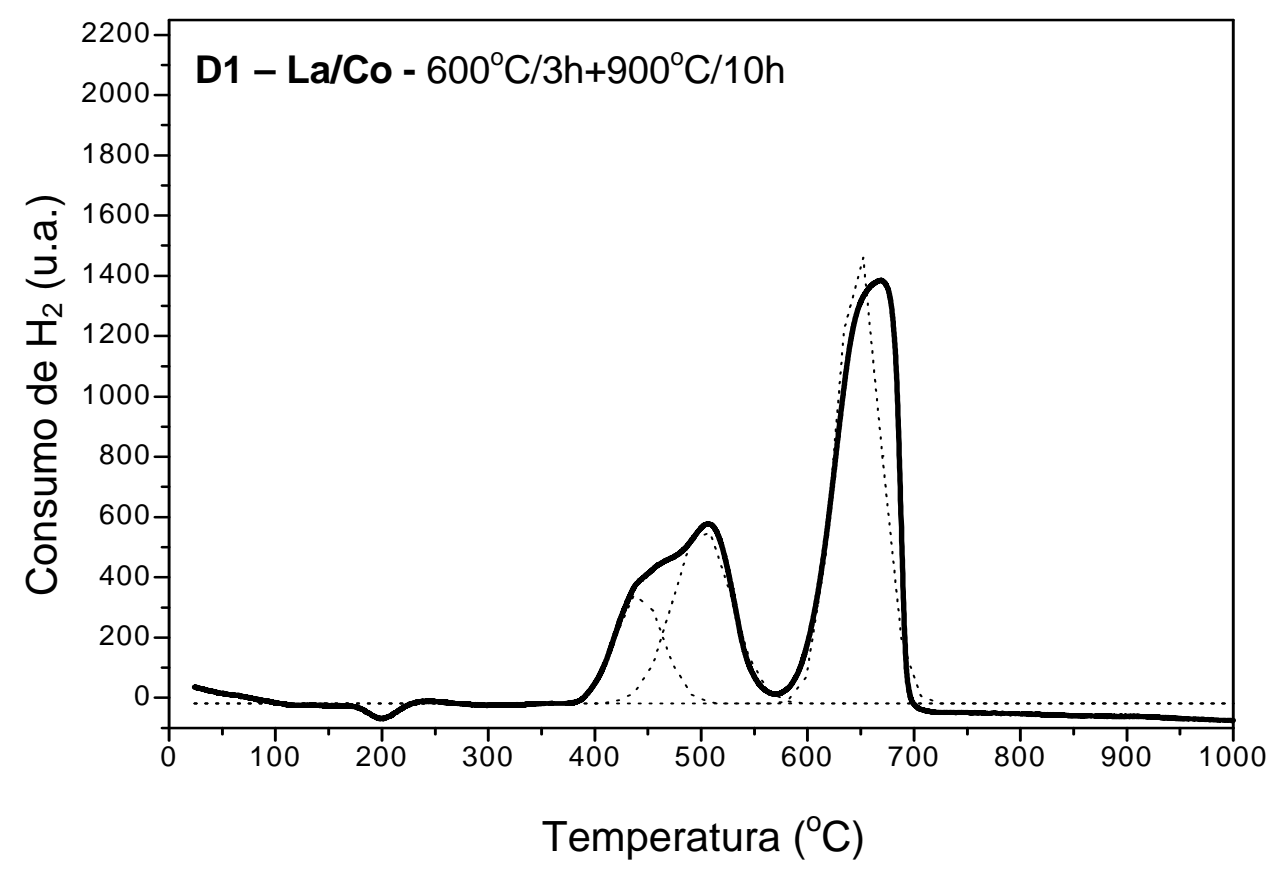

Figura 20: Perfil de RTP da amostra D1. D1 - amostra de La/ Co précalcinada em $600^{\circ} \mathrm{C}$ e calcinada em $900^{\circ} \mathrm{C}$.

Tabela 10: Temperatura, área e número de moles de $\mathrm{H}_{2}$ consumido em cada pico do perfil de RTP da amostra D1 (Figura 20).

\begin{tabular}{c|c|c}
\hline $\begin{array}{c}\text { Temperatura do } \\
\text { pico }\left({ }^{\circ} \mathbf{C}\right)\end{array}$ & $\begin{array}{c}\text { Área do pico } \\
\text { (u.a.) }\end{array}$ & $\begin{array}{c}\text { Número de moles } \\
\text { de } \mathbf{H}_{\mathbf{2}} \text { consumido }\end{array}$ \\
\hline 441,7 & $2,03 \cdot 10^{4}$ & $8,64 \cdot 10^{-6}$ \\
\hline 501,2 & $3,96 \cdot 10^{4}$ & $1,69 \cdot 10^{-5}$ \\
\hline 647,6 & $7,83 \cdot 10^{4}$ & $3,33 \cdot 10^{-5}$ \\
\hline \hline
\end{tabular}




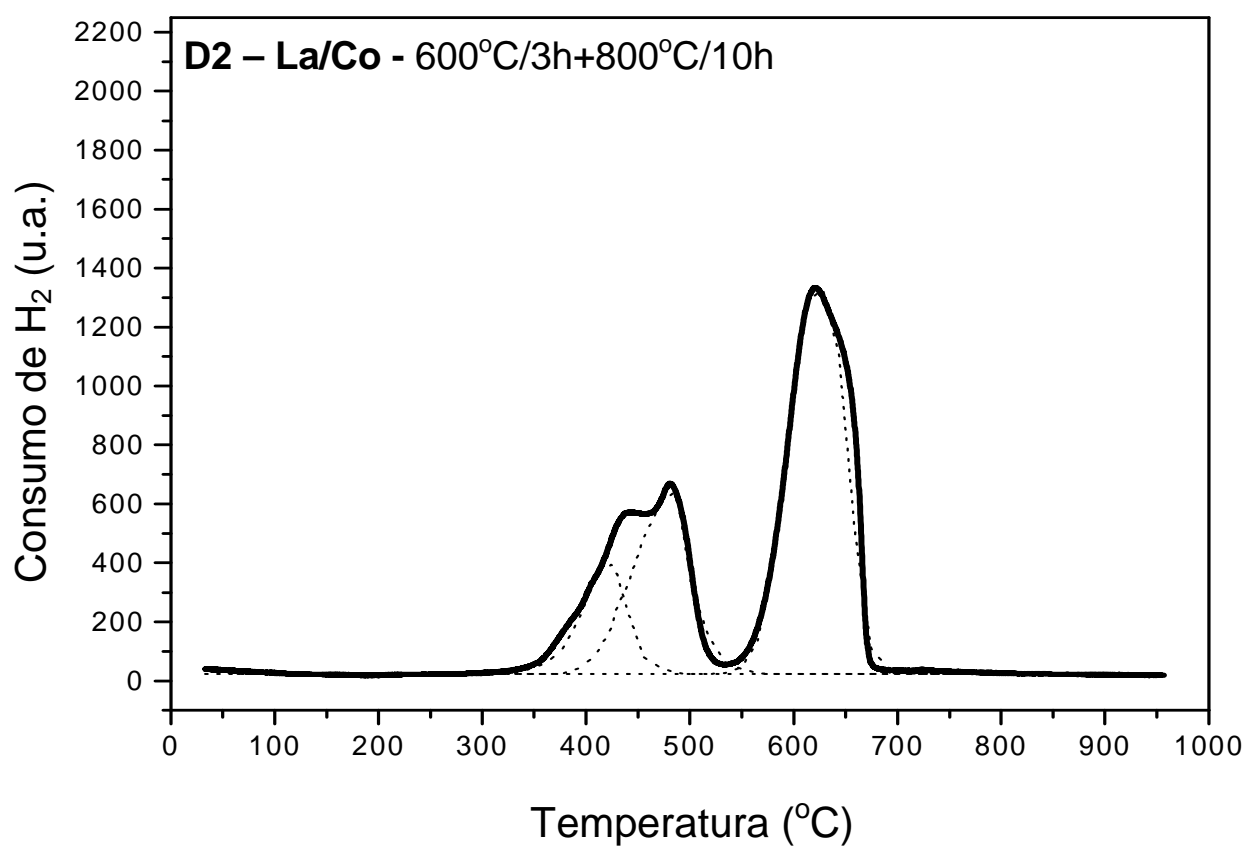

Figura 21: Perfil de RTP da amostra D2. D2 - amostra de La/ Co précalcinada em $600^{\circ} \mathrm{C}$ e calcinada em $800^{\circ} \mathrm{C}$.

Tabela 11: Temperatura, área e número de moles de $\mathrm{H}_{2}$ consumido em cada pico do perfil de RTP da amostra D2 (Figura 21).

\begin{tabular}{c|c|c}
\hline $\begin{array}{c}\text { Temperatura do } \\
\text { pico }\left({ }^{\circ} \mathrm{C} \text { ) }\right.\end{array}$ & $\begin{array}{c}\text { Área do pico } \\
\text { (u.a.) }\end{array}$ & $\begin{array}{c}\text { Número de moles } \\
\text { de } \mathrm{H}_{2} \text { consumido }\end{array}$ \\
\hline 424,3 & $2,07 \cdot 10^{4}$ & $8,83 \cdot 10^{-6}$ \\
\hline 486,9 & $4,17 \cdot 10^{4}$ & $1,78 \cdot 10^{-5}$ \\
\hline 627,8 & $8,70 \cdot 10^{4}$ & $3,71 \cdot 10^{-5}$ \\
\hline
\end{tabular}

A Tabela 12 apresenta o número de moles de $\mathrm{LaCoO}_{3}$ estimado e o número de moles obtido experimentalmente nas amostras D1 e D2. 
Tabela 12: Número estimado de moles de $\mathrm{LaCoO}_{3}$ e valores obtidos experimentalmente, correspondentes à massa reduzida nas amostras D1 e D2.

\begin{tabular}{c|c|c|c|c}
\hline \hline $\begin{array}{c}\text { Massa } \\
\text { Molar }\end{array}$ & $\begin{array}{c}\text { Massa } \\
\text { reduzida }\end{array}$ & $\begin{array}{c}\text { No estimado de } \\
\text { moles de } \\
\mathrm{LaCoO}_{3}(\mathbf{g})\end{array}$ & $\begin{array}{c}\text { No de moles de } \\
\text { Co na } \mathrm{LaCoO}_{3} \\
\text { naCoO }_{3}\end{array}$ & $\begin{array}{c}\text { No de moles de } \\
\text { Co na LaCoO }\end{array}$ \\
\hline \hline 245,83 & 0,010 & $4,07 \cdot 10^{-5}$ & $3,91 \cdot 10^{-5}$ & $4,30 \cdot 10^{-5}$ \\
\hline \hline
\end{tabular}

Os números de moles de $\mathrm{LaCoO}_{3}$ obtidos experimentalmente foram bastante próximos do número teórico $\left(4,07 \cdot 10^{-5}\right)$, confirmando a existência de uma fase única perovskita.

Para as amostras de lantânio e níquel (amostras E1 e E2) pode-se sugerir o mesmo mecanismo de redução, apresentada pelas Equações 5.14, 5.15 e $5.16:$

$$
\begin{aligned}
& 2 \mathrm{LaNiO}_{3}+3 \mathrm{H}_{2} \rightarrow \mathrm{La}_{2} \mathrm{O}_{3}+2 \mathrm{Ni}^{0}+3 \mathrm{H}_{2} \mathrm{O} \quad \text { (Equação 5.14) } \\
& 2 \mathrm{LaNiO}_{3}+\mathrm{H}_{2} \rightarrow \mathrm{La}_{2} \mathrm{Ni}_{2} \mathrm{O}_{5}+\mathrm{H}_{2} \mathrm{O} \quad \text { (Equação 5.15) } \\
& \mathrm{La}_{2} \mathrm{Ni}_{2} \mathrm{O}_{5}+2 \mathrm{H}_{2} \rightarrow \mathrm{La}_{2} \mathrm{O}_{3}+2 \mathrm{Ni}^{0}+2 \mathrm{H}_{2} \mathrm{O} \text { (Equação 5.16) }
\end{aligned}
$$

Assim, o primeiro pico (entre $369-381^{\circ} \mathrm{C}$ ) pode ser atribuído à redução de $\mathrm{Ni}^{3+} \rightarrow \mathrm{Ni}^{0}$, como demonstrado pela Equação 5.14, o segundo pico $\left(402-415^{\circ} \mathrm{C}\right)$ à redução de $\mathrm{Ni}^{3+} \rightarrow \mathrm{Ni}^{2+}$ (Equação 5.15) e o último pico (entre $518-535^{\circ} \mathrm{C}$ ) à redução de $\mathrm{Ni}^{2+} \rightarrow \mathrm{Ni}^{0}$, pela reação descrita na Equação 5.16. Estas observações concordam com aquelas de S. M. 
Lima ${ }^{(57)}$. As curvas de RTP das amostras E1 e E2 são apresentadas nas Figuras 22 e 23, respectivamente. As áreas dos picos e o consumo de $\mathrm{H}_{2}$ correspondente a cada pico são apresentados nas Tabelas 13 para a amostra E1 e 14 para a amostra E2.

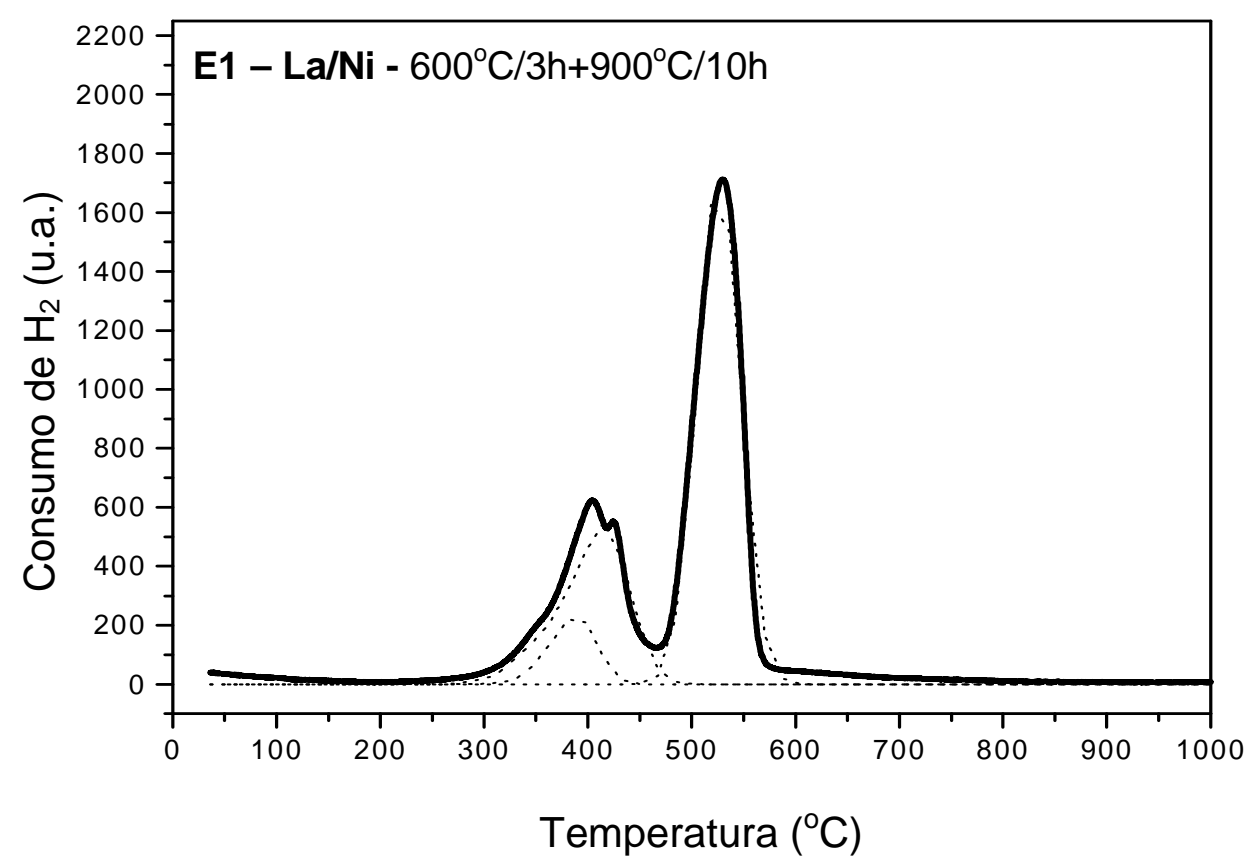

Figura 22: Perfil de RTP da amostra E1. E1 - amostra de La/ Ni précalcinada em $600^{\circ} \mathrm{C}$ e calcinada em $900^{\circ} \mathrm{C}$.

Tabela 13: Temperatura, área e número de moles de $\mathrm{H}_{2}$ consumido em cada pico do perfil de RTP da amostra E1 (Figura 22).

\begin{tabular}{c|c|c}
\hline $\begin{array}{c}\text { Temperatura do } \\
\text { pico }\left({ }^{\circ} \mathbf{C}\right)\end{array}$ & $\begin{array}{c}\text { Área do pico } \\
\text { (u.a.) }\end{array}$ & $\begin{array}{c}\text { Número de moles } \\
\text { de } \mathbf{H}_{2} \text { consumido }\end{array}$ \\
\hline \hline 381,0 & $1,30 \cdot 10^{4}$ & $5,53 \cdot 10^{-6}$ \\
\hline 415,5 & $4,29 \cdot 10^{4}$ & $1,83 \cdot 10^{-5}$ \\
\hline 519,0 & $8,94 \cdot 10^{4}$ & $3,81 \cdot 10^{-5}$ \\
\hline \hline
\end{tabular}




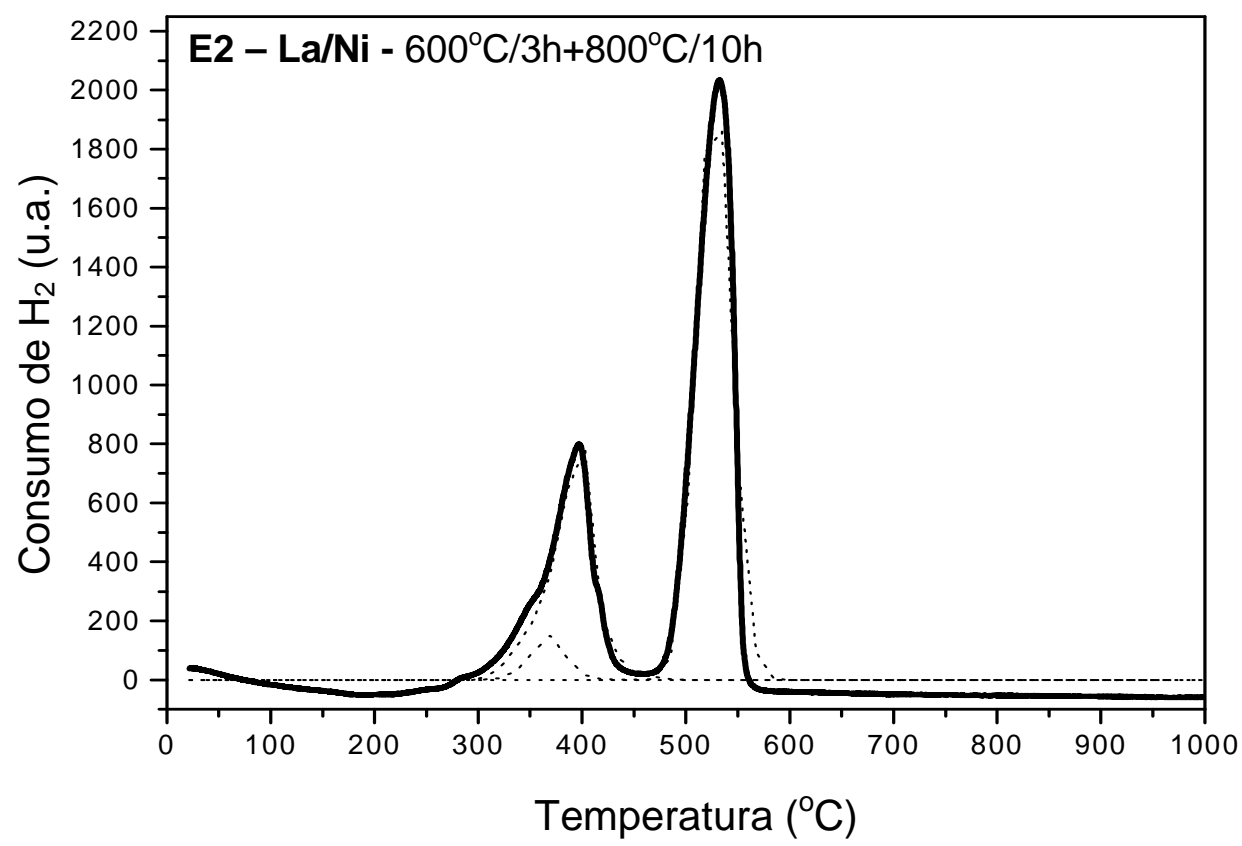

Figura 23: Perfil de RTP da amostra E2. E2 - amostra de La/ Ni précalcinada em $600^{\circ} \mathrm{C}$ e calcinada em $800^{\circ} \mathrm{C}$.

Tabela 14: Temperatura, área e número de moles de $\mathrm{H}_{2}$ consumido em cada pico do perfil de RTP da amostra E2 (Figura 23).

\begin{tabular}{c|c|c}
\hline \hline $\begin{array}{c}\text { Temperatura do } \\
\text { pico }\left({ }^{\circ} \mathrm{C} \text { ) }\right.\end{array}$ & $\begin{array}{c}\text { Área do pico } \\
\text { (u.a.) }\end{array}$ & $\begin{array}{c}\text { Número de moles } \\
\text { de } \mathrm{H}_{2} \text { consumido }\end{array}$ \\
\hline 369,5 & $6,21 \cdot 10^{3}$ & $2,65 \cdot 10^{-6}$ \\
\hline 402,6 & $4,08 \cdot 10^{4}$ & $1,74 \cdot 10^{-5}$ \\
\hline 535,0 & $8,50 \cdot 10^{4}$ & $3,62 \cdot 10^{-5}$ \\
\hline
\end{tabular}

O número estimado de moles de $\mathrm{LaNiO}_{3}$ e o número de moles obtido experimentalmente para as amostras E1 e E2 são apresentados na Tabela 15. 
Tabela 15: Número estimado de moles de $\mathrm{LaNiO}_{3}$ e valores obtidos experimentalmente, correspondentes à massa reduzida nas amostras E1 e E2.

\begin{tabular}{|c|c|c|c|c|}
\hline $\begin{array}{c}\text { Massa } \\
\text { Molar } \\
\text { LaNiO }_{3}(g)\end{array}$ & $\begin{array}{c}\text { Massa } \\
\text { reduzida } \\
\text { no } \operatorname{RTP}(\mathbf{g})\end{array}$ & $\begin{array}{c}\text { № estimado de } \\
\text { moles de } \\
\mathrm{LaNiO}_{3}\end{array}$ & $\begin{array}{l}\text { № de moles de } \\
\text { Ni na } \text { LaNiO }_{3} \\
\text { (Amostra E1) }\end{array}$ & $\begin{array}{c}\text { № de moles de } \\
\text { Ni na } \mathrm{LaNiO}_{3} \\
\text { (Amostra E2) }\end{array}$ \\
\hline 245,60 & 0,010 & $4,07 \cdot 10^{-5}$ & $4,18 \cdot 10^{-5}$ & $3,80 \cdot 10^{-5}$ \\
\hline
\end{tabular}

Assim como nas amostras de lantânio e cobalto, o número de moles de $\mathrm{LaNiO}_{3}$ obtido experimentalmente foi bastante próximo do valor teórico, confirmando o que foi observado na difração de raios- $X$, ou seja, que as amostras tem uma única fase perovskita.

As amostras de lantânio, cobre e níquel (amostras F1 e F2), apresentaram um perfil de RTP correspondente à soma das reduções de $\mathrm{La}_{2} \mathrm{CuO}_{4}$ e $\mathrm{LaNiO}_{3}$. Uma pequena variação nas temperaturas de redução foi observada, o que provavelmente ocorre devido à interações entre as fases presentes.

Os perfis de RTP das amostras F1 e F2 são apresentados nas Figuras 24 e 25, respectivamente. As Tabelas 16 (amostra F1) e 17 (amostra F2) apresentam a temperatura de redução de cada pico com suas respectivas áreas e consumo de $\mathrm{H}_{2}$.

São observados dois picos, sendo o primeiro entre 415 e $465^{\circ} \mathrm{C}$, correspondente à soma das reduções parcial e total do cobre $\left(\mathrm{Cu}^{2+} \rightarrow \mathrm{Cu}^{1+} \mathrm{e}\right.$ $\left.\mathrm{Cu}^{2+} \rightarrow \mathrm{Cu}^{0}\right)$ e do níquel $\left(\mathrm{Ni}^{3+} \rightarrow \mathrm{Ni}^{2+}\right.$ e $\left.\mathrm{Ni}^{3+} \rightarrow \mathrm{Ni}^{0}\right)$ e o segundo, entre 
$480-515^{\circ} \mathrm{C}$, correspondente a somas das reduções parciais do cobre $\left(\mathrm{Cu}^{1+} \rightarrow \mathrm{Cu}^{0}\right)$ e do níquel $\left(\mathrm{Ni}^{2+} \rightarrow \mathrm{Ni}^{0}\right)$.

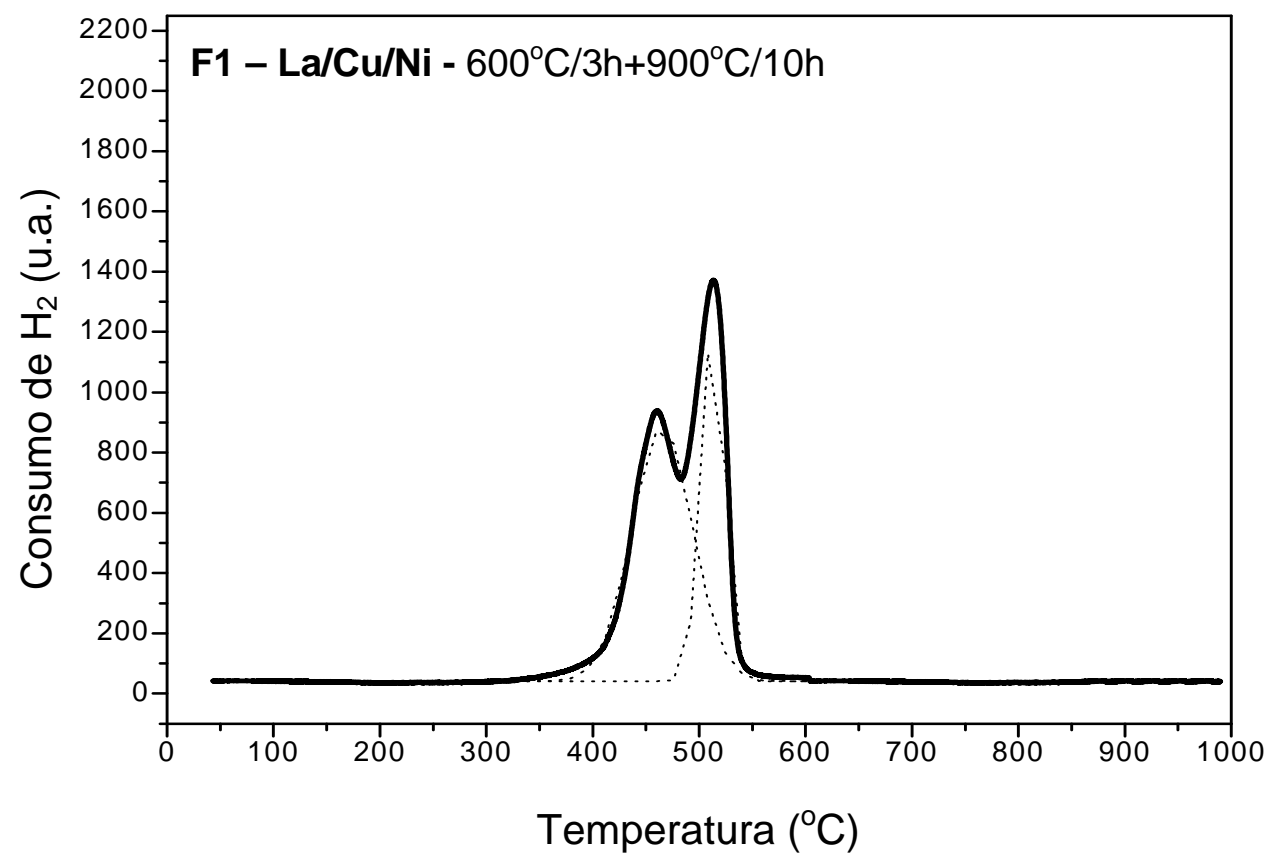

Figura 24: Perfil de RTP da amostra F1. F1 - amostra de La/ Cu/ Ni précalcinada em $600^{\circ} \mathrm{C}$ e calcinada em $900^{\circ} \mathrm{C}$.

Tabela 16: Temperatura, área e número de moles de $\mathrm{H}_{2}$ consumido em cada pico do perfil de RTP da amostra F1 (Figura 24).

\begin{tabular}{c|c|c}
\hline $\begin{array}{c}\text { Temperatura do } \\
\text { pico }\left({ }^{\circ} \mathbf{C}\right)\end{array}$ & $\begin{array}{c}\text { Área do pico } \\
\text { (u.a.) }\end{array}$ & $\begin{array}{c}\text { Número de moles } \\
\text { de } \mathbf{H}_{\mathbf{2}} \text { consumido }\end{array}$ \\
\hline \hline 465,4 & $6,01 \cdot 10^{4}$ & $2,56 \cdot 10^{-5}$ \\
\hline 513,0 & $3,31 \cdot 10^{4}$ & $1,41 \cdot 10^{-5}$ \\
\hline \hline
\end{tabular}




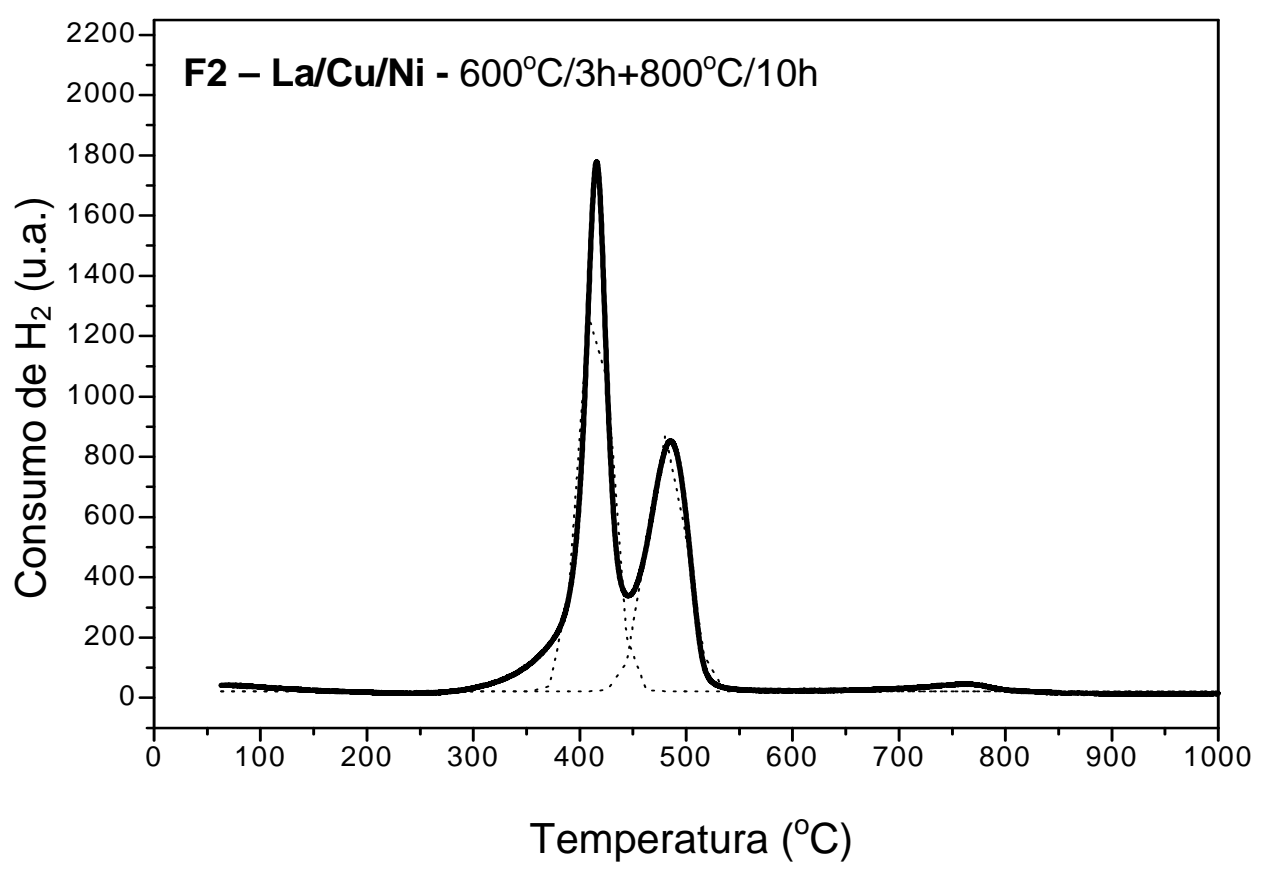

Figura 25: Perfil de RTP da amostra F2. F2 - amostra de La/ Cu/ Ni précalcinada em $600^{\circ} \mathrm{C}$ e calcinada em $800^{\circ} \mathrm{C}$.

Tabela 17: Temperatura, área e número de moles de $\mathrm{H}_{2}$ consumido em cada pico do perfil de RTP da amostra F2 (Figura 25).

\begin{tabular}{c|c|c}
\hline $\begin{array}{c}\text { Temperatura do } \\
\text { pico }\left({ }^{\circ} \mathrm{C} \text { ) }\right.\end{array}$ & $\begin{array}{c}\text { Área do pico } \\
\text { (u.a.) }\end{array}$ & $\begin{array}{c}\text { Número de moles } \\
\text { de } \mathrm{H}_{2} \text { consumido }\end{array}$ \\
\hline 414,7 & $5,12 \cdot 10^{4}$ & $2,18 \cdot 10^{-5}$ \\
\hline 481,5 & $3,82 \cdot 10^{4}$ & $1,62 \cdot 10^{-5}$ \\
\hline
\end{tabular}

Apesar de intensidade dos picos nos RTPs das amostras F1 e F2 serem diferentes, as áreas são próximas tanto para a amostra calcinada em $900^{\circ} \mathrm{C}$ quanto para aquela calcinada em $800^{\circ} \mathrm{C}$.

Como as reduções das espécies de $\mathrm{Cu}$ e $\mathrm{Ni}$ acontecem nas mesmas temperaturas, não foi possível quantificar cada espécie. 


\subsection{Análise da Composição dos Sólidos}

Os cálculos das concentrações dos metais foram feitos com relação à mistura de óxidos e estão apresentados na Tabela 18. A massa molar da respectiva mistura de óxidos de cada amostra é apresentada, seguindo a estequiometria que leva à formação da perovskita. Nessa estequiometria, a massa molar da mistura de óxidos é igual à da perovskita.

Tabela 18: Mistura de óxidos após a pré-calcinação em $600^{\circ} \mathrm{C}$ por 3 horas, perovskita formada após calcinação e massa molecular da mistura de óxidos.

\begin{tabular}{|c|c|c|c|}
\hline $\begin{array}{c}\text { Amostra } \\
\text { (pré-calcinada em } \\
600^{\circ} \mathrm{C} / 3 \text { horas) }\end{array}$ & $\begin{array}{l}\text { Mistura de óxidos } \\
\text { (proporção da perovskita) }\end{array}$ & $\begin{array}{c}\text { Perovskita } \\
\text { formada }\end{array}$ & $\begin{array}{c}\text { Massa } \\
\text { Molar } \\
(\mathrm{g} / \mathrm{mol})\end{array}$ \\
\hline $\mathbf{A}-\mathrm{La} / \mathrm{Cu}$ & $\mathrm{La}_{2} \mathrm{O}_{3}+\mathrm{CuO}$ & $\mathrm{La}_{2} \mathrm{CuO}_{4}$ & 405,30 \\
\hline $\mathbf{B}-\mathrm{La} / \mathrm{Ce} / \mathrm{Cu}$ & $\begin{array}{lll}0,7 \quad \mathrm{La}_{2} \mathrm{O}_{3}+0,3 & \mathrm{Ce}_{2} \mathrm{O}_{3} \\
+\mathrm{CuO}\end{array}$ & $\mathrm{La}_{1,4} \mathrm{Ce}_{0,6} \mathrm{CuO}_{4}$ & 406,50 \\
\hline C - La/Mo & $\mathrm{La}_{2} \mathrm{O}_{3}+2 \mathrm{MoO}_{3}$ & $\mathrm{La}_{2} \mathrm{Mo}_{2} \mathrm{O}_{9}$ & 613,68 \\
\hline D - La/Co & $0,5 \mathrm{La}_{2} \mathrm{O}_{3}+0,5 \mathrm{Co}_{2} \mathrm{O}_{3}$ & $\mathrm{LaCoO}_{3}$ & 245,83 \\
\hline $\mathbf{E}-\mathrm{La} / \mathrm{Ni}$ & $0,5 \mathrm{La}_{2} \mathrm{O}_{3}+0,5 \mathrm{Ni}_{2} \mathrm{O}_{3}$ & $\mathrm{LaNiO}_{3}$ & 245,60 \\
\hline $\mathbf{F}-\mathrm{La} / \mathrm{Cu} / \mathrm{Ni}$ & $\begin{array}{ll}0,75 \mathrm{La}_{2} \mathrm{O}_{3}+0,25 \mathrm{Ni}_{2} \mathrm{O}_{3} \\
+0,5 \mathrm{CuO}\end{array}$ & $\begin{array}{c}0,5 \mathrm{La}_{2} \mathrm{CuO}_{4}+ \\
\mathrm{LaNiO}_{3}\end{array}$ & 325,45 \\
\hline
\end{tabular}

A Tabela 19 apresenta a concentração estimada de cada metal nas amostras pré-calcinadas e os valores obtidos experimentalmente pelas 
análises de espectrometria de emissão atômica por plasma induzido e espectrofotometria de absorção atômica.

Tabela 19: Concentração de metais nas amostras (\% em massa).

\begin{tabular}{|c|c|c|c|c|c|c|}
\hline Amostra & \multicolumn{3}{|c|}{$\begin{array}{c}\% \text { estimada de metais } \\
\text { (\% em massa) }\end{array}$} & \multicolumn{3}{|c|}{$\begin{array}{c}\% \text { real de metais } \\
\text { (\% em massa) }\end{array}$} \\
\hline \multirow{2}{*}{$\begin{array}{c}\mathbf{A}-\mathrm{La} / \mathrm{Cu} \\
\quad \text { Em relação a } \\
\left(\mathrm{La}_{2} \mathrm{O}_{3}+\mathrm{CuO}\right) \\
\end{array}$} & \multicolumn{2}{|l|}{$\mathrm{La}$} & $\mathrm{Cu}$ & \multicolumn{2}{|l|}{$\mathrm{La}^{\mathrm{b}}$} & $\mathrm{Cu}^{\mathrm{a}}$ \\
\hline & \multicolumn{2}{|c|}{68,54} & 15,67 & \multicolumn{2}{|c|}{59,78} & 16,13 \\
\hline \multirow{2}{*}{$\begin{array}{l}\mathbf{B}-\mathrm{La} / \mathrm{Ce} / \mathrm{Cu} \\
\text { Em relação a }\left(0,7 \mathrm{La}_{2} \mathrm{O}_{3}\right. \\
\left.+0,3 \mathrm{Ce}_{2} \mathrm{O}_{3}+\mathrm{CuO}\right)\end{array}$} & La & $\mathrm{Ce}$ & $\mathrm{Cu}$ & $\mathrm{La}^{\mathrm{b}}$ & $\mathrm{Ce}^{\mathrm{b}}$ & $\mathrm{Cu}^{\mathrm{a}}$ \\
\hline & 47,84 & 20,80 & 15,62 & 41,91 & 12,56 & 16,43 \\
\hline \multirow{2}{*}{$\begin{array}{r}\mathbf{C}-\mathrm{La} / \mathrm{Mo} \\
\text { Em relação a } \\
\left(\mathrm{La}_{2} \mathrm{O}_{3}+2 \mathrm{MoO}_{3}\right) \\
\end{array}$} & \multicolumn{2}{|l|}{$\mathrm{La}$} & Mo & \multicolumn{2}{|c|}{$\mathrm{La}^{\mathrm{b}}$} & $\mathrm{Mo}^{\mathrm{b}}$ \\
\hline & \multicolumn{2}{|c|}{45,27} & 31,27 & \multicolumn{2}{|c|}{37,74} & 34,78 \\
\hline \multirow{2}{*}{$\begin{array}{r}\text { D - La/ Co } \\
\text { Em relação a } \\
\left(\mathrm{La}_{2} \mathrm{O}_{3}+\mathrm{Co}_{2} \mathrm{O}_{3}\right) \\
\end{array}$} & \multicolumn{2}{|l|}{$\mathrm{La}$} & Co & \multicolumn{2}{|l|}{$\mathrm{La}^{\mathrm{b}}$} & $\mathrm{Co}^{\mathrm{a}}$ \\
\hline & \multicolumn{2}{|c|}{56,50} & 23,97 & \multicolumn{2}{|c|}{46,43} & 18,73 \\
\hline \multirow{2}{*}{$\begin{array}{r}\mathbf{E}-\mathrm{La} / \mathrm{Ni} \\
\mathrm{Em} \text { relação a } \\
\left(\mathrm{La}_{2} \mathrm{O}_{3}+\mathrm{Ni}_{2} \mathrm{O}_{3}\right) \\
\end{array}$} & \multicolumn{2}{|l|}{$\mathrm{La}$} & $\mathrm{Ni}$ & \multicolumn{2}{|l|}{$\mathrm{La}^{\mathrm{b}}$} & $\mathrm{Ni}^{\mathrm{a}}$ \\
\hline & 56,55 & & 23,90 & 49,35 & & 19,54 \\
\hline F - La/ Cu/ Ni & $\mathrm{La}$ & $\mathrm{Cu}$ & $\mathrm{Ni}$ & $\mathrm{La}^{\mathrm{b}}$ & $\mathrm{Cu}^{\mathrm{a}}$ & $\mathrm{Ni}^{\mathrm{a}}$ \\
\hline $\begin{array}{r}\text { Em relação a }(0,75 \\
\mathrm{La}_{2} \mathrm{O}_{3}+0,25 \mathrm{Ni}_{2} \mathrm{O}_{3}+0,5 \\
\text { CuO) } \\
\end{array}$ & 64,02 & 9,76 & 9,02 & 56,69 & 8,82 & 7,65 \\
\hline
\end{tabular}

As análises feitas por absorção atômica apresentaram resultados próximos dos valores esperados, enquanto aquelas feitas por emissão atômica por plasma induzido apresentaram valores um pouco mais distantes. Essa diferença entre as concentrações calculadas e as obtidas 
experimentalmente pode ser atribuída ao excesso de água nos reagentes ou ainda a diferenças de calibração entre os equipamentos.

\section{4 Área Superficial}

A Tabela 20 apresenta as áreas específicas obtidas por fisissorção de nitrogênio (B.E.T.) para as amostras.

Tabela 20: Área específica obtida por fisissorção de nitrogênio (B.E.T.).

\begin{tabular}{l|c}
\hline \multicolumn{1}{c|}{ Amostras } & Área superficial $\left(\mathbf{m}^{2} \mathbf{g}^{-1}\right)$ \\
\hline \hline $\mathbf{A 1}-\mathrm{La}_{2} \mathrm{CuO}_{4}$ & $\leq 0,1$ \\
\hline $\mathbf{A} 2-\mathrm{La}_{2} \mathrm{CuO}_{4}$ & 0,23 \\
\hline $\mathbf{B} 1-\mathrm{La}_{1,4} \mathrm{Ce}_{0,6} \mathrm{CuO}_{4}$ & $\leq 0,1$ \\
\hline $\mathbf{B 2}-\mathrm{La}_{1,4} \mathrm{Ce}_{0,6} \mathrm{CuO}_{4}$ & 0,15 \\
\hline $\mathbf{C} 1-\mathrm{La}_{2} \mathrm{MO}_{2} \mathrm{O}_{9}$ & $\leq 0,1$ \\
\hline $\mathbf{C} 2-\mathrm{La}_{2} \mathrm{Mo}_{2} \mathrm{O}_{9}$ & - \\
\hline $\mathbf{D} 1-\mathrm{LaCoO}_{3}$ & 0,57 \\
\hline $\mathbf{D} 2-\mathrm{LaCoO}_{3}$ & 1,32 \\
\hline E1 $-\mathrm{LaNiO}_{3}$ & 1,38 \\
\hline E2 $-\mathrm{LaNiO}_{3}$ & - \\
\hline F1 $-\mathrm{La}_{2} \mathrm{CuO}_{4} / \mathrm{LaNiO}_{3}$ & 0,23 \\
\hline F2 $-\mathrm{La}_{2} \mathrm{CuO}_{4} / \mathrm{LaNiO}_{3}$ & - \\
\hline \hline
\end{tabular}

As áreas superficiais dos compostos preparados foram baixas, devido à alta temperatura de calcinação necessária para que ocorra a reação de estado sólido entre os óxidos dos metais, que leva à formação da perovskita. A alta temperatura favorece a sinterização, aumentando o tamanho das partículas e diminuindo a área superficial do composto. 
O método utilizado para a preparação dos catalisadores apresentava a expectativa de levar à formação de compostos com áreas específicas maiores que aquelas reportadas na literatura ${ }^{(46)}$, mas os catalisadores obtidos apresentaram áreas específicas dentro da média ${ }^{(6-7,27-28,33,43-45)}$.

\subsection{Ensaios Catalíticos}

Os catalisadores serão analisados separadamente com relação a suas atividade, devido a problemas na homogeneidade da mistura $0,96 \%$ $\mathrm{NO} / \mathrm{He}$, que não se manteve constante ao longo do período de realizações dos ensaios catalíticos.

As condições dos ensaios catalíticos para todas as amostras foram as seguintes:

Massa de catalisador: $150 \mathrm{mg}$;

Fluxo de alimentação: $25 \mathrm{~mL} \mathrm{~min}^{-1}$ de $\mathrm{NO} / \mathrm{He}+25 \mathrm{~mL} \min ^{-1}$ de $\mathrm{CO} / \mathrm{He}$; $W / F: 3,0 \mathrm{mg}_{\text {cat. }}$ min $\mathrm{mL}_{\text {mist. }}{ }^{-1}$

Temperatura da reação: $500^{\circ} \mathrm{C}$;

Taxa de aquecimento do forno: $10^{\circ} \mathrm{C} \mathrm{min}^{-1}$;

Tempo de ensaio: 6 horas.

Foram feitas injeções da mistura $\mathrm{NO}$ e $\mathrm{CO}$ 0,5\% cada em He antes do início de cada ensaio, para registro da área máxima destes compostos, para com esses valores calcular a conversão dos reagentes.

De modo geral é possível analisar o comportamento dos reagentes e 
dos produtos durante as reações. O CO pode reagir com NO para formar $\mathrm{CO}_{2}$ e $\mathrm{N}_{2}$ ou $\mathrm{N}_{2} \mathrm{O}$, como foi demonstrado pelas Equações 3.17 e 3.19, reapresentadas abaixo, ou pode se decompor em carbono (coque) e $\mathrm{O}_{2}$ (Equação 5.17)

$\begin{array}{llll}\mathrm{CO}+\mathrm{NO} & \rightarrow 1 / 2 \mathrm{~N}_{2}+\mathrm{CO}_{2} & \text { (Equação 3.17) } \\ \mathrm{CO}+2 \mathrm{NO} & \rightarrow \mathrm{N}_{2} \mathrm{O}+\mathrm{CO}_{2} & \text { (Equação 3.19) } \\ 2 \mathrm{CO} & \rightarrow 2 \mathrm{C}_{(\text {coque })}+\mathrm{O}_{2} & \text { (Equação 5.17) }\end{array}$

A condutividade térmica do oxigênio é alta e qualquer traço de $\mathrm{O}_{2}$ poderia ser detectado. Não houve a formação de $\mathrm{O}_{2}$ durante os ensaios, nem alterações nas características dos catalisadores, o que deveria acontecer no caso da formação de coque (desativação do catalisador devido ao recobrimento dos sítios ativos por carbono). Com isso é possível concluir que o carbono reagiu durante os testes com $\mathrm{NO}$ para forma $\mathrm{CO}_{2}$.

Devido à baixa concentração de $\mathrm{CO}_{2}$ durante a reação $(0,5 \%)$, 0 cromatógrafo não detectou a presença deste, assim como não foi observada nos cromatogramas a presença de $\mathrm{N}_{2} \mathrm{O}$. Como na temperatura da reação $\left(500^{\circ} \mathrm{C}\right)$ o $\mathrm{NO}$ reage com seletividade para formar $\mathrm{N}_{2}{ }^{(5,24,29-30)}$, a formação de $\mathrm{N}_{2} \mathrm{O}$ é improvável.

Partindo do princípio que o CO somente reage com NO pela Equação 3.16, ou seja, para a formação de $\mathrm{CO}_{2}$ e $\mathrm{N}_{2}$, o consumo de $\mathrm{CO}$ e o de $\mathrm{NO}$ devem ser próximos. Caso exista uma diferença entre estes consumos, isso indica que a mistura de NO estava mais ou menos concentrada naquele momento, dependendo da situação. 
Admitindo que as concentrações de $\mathrm{NO}$ e $\mathrm{CO}$ durante um ensaio sejam iguais, ou seja, $1 \%$, para uma reação com consumo de $100 \%$ de CO, $100 \%$ do NO também será consumido e a formação de $N_{2}$ será a máxima possível, ou seja, rendimento de $100 \%$.

Este consumo de $100 \%$ de CO e $100 \%$ de NO foi observado para a amostra B2, e o rendimento em $\mathrm{N}_{2}$ desta amostra foi considerado máximo, ou seja, $100 \%$. Com este valor foram feitos os cálculos de rendimento das outras amostras. Os gráficos de conversão de $\mathrm{NO}$ e $\mathrm{CO}$ e de rendimento em $\mathrm{N}_{2}$ da amostra B2 são apresentados mais adiante, nas Figuras 32 e 33.

Se observarmos as conversões de $\mathrm{NO}$ e $\mathrm{CO}$ no ensaio catalítico da amostra A1 ( $\left.\mathrm{La} / \mathrm{Cu}-600^{\circ} \mathrm{C} / 3 \mathrm{~h}+900^{\circ} \mathrm{C} / 10 \mathrm{~h}\right)$, apresentadas na Figura 26, podemos notar que a conversão de $\mathrm{NO}$ foi um pouco maior que a de $\mathrm{CO}$, ficando em torno de $95 \%$, enquanto a de $\mathrm{CO}$ foi de $80 \%$. O rendimento em $\mathrm{N}_{2}$ deste catalisador, apresentado na Figura 27, foi em torno de $70 \%$, abaixo do esperado em relação à conversão de NO. Uma possibilidade neste caso é a de a concentração de NO na mistura reagente ser menor que o esperado, ou seja, menor que $1 \%$, sendo quase totalmente convertida enquanto uma conversão em menor porcentagem de CO corresponde a estequiometria esperada. Estando em menor concentração que a esperada, o rendimento em $\mathrm{N}_{2}$ também será menor. 


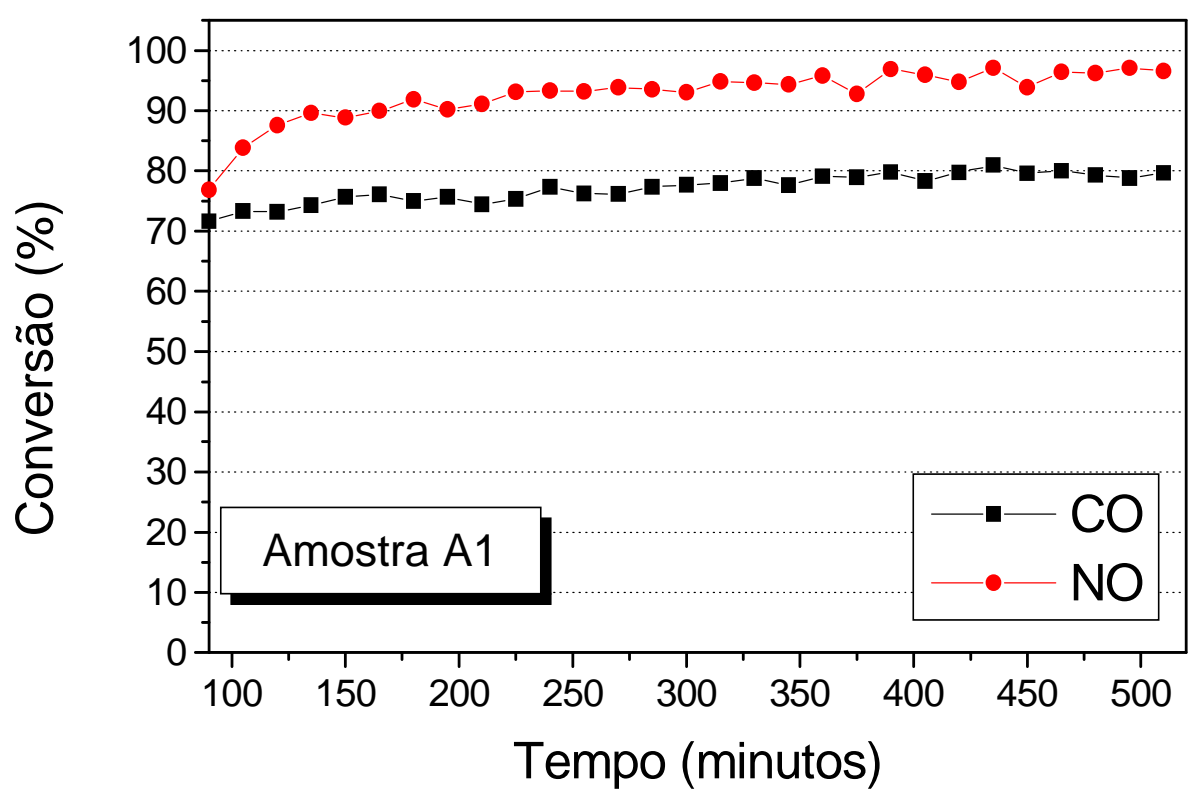

Figura 26: Conversão de NO e CO da amostra A1. A1 - amostra de La/ Cu pré-calcinada em $600^{\circ} \mathrm{C}$ e calcinada em $900^{\circ} \mathrm{C}$.

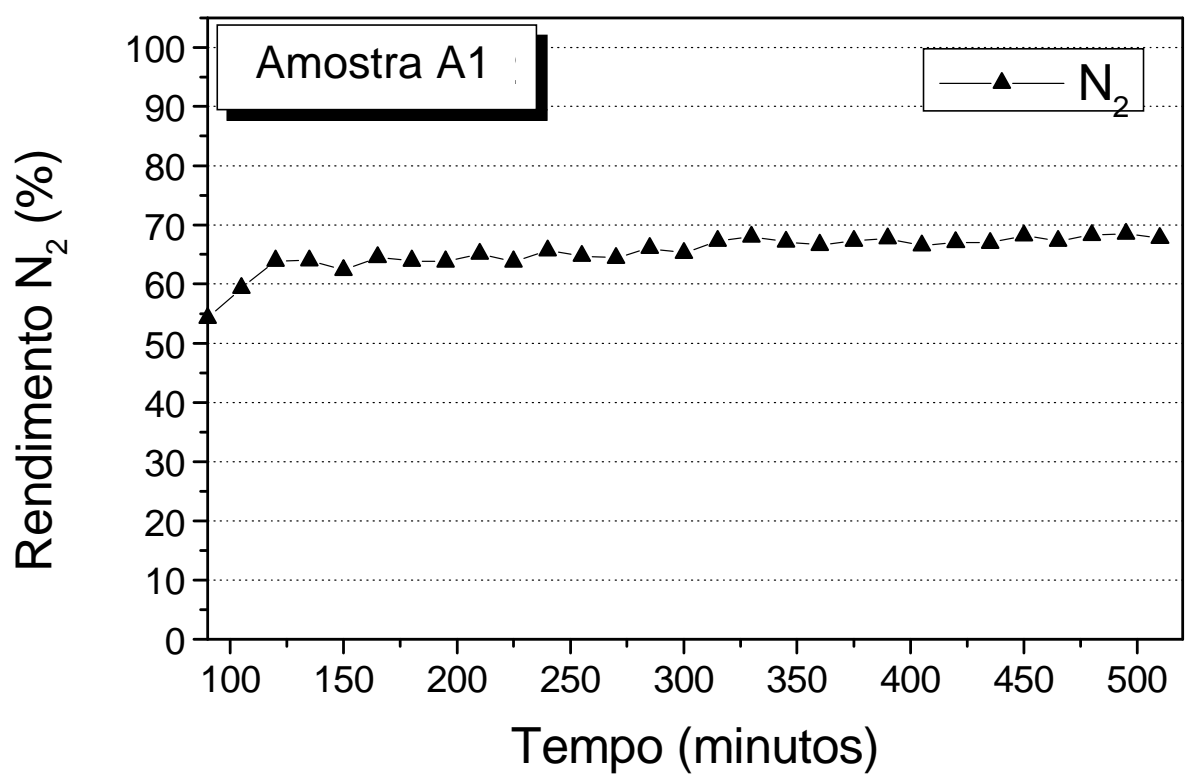

Figura 27: Produção de $\mathrm{N}_{2}$ da amostra A1. A1 - amostra de La/ Cu précalcinada em $600^{\circ} \mathrm{C}$ e calcinada em $900^{\circ} \mathrm{C}$. 
A amostra A2 (La/ $\mathrm{Cu}-600^{\circ} \mathrm{C} / 3 \mathrm{~h}+800^{\circ} \mathrm{C} / 10 \mathrm{~h}$ ) apresentou melhor atividade que a amostra de lantânio e cobre calcinada em $900^{\circ} \mathrm{C}$ (amostra A1), sendo a conversão de NO e CO ambas entre 90 e 100\% e o rendimento em $\mathrm{N}_{2}$ também tendo ficado nesta faixa. Como as conversões de NO e CO foram próximas, provavelmente neste momento a mistura estava com concentrações iguais destes compostos.

O ensaio catalítico da amostra B1 ( $\left.\mathrm{La} / \mathrm{Ce} / \mathrm{Cu}-600^{\circ} \mathrm{C} / 3 \mathrm{~h}+900^{\circ} \mathrm{C} / 10 \mathrm{~h}\right)$ mostrou que a conversão de NO deste catalisador foi um pouco variável, mas ainda assim sendo maior que a conversão de CO, que ficou entre 60 e $70 \%$ (Figura 30), indicando que provavelmente a concentração de NO estava menor que $1 \%$ neste momento. $O$ rendimento em $\mathrm{N}_{2}$ (Figura 31) ficou entre 70 e $80 \%$, abaixo da conversão de NO, confirmando a probabilidade de a concentração de NO ser menor neste ensaio.

Como já foi comentado no início do capítulo, o catalisador de lantânio, cério e cobre calcinado em $800^{\circ} \mathrm{C}$ por 10 horas (amostra B2) converteu $100 \%$ de ambos os reagentes, NO e CO (Figura 32), tendo rendimento em $\mathrm{N}_{2}$ (Figura 33) também próximo de $100 \%$, ou seja, máximo.

Nenhum dos catalisadores de lantânio e molibdênio (amostras C1 e C2) apresentou atividade frente a reação de redução de $\mathrm{NO}$ com $\mathrm{CO}$. As curvas de conversão de $\mathrm{NO}$ e $\mathrm{CO}$ e rendimento em $\mathrm{N}_{2}$ das amostras $\mathbf{C} 1$ e C2 são apresentadas nas Figuras 34 e 35 (amostra C1) e nas Figuras 36 e 37 (amostra C2). 


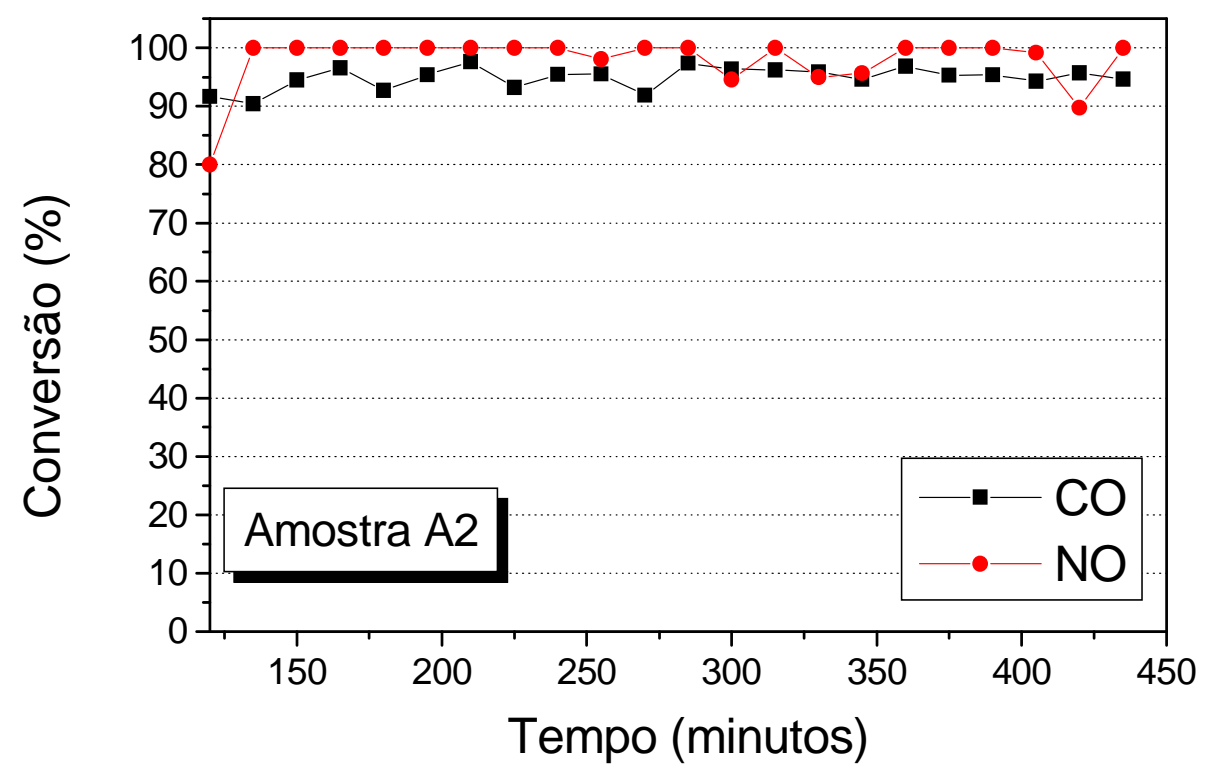

Figura 28: Conversão de $\mathrm{NO}$ e $\mathrm{CO}$ da amostra A2. A2 - amostra de La/ Cu pré-calcinada em $600^{\circ} \mathrm{C}$ e calcinada em $800^{\circ} \mathrm{C}$.

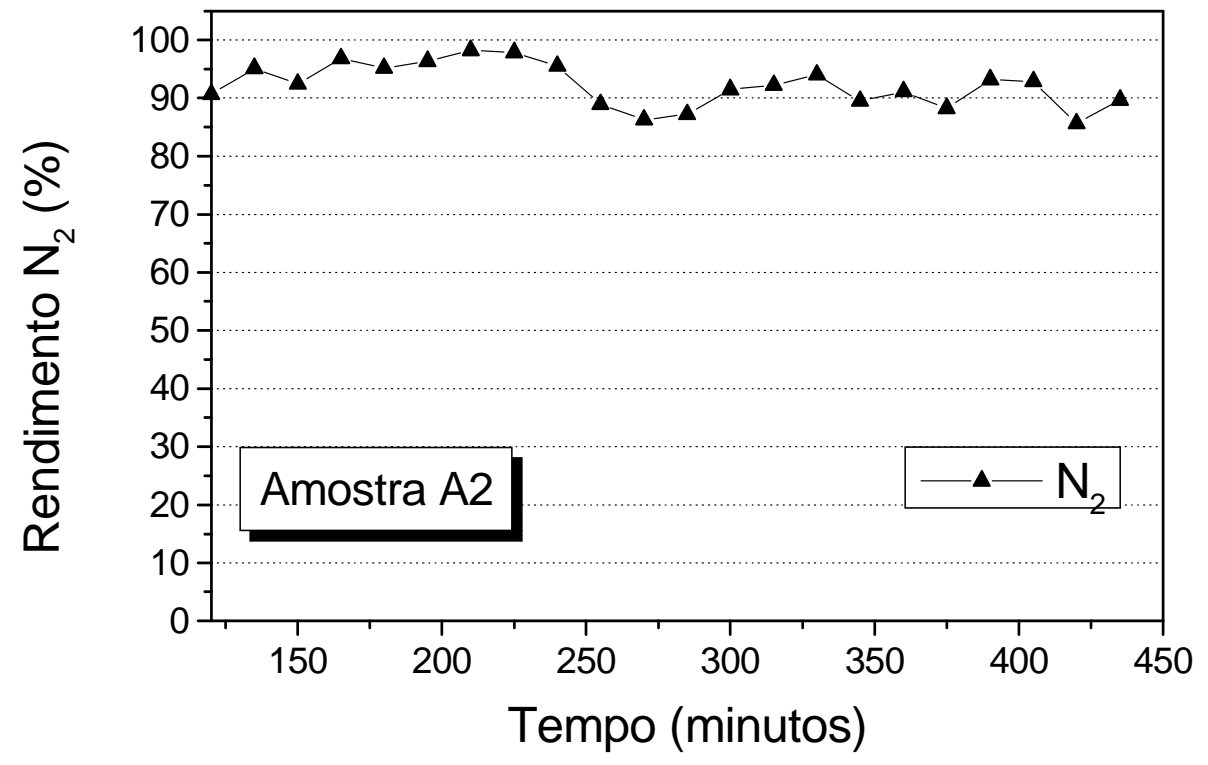

Figura 29: Produção de $\mathrm{N}_{2}$ da amostra A2. A2 - amostra de La/ Cu précalcinada em $600^{\circ} \mathrm{C}$ e calcinada em $800^{\circ} \mathrm{C}$. 


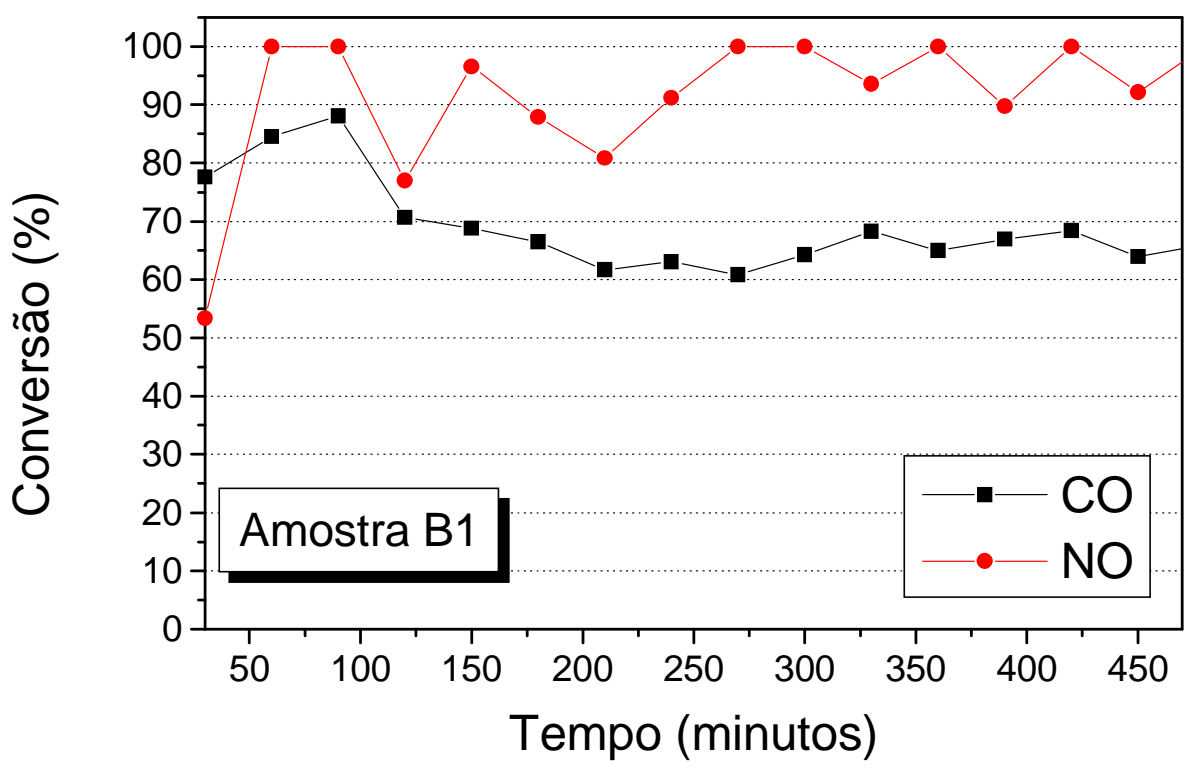

Figura 30: Conversão de NO e CO da amostra B1. B1 - amostra de La/ Ce/ Cu pré-calcinada em $600^{\circ} \mathrm{C}$ e calcinada em $900^{\circ} \mathrm{C}$.

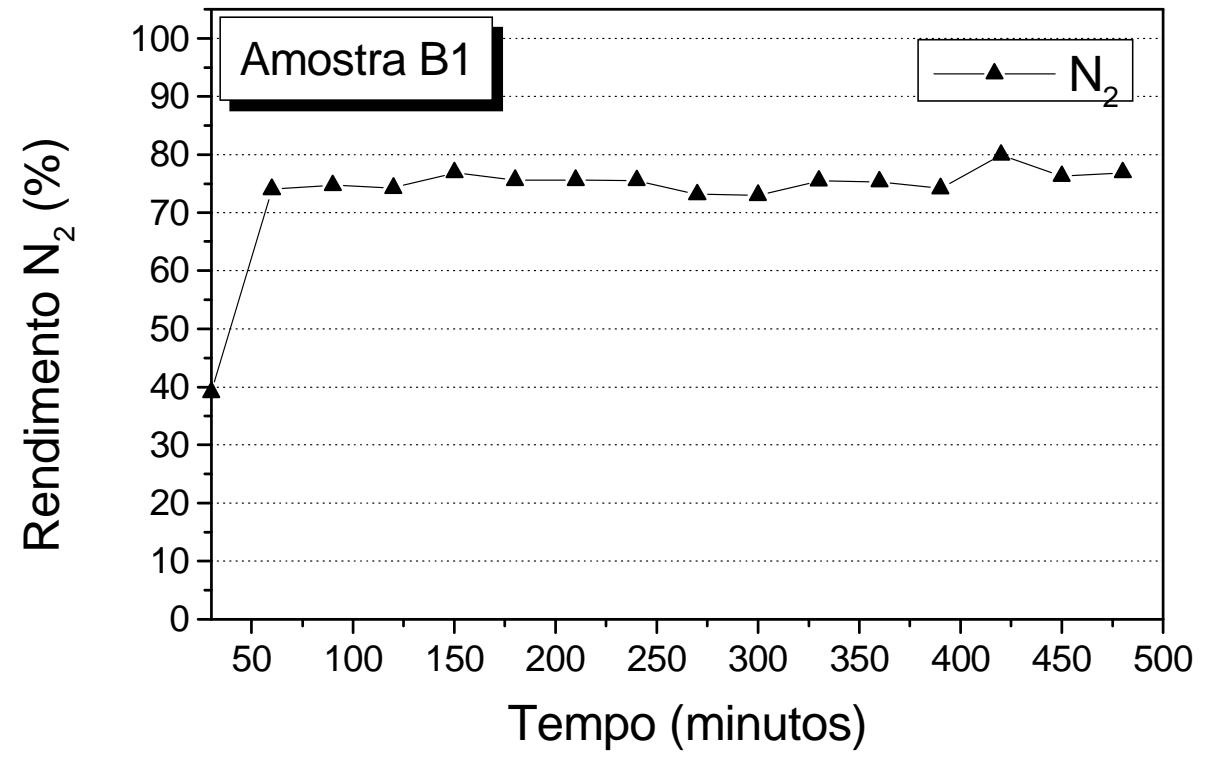

Figura 31: Produção de $\mathrm{N}_{2}$ da amostra B1. B1 - amostra de La/ Ce/ Cu précalcinada em $600^{\circ} \mathrm{C}$ e calcinada em $900^{\circ} \mathrm{C}$. 


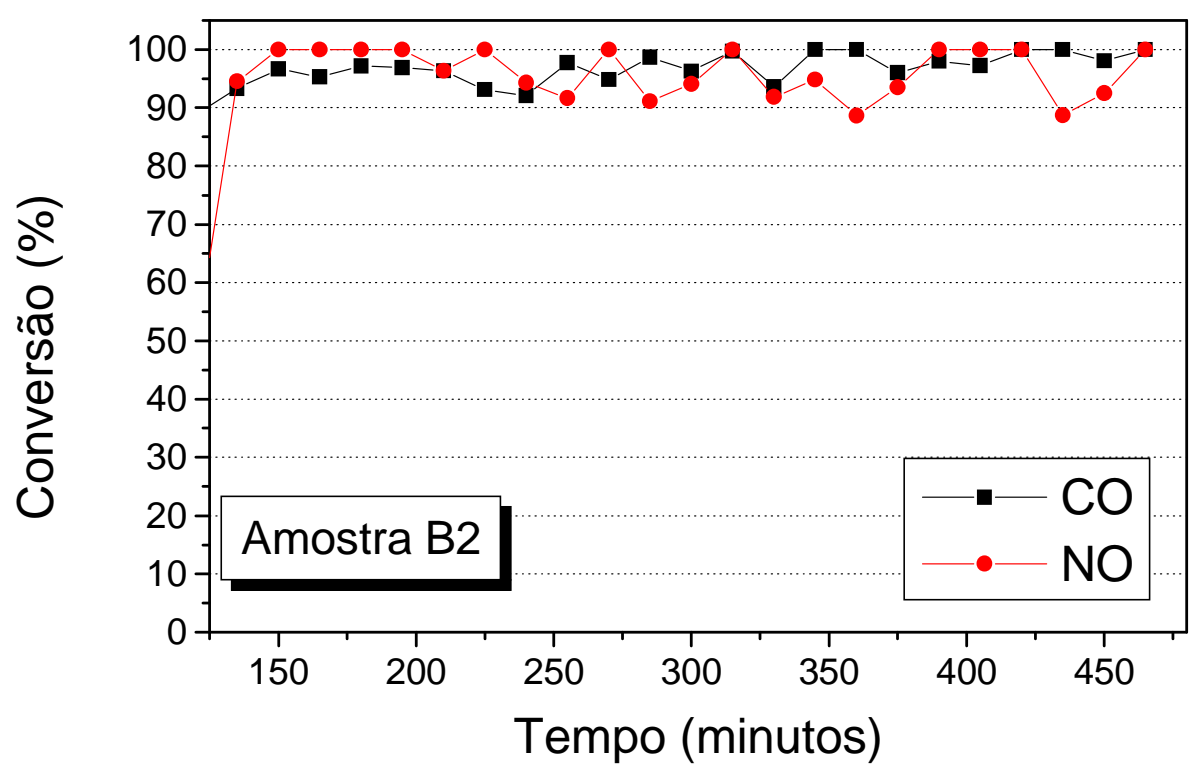

Figura 32: Conversão de NO e CO da amostra B2. B2 - amostra de La/ Ce/ Cu pré-calcinada em $600^{\circ} \mathrm{C}$ e calcinada em $800^{\circ} \mathrm{C}$.

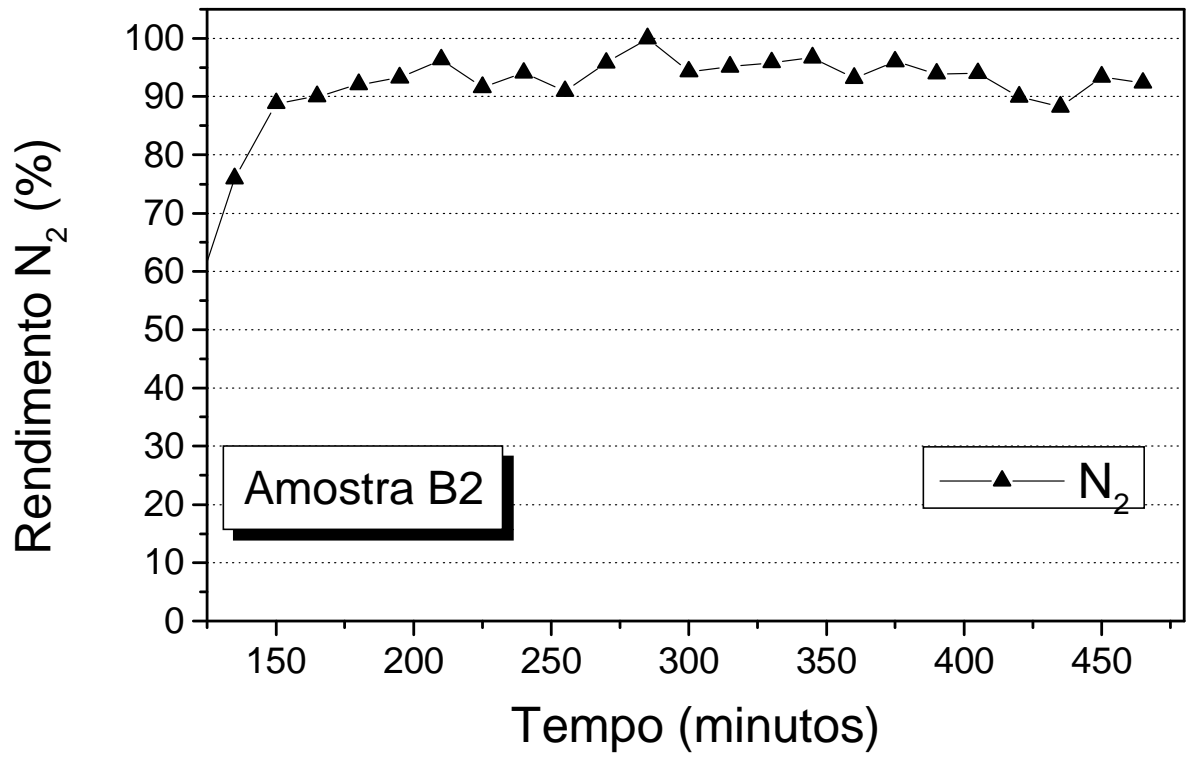

Figura 33: Produção de $\mathrm{N}_{2}$ da amostra B2. B2 - amostra de La/ Ce/ Cu précalcinada em $600^{\circ} \mathrm{C}$ e calcinada em $800^{\circ} \mathrm{C}$. 


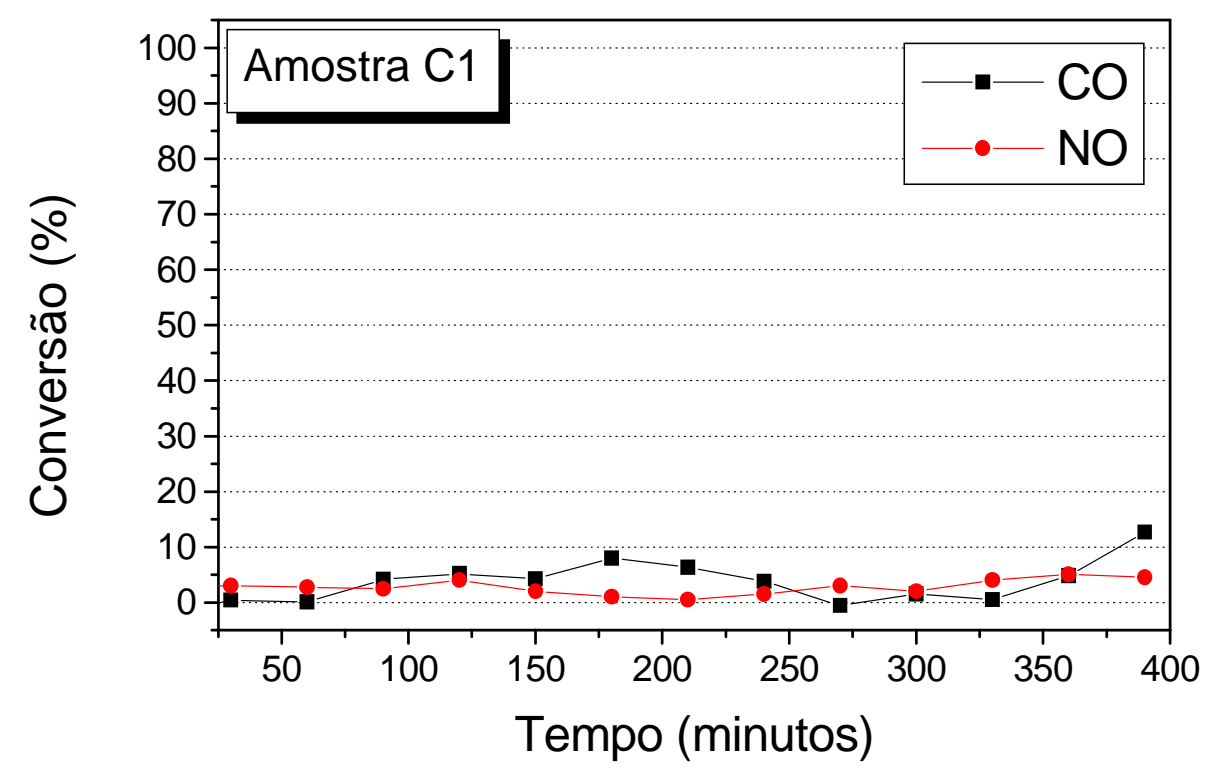

Figura 34: Conversão de NO e CO da amostra C1. C1 - amostra de La/ Mo pré-calcinada em $600^{\circ} \mathrm{C}$ e calcinada em $900^{\circ} \mathrm{C}$.

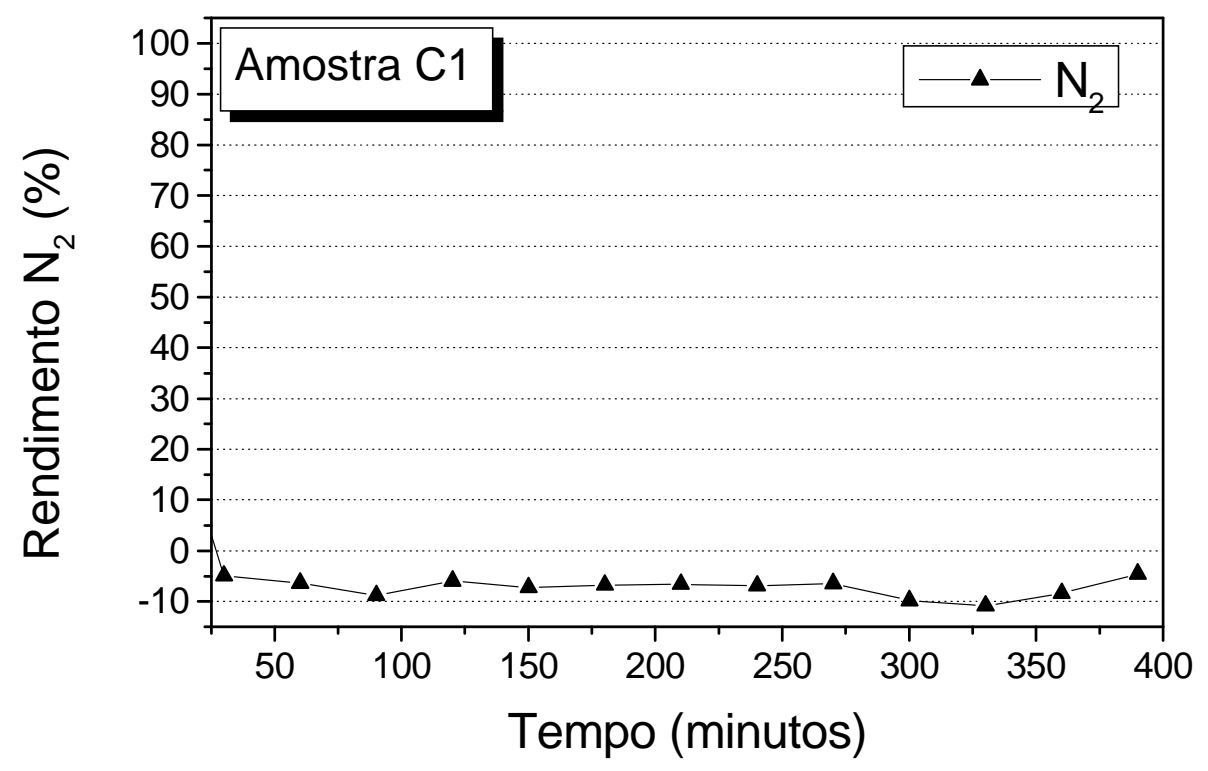

Figura 35: Produção de $N_{2}$ da amostra C1. C1 - amostra de La/ Mo précalcinada em $600^{\circ} \mathrm{C}$ e calcinada em $900^{\circ} \mathrm{C}$. 


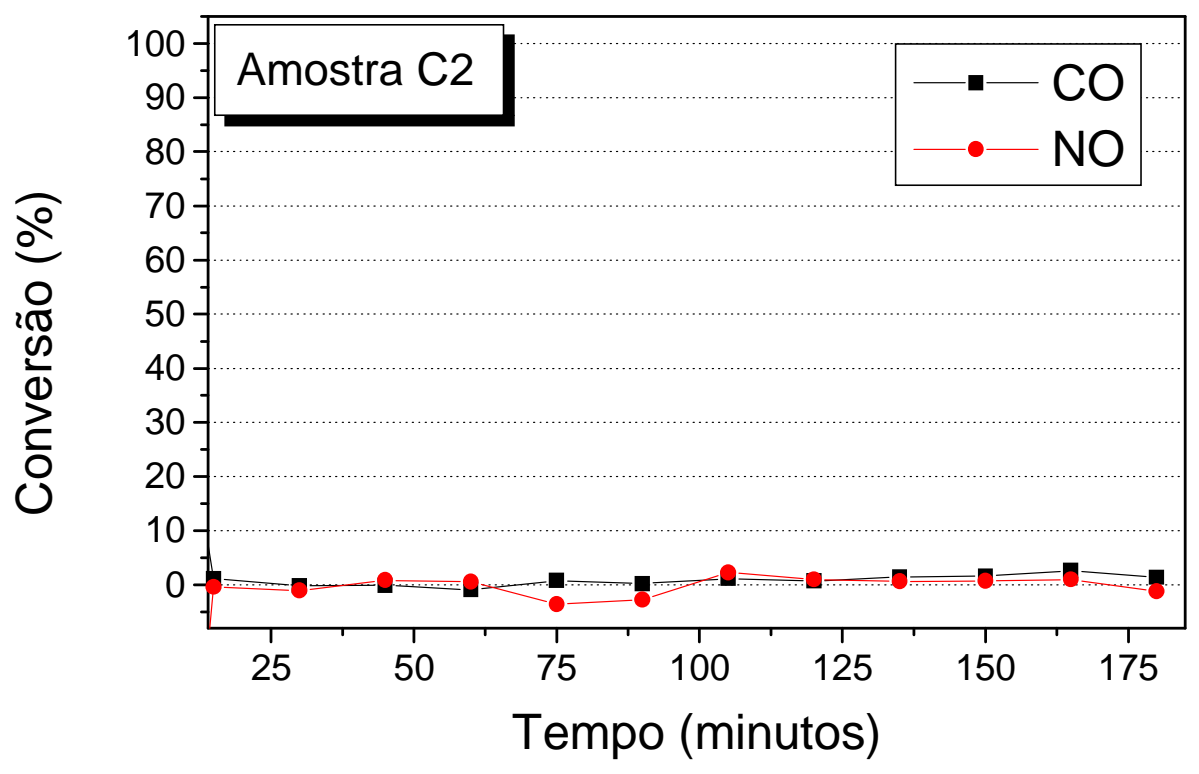

Figura 36: Conversão de NO e CO da amostra C2. C2 - amostra de La/ Mo pré-calcinada em $600^{\circ} \mathrm{C}$ e calcinada em $800^{\circ} \mathrm{C}$.

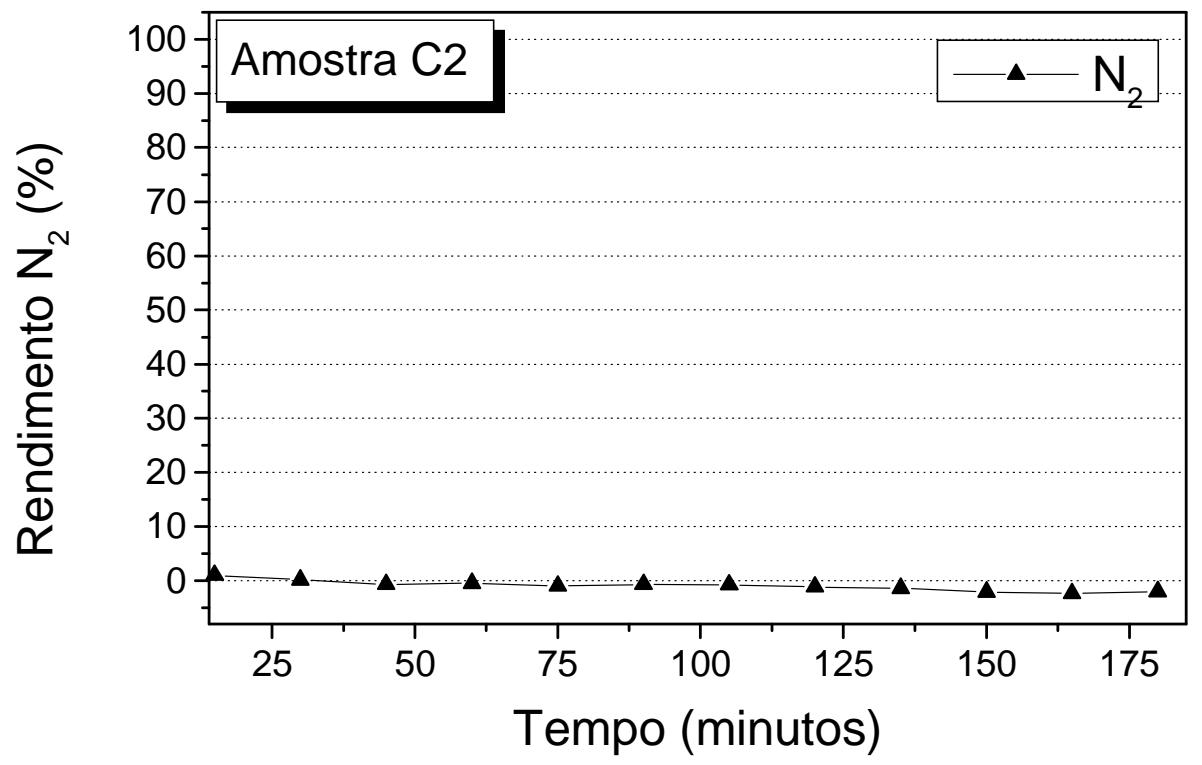

Figura 37: Produção de $\mathrm{N}_{2}$ da amostra C2. C2 - amostra de La/ Mo précalcinada em $600^{\circ} \mathrm{C}$ e calcinada em $800^{\circ} \mathrm{C}$. 
A proximidade das conversões de $\mathrm{CO}$ e $\mathrm{NO}$ nos ensaios catalíticos das amostras de lantânio e cobalto (amostras D1 e D2), sendo da amostra calcinada em $900^{\circ} \mathrm{C}$ (amostra D1) em torno de 30\% (Figura 38) e da amostra calcinada em $800^{\circ} \mathrm{C}$ (amostra D2) perto de $80 \%$ (Figura 40), mostra que a concentração de NO na mistura reagente nestes dois ensaios estava perto de $1 \%$.

$\mathrm{O}$ rendimento em $\mathrm{N}_{2}$ nestes dois catalisadores (D1 e D2) foi próximo do esperado segundo a conversão de NO, ficando na amostra D1 em torno de 30\% (Figura 39) e na amostra D2 perto de 80\% (Figura 41).

A diferença na atividade dos catalisadores de lantânio e cobalto calcinados em 900 (amostra D1) e $800^{\circ} \mathrm{C}$ (amostra D2) pode estar associada à diferença na cristalinidade destes compostos, como observado pela difração de raios- $\mathrm{X}$, a amostra calcinada em $800^{\circ} \mathrm{C}$ é mais cristalina, além de ter área superficial maior.

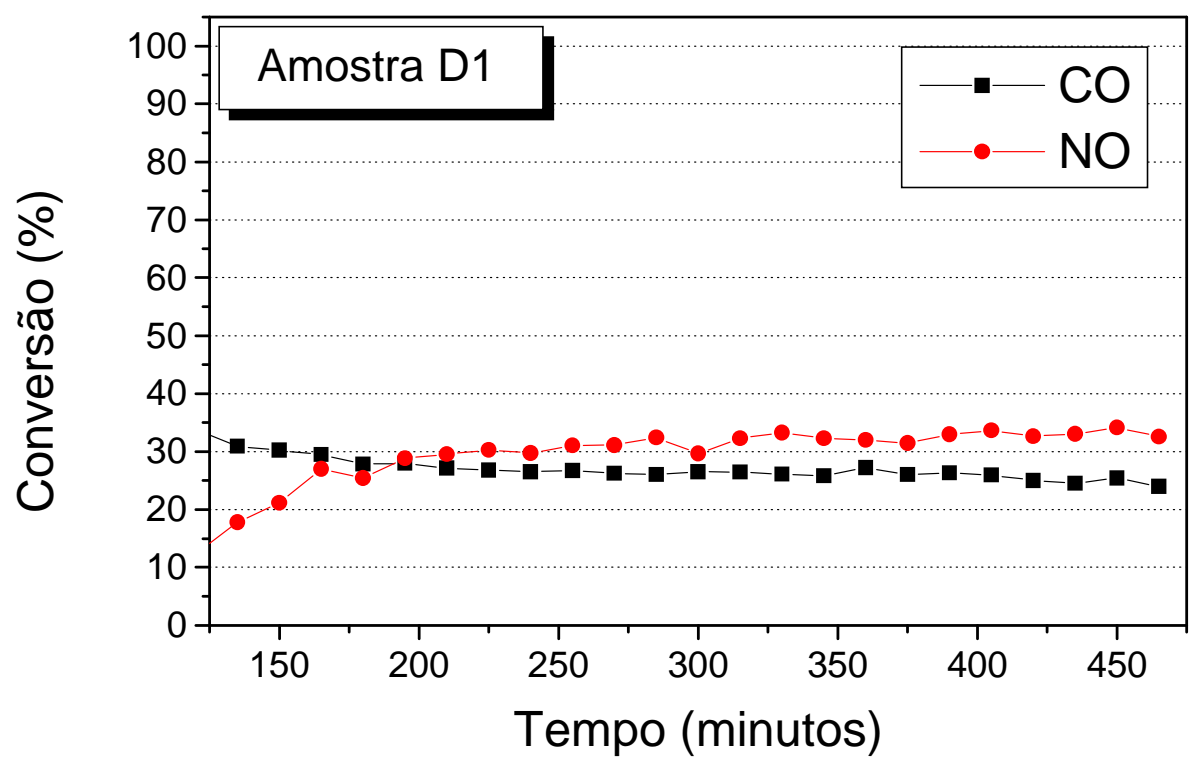

Figura 38: Conversão de NO e CO da amostra D1. D1 - amostra de La/ Co pré-calcinada em $600^{\circ} \mathrm{C}$ e calcinada em $900^{\circ} \mathrm{C}$. 


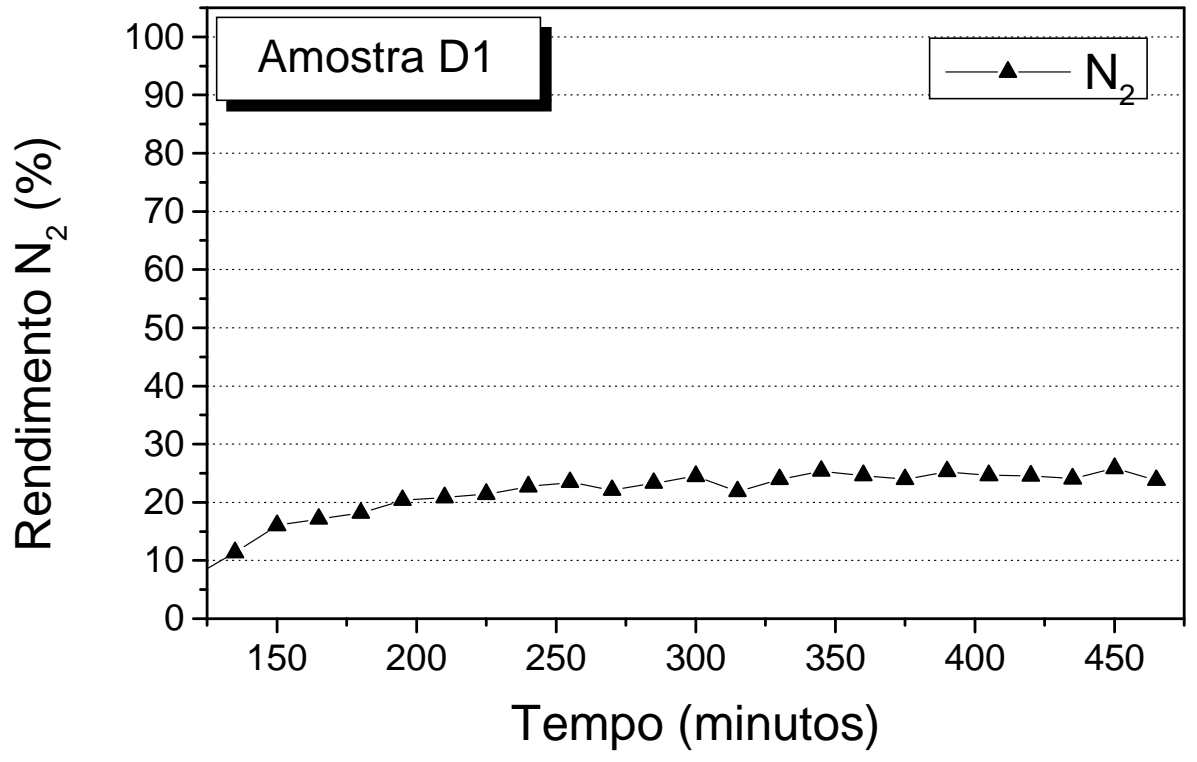

Figura 39: Produção de $N_{2}$ da amostra D1. D1 - amostra de La/ Co précalcinada em $600^{\circ} \mathrm{C}$ e calcinada em $900^{\circ} \mathrm{C}$.

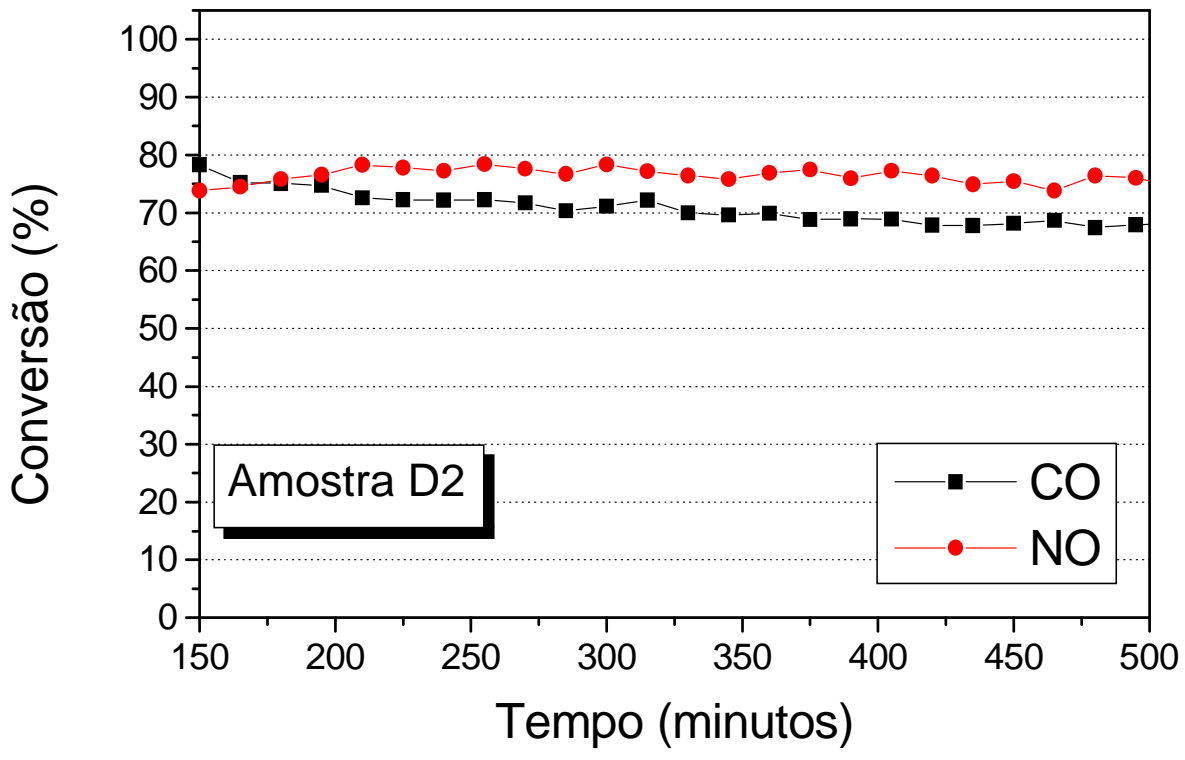

Figura 40: Conversão de NO e CO da amostra D2. D2 - amostra de La/ Co pré-calcinada em $600^{\circ} \mathrm{C}$ e calcinada em $800^{\circ} \mathrm{C}$. 


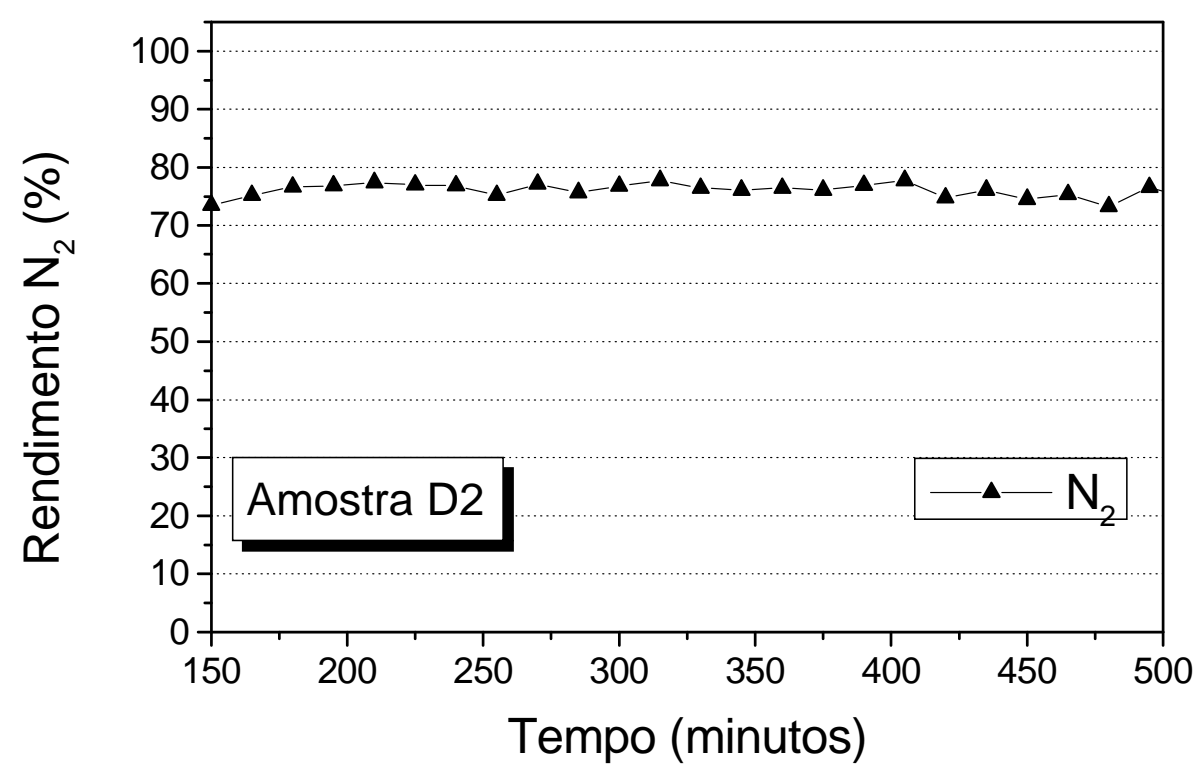

Figura 41: Produção de $\mathrm{N}_{2}$ da amostra D2. D2 - amostra de La/ Co précalcinada em $600^{\circ} \mathrm{C}$ e calcinada em $800^{\circ} \mathrm{C}$.

O mesmo pode ser observado nos ensaios das amostras de lantânio e níquel (amostras E1 e E2). As conversões de NO e CO (Figuras 42 e 44) foram bastante próximas, ficando perto de $60 \%$ na amostra calcinada em $900^{\circ} \mathrm{C}$ (amostra E1) e por volta de $80 \%$ para a amostra calcinada em $800^{\circ} \mathrm{C}$ (amostra E2), ambas apresentando leve queda na atividade, mas estabilizando em seguida. Como concluído para as amostras de lantânio e cobalto, provavelmente a mistura reagente tinha concentrações iguais de $\mathrm{CO}$ e NO. O rendimento em $\mathrm{N}_{2}$ (Figuras 43 e 45) foi correspondente à conversão de NO (60\% na amostra E1 e 80\% para a amostra E2).

Da mesma forma como observado para os catalisadores de lantânio e cobalto, a melhor atividade da amostra calcinada em $800^{\circ} \mathrm{C}$ provavelmente 
está associada à maior cristalinidade deste catalisador em relação àquele calcinado em $900^{\circ} \mathrm{C}$.

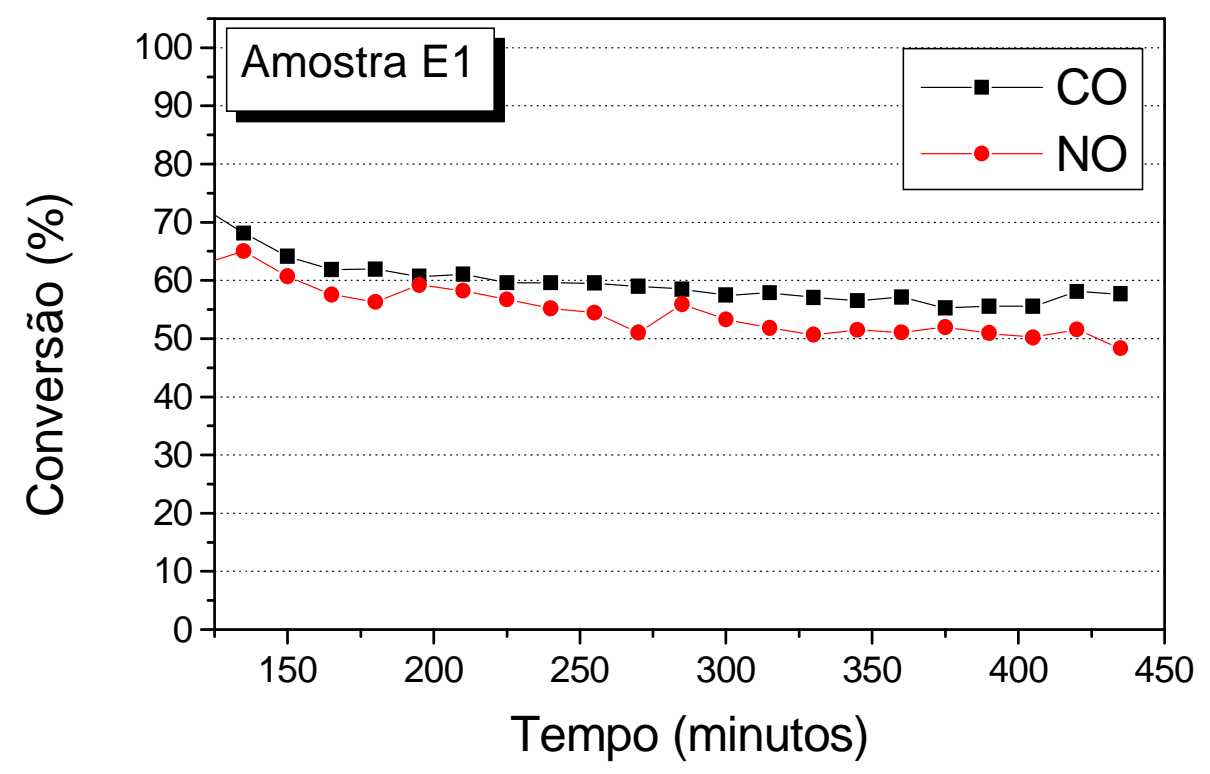

Figura 42: Conversão de NO e CO da amostra E1. E1 - amostra de La/ Ni pré-calcinada em $600^{\circ} \mathrm{C}$ e calcinada em $900^{\circ} \mathrm{C}$.

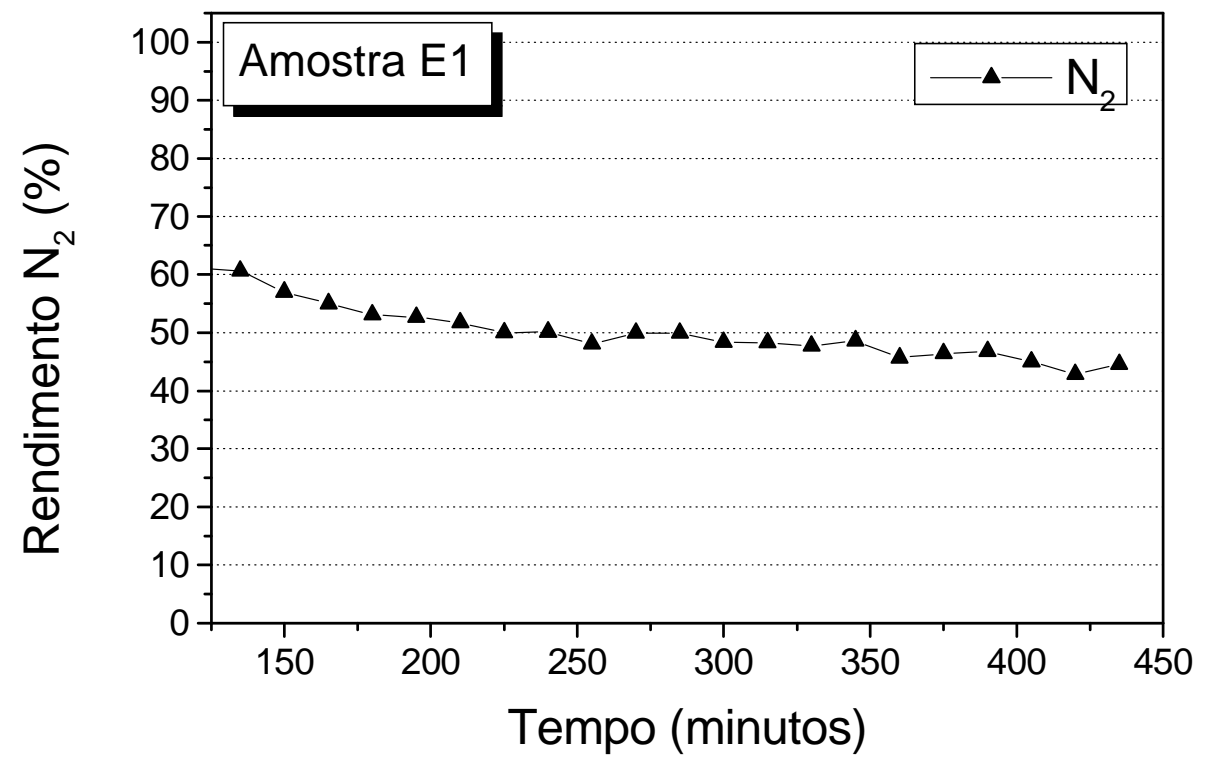

Figura 43: Produção de $\mathrm{N}_{2}$ da amostra E1. E1 - amostra de La/ Ni précalcinada em $600^{\circ} \mathrm{C}$ e calcinada em $900^{\circ} \mathrm{C}$. 


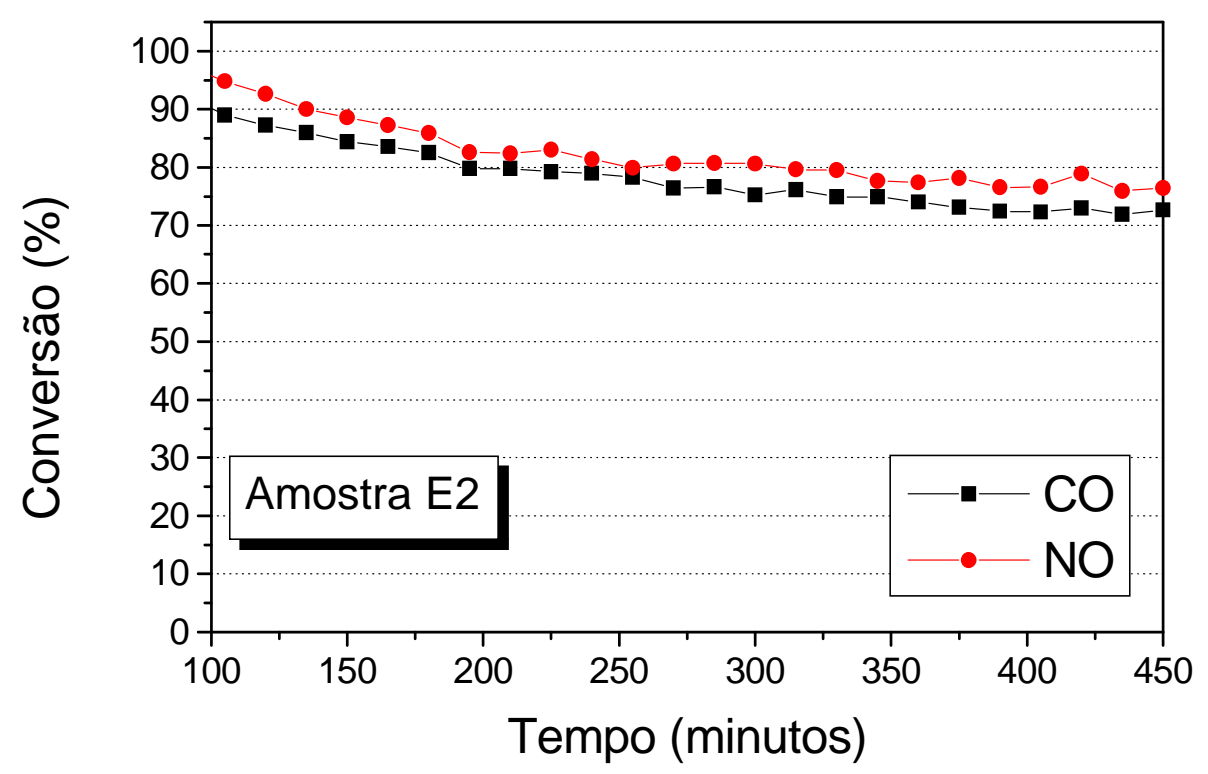

Figura 44: Conversão de NO e CO da amostra E2. E2 - amostra de La/ Ni pré-calcinada em $600^{\circ} \mathrm{C}$ e calcinada em $800^{\circ} \mathrm{C}$.

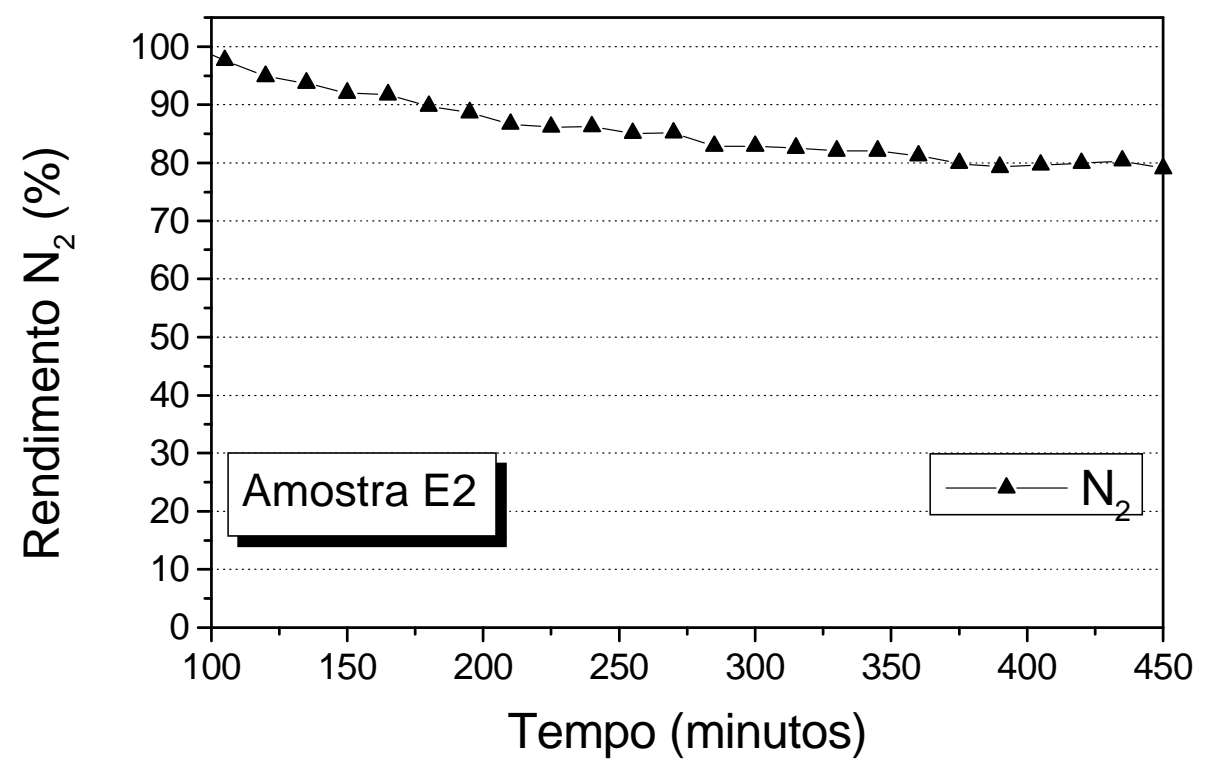

Figura 45: Produção de $\mathrm{N}_{2}$ da amostra E2. E2 - amostra de La/ Ni précalcinada em $600^{\circ} \mathrm{C}$ e calcinada em $800^{\circ} \mathrm{C}$. 
Como os catalisadores de lantânio/ cobre e lantânio/ níquel apresentaram boa atividade frente à reação de redução de $\mathrm{NO}$ com $\mathrm{CO}$, foi feita a substituição parcial dos metais, sendo preparado um catalisador com $50 \%$ de $\mathrm{Ni}$ e $50 \%$ de $\mathrm{Cu}$, a fim de estudar se este catalisador apresentaria melhor atividade frente à reação estuda.

A amostra calcinada em $900^{\circ} \mathrm{C}$ (amostra F1) apresentou atividade baixa, por volta de $30 \%$, tanto em relação ao consumo dos reagentes (Figura 46), como em relação ao rendimento em $\mathrm{N}_{2}$ (Figura 47).

Já a amostra calcinada em $800^{\circ} \mathrm{C}$ (amostra F2) apresentou conversão de $\mathrm{CO}$ em torno de $70 \%$, crescente, e de $\mathrm{NO}$ em torno de $80 \%$, também crescente. Essa diferença nas conversões de NO e CO provavelmente indica que a mistura reagente tinha concentração de NO mais baixa que de CO. O rendimento em $\mathrm{N}_{2}$, que apresentou um perfil mais próximo daquele apresentado pela conversão de $\mathrm{CO}$, ou seja, um rendimento em torno de $70 \%$, crescendo a cada medida.

A menor atividade deste catalisador substituído pode ser justificada pelo excesso de oxigênio na estrutura, como já foi observado para uma substituição parcial do cobalto por cobre ${ }^{(8)}$.

Sabe-se que cobalto está presente na estrutura do $\mathrm{LaCoO}_{3}$ no estado de oxidação $3+{ }^{(8)}$. A substituição deste por $\mathrm{Cu}^{2+}$ leva a uma deficiência de carga positiva na estrutura, que é compensada por vacâncias de oxigênios ${ }^{(8)}$. No caso da substituição de $\mathrm{Cu}^{2+}$ por $\mathrm{Ni}^{3+}$, o oposto pode ser proposto: a substituição leva a um aumento de carga positiva que é compensada por oxigênios. Esse oxigênio, como já foi lembrado por V. I. Pârvulescu et al. ${ }^{(5)}$ e comentado anteriormente, mantém a superfície 
oxidada, competindo com o NO pelo sítio ativo. Isso justifica a menor atividade deste catalisador para a reação de redução de NO com CO estudada. A interação entre as fases, diferente neste caso em relação às perovskitas dos metais separados $\left(\mathrm{La}_{2} \mathrm{CuO}_{4}\right.$ e $\left.\mathrm{LaNiO}_{3}\right)$, também pode justificar a menor atividade deste catalisador.

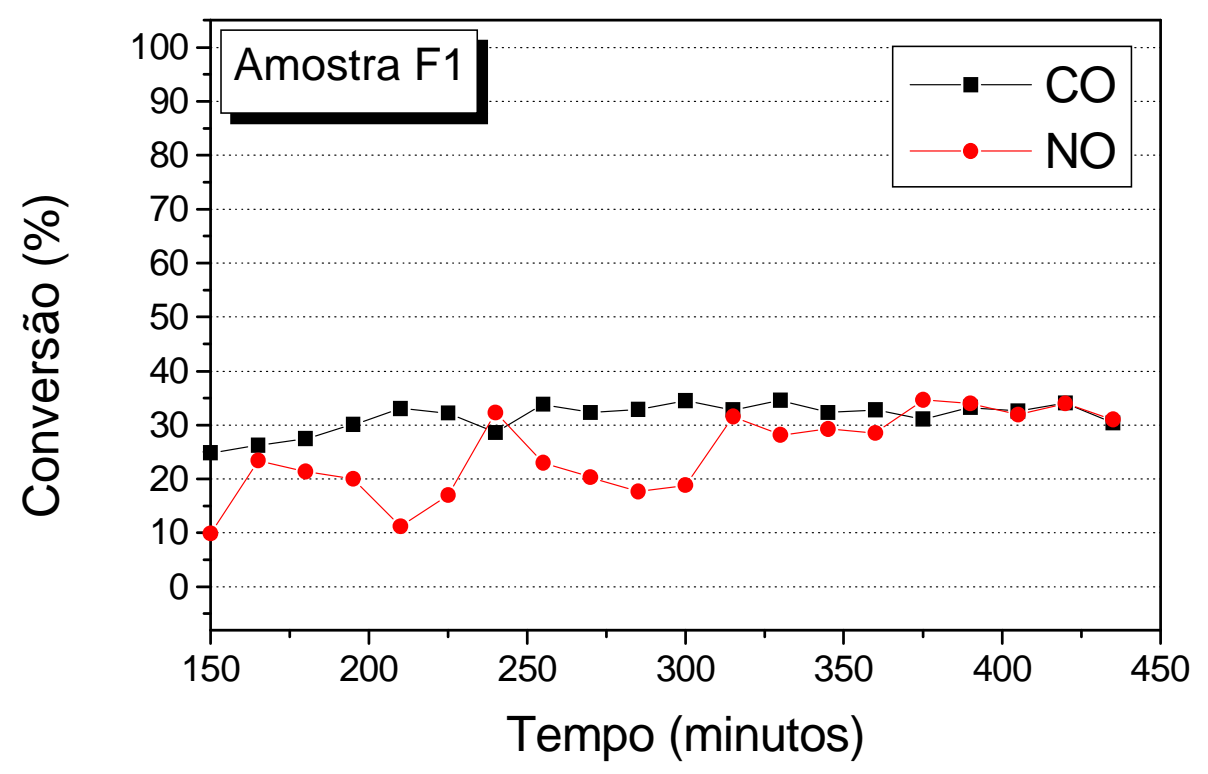

Figura 46: Conversão de NO e CO da amostra F1. F1 - amostra de La/ Cu/ Ni pré-calcinada em $600^{\circ} \mathrm{C}$ e calcinada em $900^{\circ} \mathrm{C}$. 


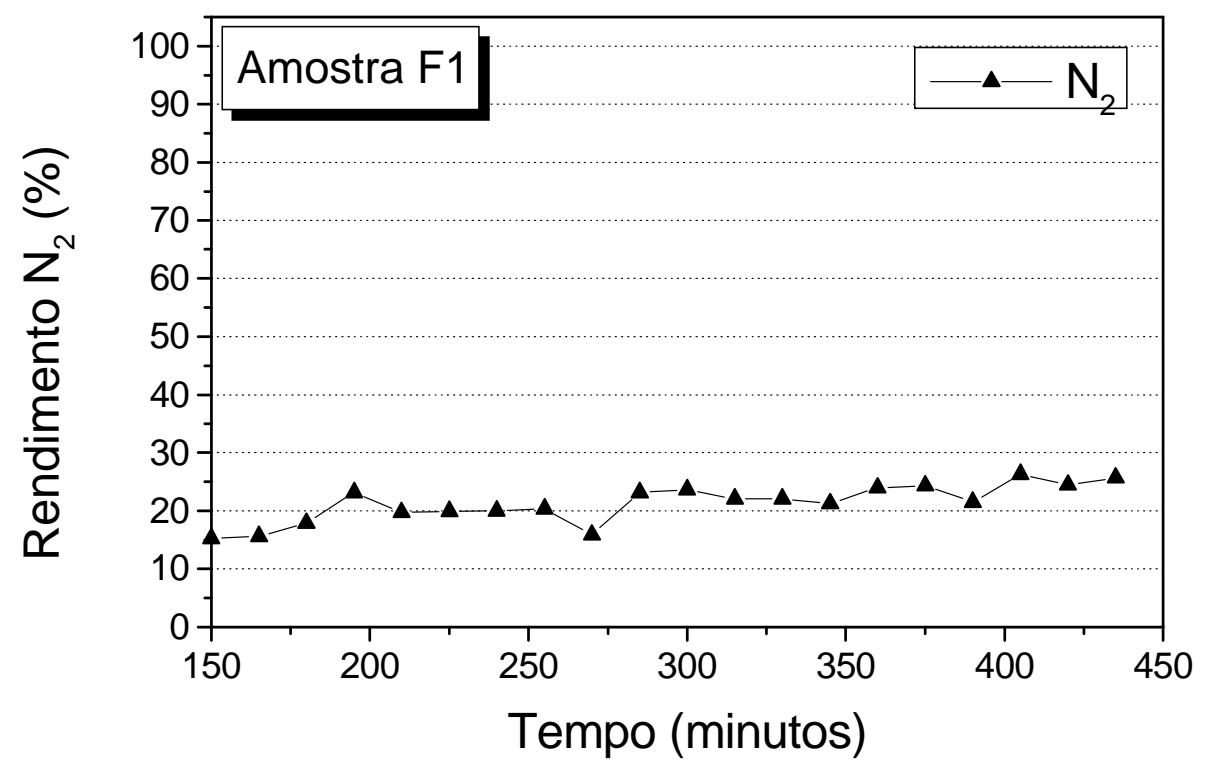

Figura 47: Produção de $\mathrm{N}_{2}$ da amostra F1. F1 - amostra de La/ Cu/ Ni précalcinada em $600^{\circ} \mathrm{C}$ e calcinada em $900^{\circ} \mathrm{C}$.

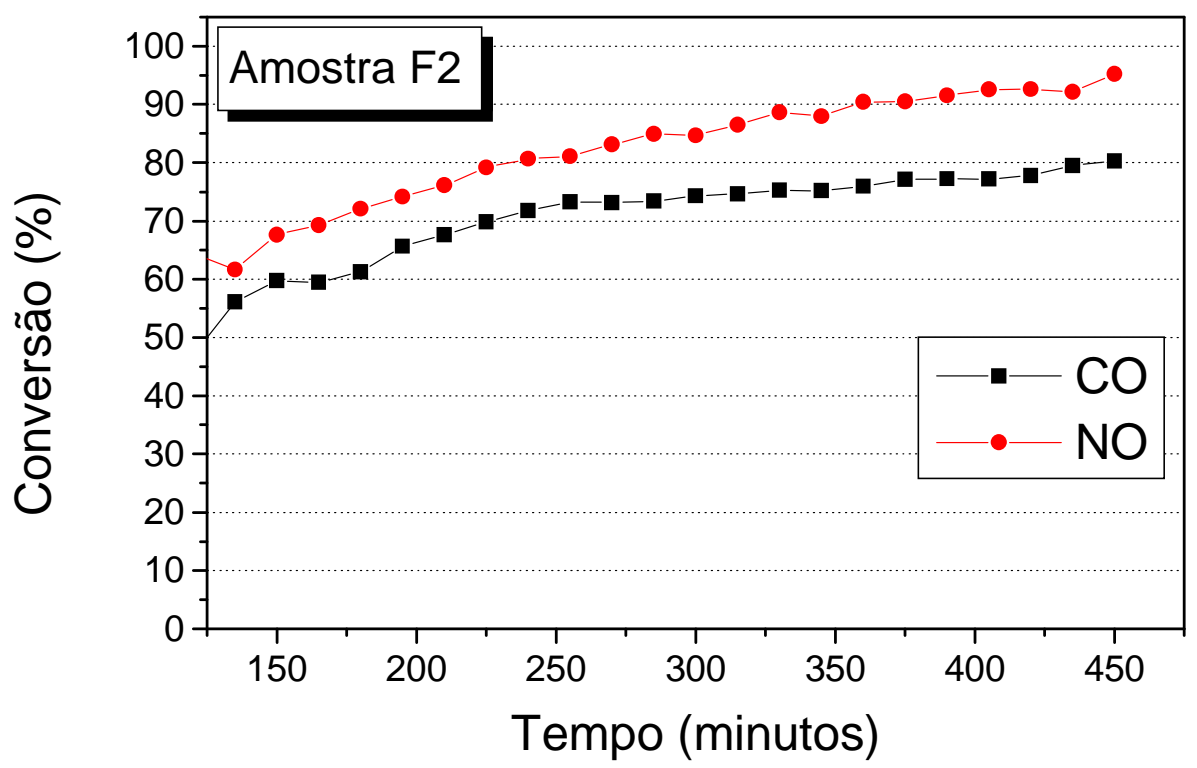

Figura 48: Conversão de NO e CO da amostra F2. F2 - amostra de La/ Cu/ Ni pré-calcinada em $600^{\circ} \mathrm{C}$ e calcinada em $800^{\circ} \mathrm{C}$. 


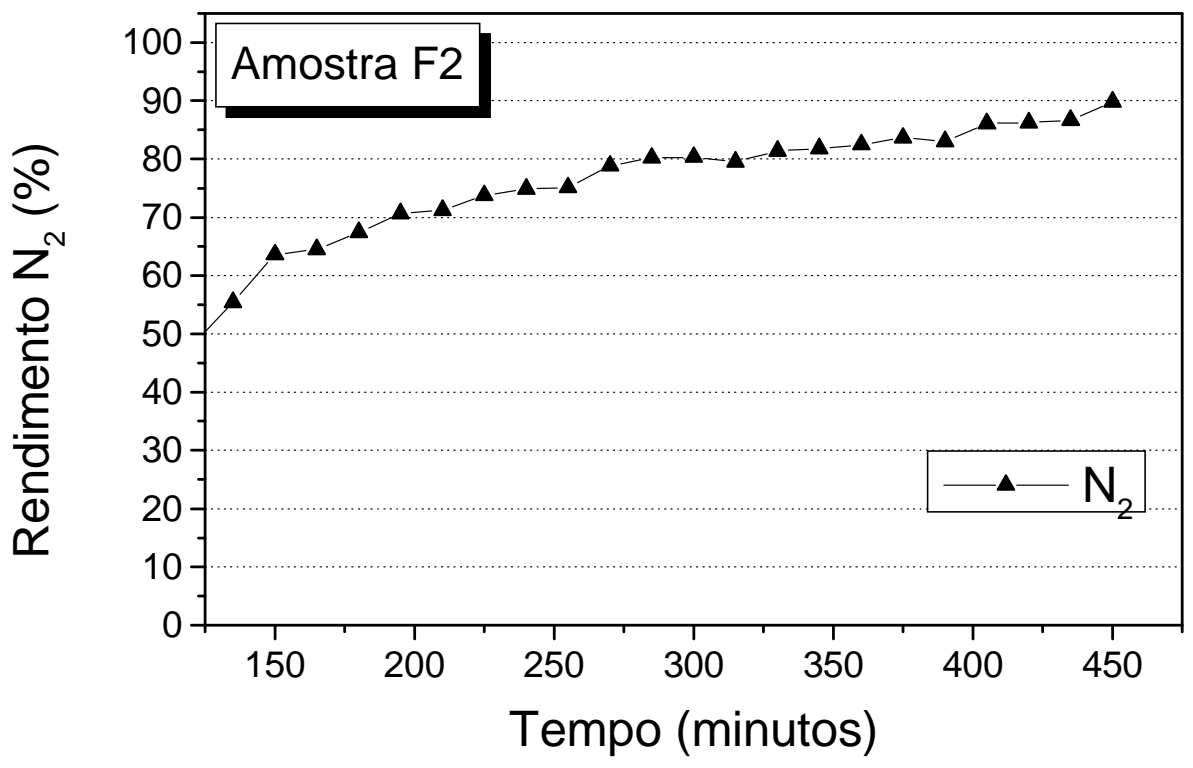

Figura 49: Produção de $\mathrm{N}_{2}$ da amostra F2. F2 - amostra de La/ Cu/ Ni précalcinada em $600^{\circ} \mathrm{C}$ e calcinada em $800^{\circ} \mathrm{C}$.

Com exceção das amostras de lantânio e molibdênio, que não foram ativas independente da temperatura de calcinação, as amostras calcinadas em $800^{\circ} \mathrm{C}$ foram mais ativas se comparadas àquelas calcinadas em $900^{\circ} \mathrm{C}$. Quanto maior a temperatura de calcinação, maior a sinterização e maior o tamanho das partículas, o que leva a uma diminuição da área superficial e da atividade do catalisador. Assim, a melhor atividade das amostras calcinadas em $800^{\circ} \mathrm{C}$ pode estar associada ao tamanho das partículas, menores se comparadas com as calcinadas em $900^{\circ} \mathrm{C}$, e à área superficial, maior devido ao tamanho de partícula menor.

Se compararmos as atividades dos catalisadores que tiveram melhor atividade, ou seja, aqueles calcinados em $800^{\circ} \mathrm{C}$, podemos notar que a amostra de $\mathrm{La}_{2} \mathrm{CuO}_{4}$ apresentou maior atividade em relação às amostras de 
$\mathrm{LaNiO}_{3}$ e $\mathrm{LaCoO}_{3}$. Uma proposta para esclarecer este fato é a diferença no preenchimento dos níveis eletrônicos dos metais na estrutura perovskita.

Quanto maior o preenchimento do orbital de valência nos metais, ou seja, do orbital mais externo, maior a disponibilidade de elétrons para a redução do NO. Uma vez que o $\mathrm{NO}$ foi reduzido a $\mathrm{N}_{2}$, o catalisador fica oxidado e a presença de $\mathrm{CO}$ facilmente reduz o metal novamente ao seu estado inicial. Assim, a etapa limitante no mecanismo é a redução do NO e oxidação do catalisador.

O cobre, em seu estado fundamental, possui um preenchimento $4 s^{1} 3 d^{10}$, ou seja, tem o orbital d completo (10 elétrons). Como o cobre está presente na perovskita no estado $2+$, neste sistema ele tem menos de 10 elétrons na banda d, não sendo possível afirmar a distribuição eletrônica da estrutura, uma vez que em sólidos os orbitais dos elementos compõem juntos a estrutura eletrônica do composto.

O níquel em seu estado fundamental tem distribuição eletrônica $4 s^{2} 3 d^{8}$, não tendo o orbital mais externo (3d) completo. Como o níquel está presente na estrutura $\mathrm{LaNiO}_{3}$ no estado $3+$, neste composto ele possui menos de 8 elétrons na banda $\mathrm{d}$, ou seja, menor número de elétrons disponíveis para reduzir o NO e portanto tem atividade menor se comparada à dos catalisadores de cobre.

O mesmo pode ser comentado para o cobalto. Em seu estado fundamental sua distribuição eletrônica é $4 s^{2} 3 d^{7}$, com o orbital d incompleto. $\mathrm{Na}$ estrutura $\mathrm{LaCoO}_{3}$ está no estado 3+, tendo menos de 7 elétrons na banda de valência e portanto tendo menor atividade se comparada ao níquel e ao cobre, o que foi observado experimentalmente. 
Também é possível comentar sobre a influência do lantânio na estrutura perovskita. O lantânio tem um nível energético maior que os outros metais $\left(6 s^{2} 5 d^{1}\right)$, o que aumenta a energia da banda de valência do composto, além de ceder elétrons para estabilizar os metais e favorecendo a redução do NO. No caso do $\mathrm{La}_{2} \mathrm{CuO}_{4}$ a quantidade de lantânio é maior que nos outros compostos, favorecendo ainda mais a redução de NO.

No caso da substituição parcial de lantânio por cério, o nível energético do cério é ainda maior que do lantânio, tendo distribuição eletrônica $6 s^{2} 4 f^{2}$, aumentando a energia da banda de valência do composto, doando elétrons para estabilizar o cobre quando este é oxidado e favorecendo a redução de NO.

A falta de atividade dos catalisadores de lantânio e molibdênio pode ser explicada pelo fato de o molibdênio estar na estrutura da perovskita no estado +6, não sendo facilmente oxidado a um estado maior e, como conseqüência, não reduzindo o NO. Em termos de distribuição eletrônica o molibdênio tem os últimos níveis $5 s^{1} 4 d^{5}$, mas na estrutura perovskita, onde está presente no estado $6+$, suas bandas de valência ficam próximas a $3 d^{10} 4 s^{2}$, tendo o octeto completo e sendo assim estável, não necessitando doar ou receber elétrons e não reduzindo o NO.

Como comentado anteriormente, a menor atividade dos catalisadores de lantânio, cobre e níquel pode ser explicada pelo excesso de oxigênio no composto, que compete com os sítios ativos diminuindo a conversão. 


\section{CONCLUSÕES}

Os catalisadores preparados pelo método do citrato não apresentaram área superficial maiores que aquelas reportadas na literatura ${ }^{(6-7,27-28,33,38,43,45-46)}$, tendo áreas menores que $1,4 \mathrm{~m}^{2} \mathrm{~g}^{-1}$.

Pelas análises químicas, as concentrações dos metais obtidas experimentalmente foram próximas dos valores teóricos. Uma diferença um pouco maior entre estes valores pode ter ocorrido por diferença na calibração dos equipamentos, já que os metais $\mathrm{Cu}, \mathrm{Ni}$ e Co foram analisados por espectrofotometria de absorção atômica e La, Mo e Ce foram analisados por espectrometria de emissão atômica por plasma induzido ou por excesso de água nos reagentes.

Nos difratogramas das amostras foram observadas as fases perovskita esperadas, exceto para o caso das amostras de lantânio e molibdênio (amostras C1 e C2), onde se esperava obter uma fase $\mathrm{La}_{2}\left(\mathrm{MoO}_{4}\right)_{3}$, mas a espécie observada foi $\mathrm{La}_{2} \mathrm{Mo}_{2} \mathrm{O}_{9}$, tendo ainda assim sendo a mesma fase obtida pela literatura seguida ${ }^{(47)}$. As fases observadas foram: $\mathrm{La}_{2} \mathrm{CuO}_{4}$ (amostras A1, A2, B1, B2, F1 e F2), $\mathrm{LaNiO}_{3}$ (amostras E1, E2, F1 e F2) e $\mathrm{LaCoO}_{3}$ (amostras D1 e D2).

$\mathrm{Na}$ amostras de lantânio e cobre (amostras A1 e A2) também foi possível observar picos de pequena intensidade referentes ao CuO. As amostras parcialmente substituídas com cério (amostras B1 e B2) apresentaram além dos picos do $\mathrm{La}_{2} \mathrm{CuO}_{4}$ picos referentes ao $\mathrm{CeO}_{2}$ e ao CuO. Os difratogramas das amostras de lantânio, cobre e níquel 
apresentaram picos referentes às estruturas do $\mathrm{La}_{2} \mathrm{CuO}_{4}$ e do $\mathrm{LaNiO}_{3}$ como esperado.

Os ensaios de Redução a Temperatura Programada (RTP) mostraram que as espécies contendo cobalto e níquel são reduzidas em 3 etapas, sendo a primeira a redução direta da espécie 3+ da estrutura perovskita para 0 , a segunda a redução parcial desta espécie para uma espécie $2+$ e a última correspondente à redução da espécie $2+$ para 0.0 cobre segue o mesmo mecanismo, mas com as duas primeiras etapas $\left(\mathrm{Cu}^{2+} \rightarrow \mathrm{Cu}^{0}\right.$ e $\left.\mathrm{Cu}^{2+} \rightarrow \mathrm{Cu}^{1+}\right)$ acontecendo na mesma temperatura e depois ocorrendo a redução do $\mathrm{Cu}^{1+}$ para $\mathrm{Cu}^{0}$.

Os RTPs das amostras de molibdênio mostram que provavelmente o $\mathrm{Mo}^{6+}$ se reduz primeiramente $\mathrm{a} \mathrm{Mo}^{4+}$ e depois esta espécie é reduzia a $\mathrm{Mo}^{0}$. Como nestes ensaios quando a temperatura atingiu $1000^{\circ} \mathrm{C}$ a redução ainda não estava completa, não se pode afirmar que o consumo de $\mathrm{H}_{2}$ dos ensaios seja referente à redução completa de todas as espécies de molibdênio.

O óxido de cério das amostras B1 e B2 foi reduzido na mesma temperatura do cobre da perovskita, não sendo possível quantificar cada uma das espécies. Pelas áreas dos picos pode-se supor que uma pequena quantidade de cério tenha se incorporado à estrutura da perovskita, sendo reduzido numa primeira etapa a $\mathrm{Ce}_{2} \mathrm{O}_{3}$ e depois a $\mathrm{Ce}^{0}$.

As amostras de lantânio, cobre e níquel (amostras F1 e F2) foram reduzidas em duas etapas, sendo estas correspondentes à somas das reduções das espécies de $\mathrm{La}_{2} \mathrm{CuO}_{4}$ e $\mathrm{LaNiO}_{3}$.

Com os ensaios catalíticos foi possível observar que as amostras que apresentaram melhor atividade foram aquelas contendo lantânio/ cobre ou 
lantânio/ cério/ cobre, seguidas daquelas contendo lantânio/ níquel e depois lantânio/ cobalto. As amostras com menor atividade foram aquelas contendo lantânio/ cobre/ níquel, sendo que as amostras de lantânio/ molibdênio não foram ativas.

A menor atividade das amostras contendo lantânio, cobre e níquel (amostras F1 e F2) pode ser atribuída ao aumento da quantidade de oxigênio no composto, já que a substituição do $\mathrm{Cu}^{2+}$ por $\mathrm{Ni}^{3+}$ leva a uma deficiência eletrônica que é compensada com oxigênios. Este oxigênio compete com os sítios ativos, diminuindo a estabilidade do catalisador.

O fato das amostras contendo lantânio e molibdênio não serem ativas pode estar associado ao estado de oxidação 6+ do molibdênio na estrutura $\mathrm{La}_{2} \mathrm{Mo}_{2} \mathrm{O}_{9}$. O molibdênio não é facilmente oxidado a um estado de oxidação maior que $6+$, o que o impede de reduzir o NO.

A melhor atividade das outras espécies contendo cobre pode ser justificada pela distribuição eletrônica do cobre na estrutura perovskita, que favorece a redução do NO mais que as distribuições eletrônicas do níquel e do cobalto. Quanto maior o número de elétrons na banda mais externa do composto, maior a tendência a reduzir NO e melhor atividade do catalisador.

As amostras calcinadas em $800^{\circ} \mathrm{C}$ foram mais ativas que aquelas calcinadas em $900^{\circ} \mathrm{C}$. Uma possível explicação pode ser o fato de quanto maior a temperatura de calcinação, maior a sinterização e o tamanho das partículas, o que diminui a área superficial do catalisador e conseqüentemente a sua atividade. 
Assim, os objetivos propostos para o trabalho foram atingidos, tendo sido os catalisadores preparados, caracterizados e testados frente à reação de redução de $\mathrm{NO}$ com $\mathrm{CO}$. 


\section{REFERÊNCIAS BIBLIOGRÁFICAS}

1. SÃO PAULO (Estado). Companhia de Tecnologia e Saneamento Ambiental CETESB. Departamento de Qualidade Ambiental. Divisão de Qualidade do Ar. Relatório de Qualidade do Ar 2000 - São Paulo, 2001.

2. Ministério do Meio Ambiente, dos Recursos Hídricos e da Amazônia Legal. IBAMA - Instituto Brasileiro do Meio Ambiente e dos Recursos Naturais Renováveis. Programa de Controle da Poluição do Ar por Veículos Automotores - PROCONVE, 2ª Edição, Brasília (1998).

3. SÃO PAULO (Estado). CETESB. Disponível em http:// www.cetesb.sp.gov.br. Acesso em 01/03/2003 às $15 \mathrm{~h}$.

4. Poluição. O Estado de São Paulo, São Paulo, 12 dez. 2000. CIDADES.

5. V. I. Pârvulescu, P. Grange, B. Delmon, Catalysis Today 46 (1998) $233-316$.

6. N. Mizuno, M. Yamato, M. Tanaka, M Misono, Chemistry of Materials 1 (1989) $232-336$.

7. N. Guilhaume, S. D. Peter, M. Primet, Applied Catalysis B: Environmental 10 (1996) $325-344$.

8. V. Porta, S. D. Rossi, M. Faticanti, G. Minelli, I. Pettiti, L. Lisi, M. Turco, Journal of Solid State Chemistry 146 (1999) 291 - 304.

9. I. Halasz, A. Brenner, M. Shelef, Applied Catalysis B: Environmental 2 (1993) $131-146$.

10. M. A. S. Baldanza, L. F. Mello, A. Vannice, F. B. Noronha, M. Schmal, Journal of Catalysis 192 (2000) $64-76$. 
11. J. S. Garcia, Estudo da poluição por Ozônio encontrada no Pico do Jaraguá e na cidade de Judiaí. Campinas, 2002, 71p. Monografia (Especialização) - Faculdade de Engenharia Mecânica, Universidade Estadual de Campinas.

12. V.L.D. Novais, Química: Físico-Química e Química Ambiental, São Paulo. Ed. Atual, 1994, Volume 2, cap.8.

13. W.L.R. Gallo, “Política Energética” - Curso de especialização em gestão Ambiental - FEM, Campinas. Unicamp, 2001, 43.

14. J. G. Calvert, Pure and Applied Chemistry 69 (1997) 1 - 12.

15. UNITED STATES ENVIRONMENTAL AGENCY (EPA). Air Quality Criteria for Ozone and Related Photochemical Oxidants. 3 v., July 1996. EPA/600/;p-93/004aF.

16. J. P. Beck, M. Krzyzanowski, B. Koffi. Troposferic Ozone in the European Union “The Consolidated Report”, European Environment Agecy (EEA). November 1998.

17. SÃO PAULO (Estado). Companhia de Tecnologia e Saneamento Ambiental CETESB. Departamento de Qualidade Ambiental. Divisão de Qualidade do Ar. Estudo do Comportamento do Ozônio na Região Metropolitana de São Paulo - São Paulo, 2000.

18. Manufactures of Emission Controls Association. Disponível em http://www.meca.org. Acesso em 20/08/2002 às 10h.

19. L. Kundakovic, M. Flytzani-Stephanopoulos, Applied Catalysis A: General $171(1998) 13-29$. 
20. W. P. Dow, Y. P. Wang, T. J. Huang, Applied Catalysis A: General 190 (2000) $25-34$.

21. Laboratory for Surface Science and Technology - ETH Zürich Department of Materials. Disponível em http://www.surface.mat.ethz.ch/lsst/research/ catalysis/default.htm. Acesso em 19/11/2001 às 17h.

22. Informaçãp pessoal.

23. Y. Yokoi, H. Uchida, Catalysis Today 42 (1998) 167 - 174.

24. K. Yokota, M. Fukui, T. Tanaka, Applied Surface Science 121/122 (1997) $273-277$.

25. A. A. Nikolopoulos, E. S. Stergioula, E. A. Efthimiadis, I. A. Vasalos, Catalysis Today 54 (1999) 439 - 450.

26. M. J. Illán-Gómez, E. Raymundo-Piñero, A. García-García, A. LinaresSolano, C. S. M. Lecea, Applied Catalysis B: Environmental 20 (1999) $267-275$

27. L. Forni, C. Oliva, F. P. Vatti, M. A. Ezerets, A. V. Vishniakov, Applied Catalysis B: Environmental 7 (1996) $269-284$.

28. L. Simonot, F. Garin, G. Maire, Applied Catalysis B: Environmental 11 (1997) $167-179$.

29. L. Simonot, F. Garin, G. Maire, Applied Catalysis B: Environmental 11 (1997) $181-191$.

30. A. M. Pisanu, C. E. Gigola, Applied Catalysis B: Environmental 20 (1999) $179-189$.

31. Y. Wu, Z. Zhao, Y, Liu, X, Yang, Journal of Molecular Catalysis A: Chemical $155(2000) 89-100$. 
32. D. I. Kondarides, T. Chafik, X. E. Verykios, Journal of Catalysis 191 (2000) $147-164$.

33. S. D. Peter, E. Garbowski, N. Guilhaume, V. Perrichon, M. Primet, Catalysis Letters 54 (1998) $79-84$.

34. P. -Y. Lin, M. Skoglundh, L. Löwendahl, J. -E. Otterstedt, L. Dahl, K. Jansson, M. Nygren, Applied Catalysis B: Environmental 6 (1995) 237 - 254.

35. N. Mizuno, M. Yamato, M. Tanaka, M. Misono, Journal of Catalysis 132 (1991) $560-562$.

36. M. -D. Wei, Y. Teraoka, S. Kagawa, Materials Research Bulletin 35 (2000) $521-530$.

37. S. Hodjati, K. Vaezzadeh, C. Petit, V. Pitchon, A. Kiennemann, Applied Catalysis B: Environmental 26 (2000) 5 - 16.

38. Z. Zhao, X. Yang, Y. Wu, Applied Catalysis B: Environmental 8 (1996) $281-297$.

39. J. M. Longo, P. M. Raccah, Journal of Solid State Chemistry 6 (1973) $526-531$.

40. T. Yokoya, O. Akaki, H. Kumigashira, A. Chainani, T. Takahashi, H. K. Yoshida, M. Kasai, Y. Tokura, Journal of Electron Spectroscopy and Related Phenomena 78 (1996) 171 - 174.

41. Y. Maeno, H. Hashimoto, K. Yoshida, S. Nishizaki, T. Fujita, J. G. Bednorz, F. Lichtenberg, Nature 372 (1994) 532 - 534.

42. Y. Teraoka, K. Nakano, W. Shangguan, S. Kagawa, Catalysis Today 27 (1996) $107-113$. 
43. V. R. Choudhary, S. Banerjee, B. S. Uphade, Applied Catalysis A: General 197 (2000) L183 - L186.

44. K. S. Song, H. X. Cui, S. D. Kim, S. K. Kang, Catalysis Today 47 (1999) $155-160$.

45. N. Mizuno, Y. Fujiwara, M. Misono, Journal of the Chemical Society, Chemical Communications 11 (1997) 181 - 191.

46. I. Rodriguez-Ramos, A. Gerrero-Ruiz, M. L. Rojas, J. L. G. Fierro, Applied Catalysis 68 (1991) $217-228$.

47. G. P. Gonzalez-Rojas, J. Bonifácio-Martinez, E. Ordonez-Regil, S. M. Fernandez-Valverde, International Journal of Hydrogen Energy 23, 11 (1998) $999-1003$.

48. J. S. Garcia, E. M. Assaf. Preparação de $\mathrm{La}_{2} \mathrm{CuO}_{4}$ e $\mathrm{La}_{(2-x)} \mathrm{Ce}_{\mathrm{x}} \mathrm{CuO} \mathrm{O}_{4}$ pelo Método do Citrato. In: CONGRESSO BRASILEIRO DE ENGENHARIA E CIÊNCIAS DOS MATERIAIS, XV, Natal, 2002. /No prelo/

49. S. S. Maluf. Reforma a Vapor de Metano: preparação de Catalisador níquel/alumina com Promotor e Ensaios Catalíticos. São Carlos, 2001, 112p. Dissertação (Mestrado) - Instituto de Química de São Carlos, Universidade de São Paulo.

50. D. Cardoso. Introdução à Catálise Heterogênea. 1a ed. São Carlos, Editora da Universidade Federal de São Carlos, 1987, 226p.

51. Joint Commitee on Powder Diffraction Standars (JCPDS), International Center of Diffraction Data. Pensilvânia - USA, 1994 (CD-ROM) 
52. D. A. SKOOG, D. M. WEST, F. J. HOLLER. Analytical Chemistry, an Introduction. 6 6 $^{\mathrm{a}}$ ed. Orlando - EUA, Saunders College Publishing, 1994, $836 p$.

53. J. S. Garcia. Estágio em Indústria - Faber-Castell. São Carlos, 2000, 19p. Relatório - Instituto de Química de São Carlos, Universidade de São Paulo.

54. S. D. Peter, E. Garbowski, V. Perrichon, B. Pommier, M. Primet, Applied Catalysis A: General 205 (2001) 147 - 158.

55. P. Arnoldy, J. C. M. Jonge, J. A. Moulijn, The Journal of Physical Chemistry 89, 21 (1985) $4517-4526$.

56. J. O. Petunchi, E. A. Lombardo, Catalysis Today 8 (1990) $201-219$.

57. S. M. Lima. Preparação e Caracterização de Perovskitas de $\operatorname{LaNi}_{(1-x)} \mathrm{Fe}_{x} \mathrm{O}_{3}$ e $\mathrm{LaNi}_{(1-\mathrm{x})} \mathrm{Co}_{\mathrm{x}} \mathrm{O}_{3}$ para Reforna de Metano com $\mathrm{CO}_{2}$. São Carlos, 2002, 113p. Dissertação (Mestrado) - Departamento de Engenharia Química, Universidade Federal de São Carlos.

58. P. H. N. Saldiva, Revista dos Transportes Públicos - ANTP ano $222^{\circ}$ trimestre (2000) $101-113$.

59. D. I. Hammer, V. Hasselblad, B. Portnoy, P. F. Wehrle, Archives of Environmental Health 28 (1974).

60. P. H. Saldiva, Debates Sócio Ambientais 2 (1995-96).

61. P.W. Atkins. Físico Química. Trad. de Horacio Macedo, 6 ${ }^{\mathbf{a}}$ ed. Rio de Janeiro, LTC Editora, 1999. Volume 1, 252p. 


\section{ANEXO A}

\section{Curva de calibração para os ensaios de RTP.}

Uma análise de Redução a Temperatura Programada (RTP) foi realizada com 3,0 $\mathrm{mg}$ de óxido de cobre, $\mathrm{CuO}$, e sensibilidade 1. Esta análise é apresentada na Figura 50.

As condições da análise foram as seguintes:

Massa de amostra: 3,0 mg;

Velocidade de Aquecimento: $10^{\circ} \mathrm{C} \mathrm{min}^{-1}$, até $1000^{\circ} \mathrm{C}$;

Gás redutor: $\mathrm{H}_{2} 5 \%$ em $\mathrm{N}_{2}$ (em volume);

Fluxo do gás redutor: $30 \mathrm{~mL} \mathrm{~min}^{-1}$.

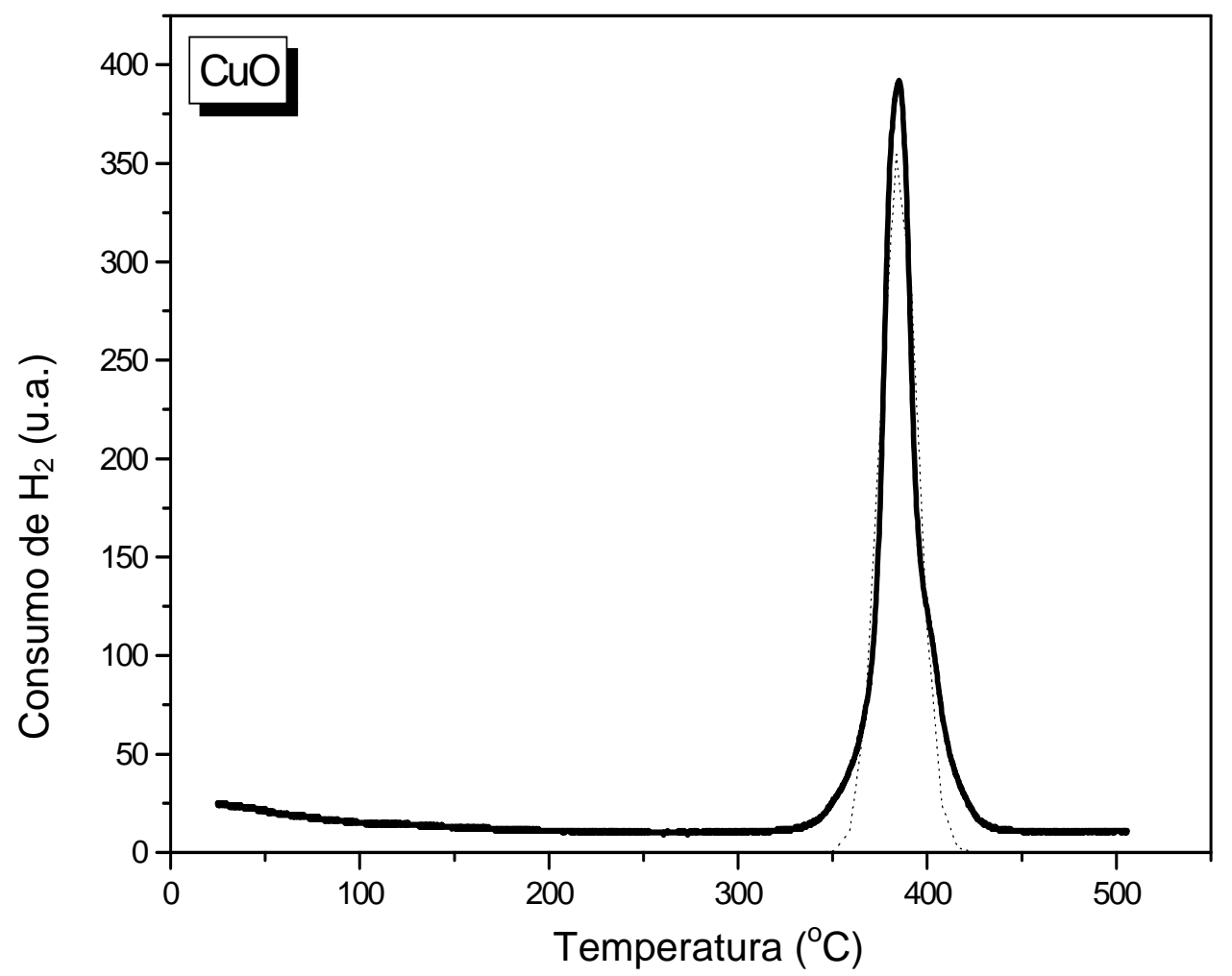

Figura 50: Perfil de RTP da amostra de CuO. 
A área do pico da Figura 50 foi 8849,4 u.a..

O CuO se reduz segundo a Equação 1:

$\mathrm{CuO}+\mathrm{H}_{2} \rightarrow \mathrm{Cu}^{0}+\mathrm{H}_{2} \mathrm{O}$

(Equação 1)

Ou seja, para cada molécula de $\mathrm{CuO}$, ou melhor, íon $\mathrm{Cu}^{2+}$, é necessária uma molécula de $\mathrm{H}_{2}$ para a redução.

Sabendo que:

massa molar de $\mathrm{CuO}=79,5 \mathrm{~g}$

número de moles de $\mathrm{CuO}$ em $3 \mathrm{mg}=3,77 \cdot 10^{-5} \mathrm{~mol}$

é possível concluir que, em uma área de 8849,4 u.a. foram consumidos $3,77 \cdot 10^{-5} \mathrm{~mol}$ de $\mathrm{H}_{2}$.

Como a sensibilidade utilizada para as análises de RTP das amostras deste estudo foi 10 , se a área do pico obtido for multiplicada por 10 teremos um valor de comparação, o qual foi utilizado para calcular a quantidade de metal que foi reduzido em cada ensaio de RTP.

Portanto $3,77 \cdot 10^{-5}$ moles de $\mathrm{H}_{2}$ correspondente à área de 88494 u.a., sendo a sensibilidade $\mathrm{x} 10$. 


\section{APÊNDICE A}

\section{Danos à vegetação e à saúde atribuídos ao ozônio}

Exposição ao ozônio induz efeitos à saúde e ao meio ambiente, causando dificuldades respiratórias em pessoas sensíveis e possíveis danos à vegetação e ao ecossistema. Pesquisas mostram que o ozônio certamente prejudica materiais como elastômeros, fibras têxteis e pinturas ${ }^{(15)}$.

O ozônio é o poluente gasoso mais prejudicial à agricultura, árvores e vegetação nativa. A exposição da vegetação ao ozônio pode inibir a fotossíntese e a captura de carbono, prejudicando o crescimento do vegetal $^{(15)}$.

Efeitos sobre a saúde humana provocados pela exposição ao ozônio incluem prejuízos aos sistemas respiratório e imunológico e inflamações. Estudos sobre a saúde de adultos mostram que $0 \mathrm{O}_{3}$ prejudica a função pulmonar, caracterizando-se por alterações no volume e no fluxo dos pulmões, entre outros danos. Sintomas respiratórios, tais como tosse e dor na respiração profundo, estão associados com estas mudanças na função pulmonar. Ainda é possível concluir por estes estudos que o ozônio também causa inflamação pulmonar como resposta à exposição. Respostas funcionais, sintomáticas e inflamatórias ao ozônio aumentam com o aumento da dose de ozônio a que se é exposto ${ }^{(3,15,58)}$. Os efeitos da exposição ao ozônio são mais aparentes durante a prática de esportes, quando pode ocorrer uma sensível redução na capacidade respiratória. Recomenda-se não praticar esportes durante períodos de alta concentração de ozônio ${ }^{(3)}$. 
Estatísticas mostram que em toda a Europa, em períodos com concentração de ozônio acima de $110 \mu \mathrm{gm}^{-3}$, o número de internações aumenta ${ }^{(16)}$. O mesmo foi observado por D. I. Hammer et al. ${ }^{(59)}$ na cidade de Los Angeles/EUA e por P. H. Saldiva ${ }^{(60)}$ em de São Paulo. Segundo P. H. Saldiva et al. ${ }^{(60)}$, estimativas mostram que cerca de 15 a $20 \%$ das internações de crianças por problemas respiratórios na cidade de São Paulo sejam promovidas pela poluição. 


\section{APÊNDICE B}

Constantes Termodinâmicas dos compostos envolvidos na reação de redução do $\mathrm{NO}$ com $\mathrm{CO}$ ou $\mathrm{H}_{2}$.

A Tabela 21 apresenta os dados termodinâmicos dos compostos envolvidos na reação de redução do $\mathrm{NO}$ com $\mathrm{CO}$ ou $\mathrm{H}_{2}{ }^{(61)}$.

Tabela 21: Dados termodinâmicos dos compostos envolvidos na reação de redução do NO com $\mathrm{CO}$ ou $\mathrm{H}_{2}{ }^{(61)}$.

\begin{tabular}{l|l|l|}
\hline \multicolumn{1}{|c|}{ Composto } & \multicolumn{1}{|c|}{$\Delta \mathrm{H}_{\mathrm{f}}^{\varnothing}\left(\mathrm{kJ} \mathrm{mol}^{-1}\right)$} & \multicolumn{1}{|c|}{$\Delta \mathrm{G}_{\mathrm{f}}^{\varnothing}\left(\mathrm{kJ} \mathrm{mol}^{-1}\right)$} \\
\hline $\mathrm{CO}_{(\mathrm{g})}$ & $-110,53$ & $-137,17$ \\
\hline $\mathrm{CO}_{2(\mathrm{~g})}$ & $-393,51$ & $-394,36$ \\
\hline $\mathrm{N}_{2(\mathrm{~g})}$ & 0 & 0 \\
\hline $\mathrm{NO}_{(\mathrm{g})}$ & $+90,25$ & $+86,55$ \\
\hline $\mathrm{N}_{2} \mathrm{O}_{(\mathrm{g})}$ & $+82,05$ & $+104,20$ \\
\hline $\mathrm{NO}_{2}(\mathrm{~g})$ & $+33,18$ & $+51,31$ \\
\hline $\mathrm{NH}_{3(\mathrm{~g})}$ & $-46,11$ & $-16,45$ \\
\hline $\mathrm{O}_{2}(\mathrm{~g})$ & 0 & 0 \\
\hline $\mathrm{H}_{2(\mathrm{~g})}$ & 0 & 0 \\
\hline \hline
\end{tabular}




\section{APÊNDICE C}

\section{Determinação da Lei de Bragg}

As seqüências de planos do cristal são iguais, pois, após vários planos diferentes, existe uma repetição. $O$ esquema da difração dos raios-X pode ser representado como mostra a Figura 51.

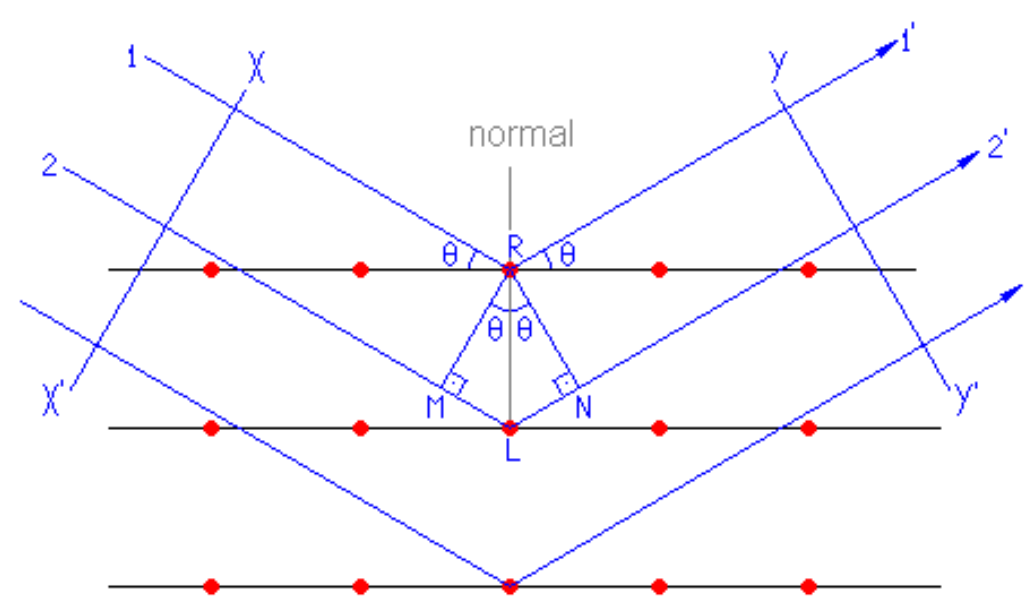

Figura 51: Esquema da difração dos raios-X. 1 e 2: raios-X incidentes; $\theta$ : ângulo de reflexão dos raios-X; 1' e 2': raios-X difratados; RL: distância entre os planos; $M L+L N$ : diferença de caminho percorrido entre os raios 1 e 2.

Os raios 1' e 2' somente serão detectados se estiverem em fase. Para estarem em fase a diferença de caminho percorrido (Equação 2) deve ser um número inteiro de comprimento de onda, $\lambda$, que é característico do tipo de radiação utilizada. 
$\neq$ caminho $=\mathrm{ML}+\mathrm{LN}=\mathrm{n} \lambda$

(Equação 2)

Com estes valores podemos, através da Lei de Bragg determinar o valor da distância entre os planos, d (Equações 3 - 5):

$\operatorname{sen} \theta=\frac{M L}{d}=\frac{L N}{d}$

$\mathrm{d}=\mathrm{RL}$

(Equação 3)

sendo

$M L=L N=d \operatorname{sen} \theta$

(Equação 4)

A partir das Equações 2, 3 e 4 constrói-se a Lei de Bragg (Equação 4.4):

$\mathrm{n} \lambda=2 \mathrm{~d} \operatorname{sen} \theta$

$\rightarrow$ Lei de Bragg

(Equação 4.4)

Sendo:

$\lambda=$ Conhecido pelo tubo utilizado como fonte de radiação;

$\theta=$ Determinado experimentalmente;

$\mathrm{d}=$ Calculado a partir da Lei de Bragg.

Os valores de "d" obtidos experimentalmente para a amostra analisada devem ser comparados com aqueles apresentados na literatura ${ }^{(51)}$ para a determinação da fase cristalina deste. 